Cochrane Database of Systematic Reviews

\title{
Indoor residual spraying for preventing malaria in communities using insecticide-treated nets (Review)
}

Choi L, Pryce J, Garner P

Choi L, Pryce J, Garner P.

Indoor residual spraying for preventing malaria in communities using insecticide-treated nets.

Cochrane Database of Systematic Reviews 2019, Issue 5. Art. No.: CD012688.

DOI: 10.1002/14651858.CD012688.pub2.

www.cochranelibrary.com 
TABLE OF CONTENTS

HEADER 1

ABSTRACT

PLAIN LANGUAGE SUMMARY

SUMMARY OF FINDINGS

BACKGROUND

OBJECTIVES

METHODS

Figure 1.

RESULTS

Figure 2.

DISCUSSION

AUTHORS' CONCLUSIONS

ACKNOWLEDGEMENTS

REFERENCES

CHARACTERISTICS OF STUDIES

DATA AND ANALYSES

Analysis 1.1. Comparison 1 Non-pyrethroid-like indoor residual spraying (IRS) plus insecticide-treated nets (ITNs) versus ITNs alone, Outcome 1 Malaria incidence.

Analysis 1.2. Comparison 1 Non-pyrethroid-like indoor residual spraying (IRS) plus insecticide-treated nets (ITNs) versus ITNs alone, Outcome 2 Malaria parasite prevalence.

Analysis 1.3. Comparison 1 Non-pyrethroid-like indoor residual spraying (IRS) plus insecticide-treated nets (ITNs) versus ITNs alone, Outcome 3 Malaria parasite prevalence (net usage subgroup analysis).

Analysis 1.4. Comparison 1 Non-pyrethroid-like indoor residual spraying (IRS) plus insecticide-treated nets (ITNs) versus ITNs alone, Outcome 4 Anaemia prevalence.

Analysis 1.5. Comparison 1 Non-pyrethroid-like indoor residual spraying (IRS) plus insecticide-treated nets (ITNs) versus ITNs alone, Outcome $5 \mathrm{kdr}$ allelic frequency.

Analysis 2.1. Comparison 2 Pyrethroid-like indoor residual spraying (IRS) plus insecticide-treated nets (ITNs) versus ITNs alone, Outcome 1 Malaria incidence.

Analysis 2.2. Comparison 2 Pyrethroid-like indoor residual spraying (IRS) plus insecticide-treated nets (ITNs) versus ITNs alone, Outcome 2 Malaria parasite prevalence.

Analysis 2.3. Comparison 2 Pyrethroid-like indoor residual spraying (IRS) plus insecticide-treated nets (ITNs) versus ITNs alone, Outcome 3 Anaemia prevalence.

ADDITIONAL TABLES

APPENDICES

WHAT'S NEW

CONTRIBUTIONS OF AUTHORS

DECLARATIONS OF INTEREST

SOURCES OF SUPPORT

DIFFERENCES BETWEEN PROTOCOL AND REVIEW

INDEX TERMS 
[Intervention Review]

\section{Indoor residual spraying for preventing malaria in communities using insecticide-treated nets}

Leslie Choi1a, Joseph Pryce ${ }^{1 b}$, Paul Garner ${ }^{1}$

1Department of Clinical Sciences, Liverpool School of Tropical Medicine, Liverpool, UK

$a_{\text {These authors contributed equally to this work.. }} b$ These authors contributed equally to this work.

Contact address: Leslie Choi, Department of Clinical Sciences, Liverpool School of Tropical Medicine, Pembroke Place, Liverpool, L3 5QA, UK. leslie.choi@lstmed.ac.uk.

Editorial group: Cochrane Infectious Diseases Group

Publication status and date: Unchanged, published in Issue 8, 2019.

Citation: Choi L, Pryce J, Garner P. Indoor residual spraying for preventing malaria in communities using insecticide-treated nets. Cochrane Database of Systematic Reviews 2019, Issue 5. Art. No.: CD012688. DOI: 10.1002/14651858.CD012688.pub2.

Copyright ( 2019 The Authors. Cochrane Database of Systematic Reviews published by John Wiley \& Sons, Ltd. on behalf of The Cochrane Collaboration. This is an open access article under the terms of the Creative Commons Attribution-Non-Commercial Licence, which permits use, distribution and reproduction in any medium, provided the original work is properly cited and is not used for commercial purposes.

\section{A B S T R A C T}

\section{Background}

Insecticide-treated nets (ITNs) and indoor residual spraying (IRS) are used to control malaria vectors. Both strategies use insecticides to kill mosquitoes that bite and rest indoors. For ITNs, the World Health Organization (WHO) only recommended pyrethroids until 2018, but mosquito vectors are becoming resistant to this insecticide. For IRS, a range of insecticides are recommended. Adding IRS to ITNs may improve control, simply because two interventions may be better than one; it may improve malaria control where ITNs are failing due to pyrethroid resistance; and it may slow the emergence and spread of pyrethroid resistance.

\section{Objectives}

To summarize the effect on malaria of additionally implementing IRS, using non-pyrethroid-like or pyrethroid-like insecticides, in communities currently using ITNs.

\section{Search methods}

We searched the Cochrane Infectious Diseases Group Specialized Register; the Cochrane Central Register of Controlled Trials (CENTRAL); MEDLINE; Embase; LILACS; the WHO International Clinical Trials Registry Platform; ClinicalTrials.gov; and the ISRCTN registry up to 18 March 2019.

\section{Selection criteria}

Cluster-randomized controlled trials (CRCTs), interrupted time series (ITS), or controlled before-and-after studies (CBAs) comparing IRS plus ITNs with ITNs alone.

\section{Data collection and analysis}

Two review authors independently assessed trials for eligibility, analyzed risk of bias, and extracted data. We used risk ratio (RR) and 95\% confidence intervals (Cl). We stratified by type of insecticide, 'pyrethroid-like' and 'non-pyrethroid-like'; the latter could improve malaria control better than adding IRS insecticides that have the same way of working as the insecticide on ITNs ('pyrethroid-like'). We used subgroup analysis of ITN usage in the trials to explore heterogeneity. We assessed the certainty of evidence using the GRADE approach. 


\section{Main results}

Six cRCTs (eight comparisons) met our inclusion criteria conducted since 2008 in sub-Saharan Africa. Malaria transmission in all sites was from mosquitoes belonging to the Anopheles gambiae s.l. complex species; two trials in Benin and Tanzania also reported the vector Anopheles funestus. Three trials used insecticide with targets different to pyrethroids (two used bendiocarb and one used pirimiphosmethyl); two trials used dichloro-diphenyl-trichlorethane (DDT), an insecticide with the same target as pyrethroids; and one trial used both types of insecticide (pyrethroid deltamethrin in the first year, switching to bendiocarb for the second-year). ITN usage was greater than $50 \%$ in three trials, and less than $50 \%$ in the remainder.

\section{Indoor residual spraying using 'non-pyrethroid-like' insecticides}

Adding IRS with a non-pyrethroid-like insecticide had mixed results. Overall, we do not know if the addition of IRS impacted on malaria incidence (rate ratio $0.93,95 \% \mathrm{Cl} 0.46$ to $1.86 ; 2$ cRCTs, 566 child-years; very low-certainty evidence); it may have reduced malaria parasite prevalence $(0.67,95 \% \mathrm{Cl} 0.35$ to $1.28 ; 5$ comparisons from 4 CRCTs, 10,440 participants; low-certainty evidence); and it may have reduced the prevalence of anaemia (RR CI 0.46, 95\% 0.18 to 1.20; 3 comparisons from 2 CRCTs, 2026 participants; low-certainty evidence). Three trials reported the impact on EIR, with variable results; overall, we do not know if IRS had any effect on the EIR in communities using ITNs (very low-certainty evidence). Trials also reported the adult mosquito density and the sporozoite rate, but we could not summarize or pool these entomological outcomes due to unreported data. ITN usage did not explain the variation in malaria outcomes between different studies. One trial reported no effect on malaria incidence or parasite prevalence in the first year, when the insecticide used for IRS had the same target as pyrethroids, but showed an effect on both outcomes in the second year, when the insecticide was replaced by one with a different target.

Two trials measured the prevalence of pyrethroid resistance before and after IRS being introduced: no difference was detected, but these data are limited.

\section{Indoor residual spraying using 'pyrethroid-like' insecticides}

Adding IRS using a pyrethroid-like insecticide did not appear to markedly alter malaria incidence (rate ratio $1.07,95 \% \mathrm{Cl} 0.80$ to $1.43 ; 2$ CRCTs, 15,717 child-years; moderate-certainty evidence), parasite prevalence (RR 1.11, 95\% Cl 0.86 to 1.44; 3 cRCTs, 10,820 participants; moderate-certainty evidence), or anaemia prevalence (RR 1.12, 95\% Cl 0.89 to 1.40; 1 cRCT, 4186 participants; low-certainty evidence). Data on the entomological inoculation rate (EIR) were limited, and therefore we do not know if IRS had any effect on the EIR in communities using ITNs (very low-certainty evidence).

\section{Authors' conclusions}

Four trials have evaluated adding IRS using 'non-pyrethroid-like' insecticides in communities using ITNs. Some of these trials showed effects, and others did not. Three trials have evaluated adding IRS using 'pyrethroid-like' insecticides in communities using ITNs, and these studies did not detect an additional effect of the IRS. Given the wide geographical variety of malaria endemicities, transmission patterns, and insecticide resistance, we need to be cautious with inferences to policy from the limited number of trials conducted to date, and to develop relevant further research to inform decisions.

17 September 2019

Up to date

All studies incorporated from most recent search

All published trials found in the last search (18 Mar, 2019) were included

\section{PLAIN LANGUAGE SUMMARY}

\section{Adding indoor residual spraying in communities using insecticide-treated nets for the prevention of malaria}

\section{What was the aim of this review?}

Indoor residual spraying (IRS) is the regular application of chemical insecticides to household walls. The insecticide lasts for at least four months, killing mosquitoes that land on them. Insecticide-treated nets (ITNs) are bed nets treated with insecticides, preventing mosquitoes from biting people and reducing the mosquito population. Both interventions help to control malaria by reducing the number of people being bitten by mosquitoes infected with malaria. Implementing IRS in communities that are using ITNs may be better for malaria control than using ITNs alone for three reasons: two interventions may be better than one; it may improve malaria control where mosquitoes have become resistant to the pyrethroid insecticides used in ITNs; and the combination of ITNs and IRS may also help to slow the emergence of pyrethroid resistance (where pyrethroids are no longer effective at killing mosquitoes).

Pyrethroids were the only class of insecticides approved for use in ITNs until 2018, but growing resistance to pyrethroids impairs their effectiveness. The addition of IRS could counteract this reduction in ITN effectiveness. We could expect that IRS insecticides that have a different way of working to pyrethroids ('non-pyrethroid-like') could restore effectiveness better than those that have the same way of 
working ('pyrethroid-like'). The aim of this review was to summarize the impact of pyrethroid-like or non-pyrethroid-like IRS on malaria, when implemented in communities that are using ITNs.

\section{Key messages}

When IRS was conducted with a non-pyrethroid-like insecticide, some studies and outcomes suggested an impact, but this was not consistent. Factors such as the number of people using nets did not explain the differences between studies. When a pyrethroid-like insecticide was used for IRS, data were limited but there was no additional effect demonstrated.

\section{What was studied in the review?}

We searched for trials that evaluated the impact on malaria transmission when IRS, using a World Health Organization (WHO)recommended dosage, was implemented in communities that were using either ready-treated ITN products or standard nets treated with insecticide at a WHO-recommended dose. We considered effects on both human health outcomes and on mosquito populations.

\section{What were the main results of the review?}

In total, we identified six trials matching our inclusion criteria, from which eight comparisons were drawn. Three trials (providing four comparisons) used a non-pyrethroid-like IRS throughout the study, and two trials (providing two comparisons) used a pyrethroid-like IRS throughout. One further trial used a pyrethroid-like IRS in the first study year and switched to a non-pyrethroid-like IRS in the subsequent years, therefore providing two different comparisons. All six trials were conducted in sub-Saharan Africa.

Adding non-pyrethroid-like IRS in communities using ITNs gave mixed results, with some trials detecting substantial effects but one trial detecting no effect. Overall, the results from the four included trials found that there may be a reduction in malaria parasite prevalence and anaemia prevalence (low-certainty evidence). We do not know if there is an impact on the malaria incidence or on the number of infected bites received per person per year (very low-certainty evidence).

When adding pyrethroid-like IRS in communities using ITNs, the data from three trials indicate there is probably no effect on malaria incidence or parasite prevalence (moderate-certainty evidence), and there may be little or no effect on the prevalence of anaemia. Data on the number of infected bites received per person per year were too limited to draw a conclusion (very low-certainty evidence).

\section{How up to date is the review?}

We searched for relevant trials up to 18 March 2019. 


\section{SUMMARY OF FINDINGS}

\section{Summary of findings for the main comparison. 'Summary of findings' table 1}

Non-pyrethroid-like indoor residual spraying (IRS) + insecticide-treated nets (ITNs) versus ITNs alone for preventing malaria

Patient or population: people at risk of malaria

Setting: sub-Saharan Africa (Benin, Tanzania, Sudan)

Intervention: combination of IRS + ITNs - using an insecticide for IRS that has a different target site to the pyrethroids used in ITNs

Comparison: ITNs alone

\begin{tabular}{|c|c|c|c|c|c|c|}
\hline \multirow[t]{2}{*}{ Outcomes } & \multicolumn{2}{|c|}{$\begin{array}{l}\text { Anticipated absolute effects* } \\
(95 \% \mathrm{Cl})\end{array}$} & \multirow[t]{2}{*}{$\begin{array}{l}\text { Relative effect } \\
(95 \% \mathrm{Cl})\end{array}$} & \multirow{2}{*}{$\begin{array}{l}\text { Number of partici- } \\
\text { pants } \\
\text { (studies) }\end{array}$} & \multirow{2}{*}{$\begin{array}{l}\text { Certainty of } \\
\text { the evidence } \\
\text { (GRADE) }\end{array}$} & \multirow{2}{*}{$\begin{array}{l}\text { Comments: } \\
\text { The combination of IRS and ITNs, when the in- } \\
\text { secticide used for IRS has a different target site } \\
\text { to the pyrethroids used in ITNs }\end{array}$} \\
\hline & $\begin{array}{l}\text { Risk with } \\
\text { ITNs alone }\end{array}$ & $\begin{array}{l}\text { Risk with IRS + } \\
\text { ITNs }\end{array}$ & & & & \\
\hline $\begin{array}{l}\text { Malaria inci- } \\
\text { dence }\end{array}$ & $\begin{array}{l}317 \text { cases per } \\
1000 \text { child- } \\
\text { years }\end{array}$ & $\begin{array}{l}294 \text { cases per } \\
1000 \text { child-years } \\
(145 \text { to } 589)\end{array}$ & $\begin{array}{l}\text { Rate ratio } 0.93 \\
(0.46 \text { to } 1.86)\end{array}$ & $\begin{array}{l}566 \text { child-years } \\
\text { ( } 2 \text { comparisons, } 2 \\
\text { cRCTs) }\end{array}$ & $\begin{array}{l}\oplus \ominus \ominus \ominus \\
\text { Very low }{ }^{a, b}\end{array}$ & $\begin{array}{l}\text { We do not know if there is an effect on malaria inci- } \\
\text { dence compared to ITNs alone. }\end{array}$ \\
\hline $\begin{array}{l}\text { Malaria par- } \\
\text { asite preva- } \\
\text { lence }\end{array}$ & $\begin{array}{l}23.8 \text { cases per } \\
100\end{array}$ & $\begin{array}{l}15.9 \text { cases per } \\
100(8.3 \text { to } 30.4)\end{array}$ & $\begin{array}{l}\mathbf{R R} 0.67(0.35 \text { to } \\
1.28)\end{array}$ & $\begin{array}{l}10,440 \text { participants } \\
5 \text { comparisons, } 4 \\
\text { CRCTs) }\end{array}$ & $\begin{array}{l}\oplus \oplus \ominus \ominus \\
\text { Lowa,c }\end{array}$ & $\begin{array}{l}\text { May sometimes have reduced malaria parasite } \\
\text { prevalence compared to ITNs alone. }\end{array}$ \\
\hline EIR & - & - & $\begin{array}{l}\text { Mean EIR was } \\
\text { lower with IRS in } \\
2 \text { of the } 3 \text { trials. }\end{array}$ & $\begin{array}{l}\text { ( } 4 \text { comparisons, } 3 \\
\text { cRCTs) }\end{array}$ & $\begin{array}{l}\oplus \ominus \ominus \ominus \\
\text { Very lowe,f }\end{array}$ & $\begin{array}{l}\text { We did not know if there was an effect on the EIR } \\
\text { compared to ITNs alone. }\end{array}$ \\
\hline $\begin{array}{l}\text { Anaemia } \\
\text { prevalence } \\
\text { (haemoglobin } \\
<8 \mathrm{~g} / \mathrm{dL} \text { ) }\end{array}$ & $\begin{array}{l}4.7 \text { cases per } \\
100\end{array}$ & $\begin{array}{l}2.1 \text { cases per } 100 \\
(0.0 \text { to } 5.7)\end{array}$ & $\begin{array}{l}\text { RR } \mathbf{0 . 4 6} \\
(0.18 \text { to } 1.20)\end{array}$ & $\begin{array}{l}2026 \text { participants } \\
\text { ( } 3 \text { comparisons, } 2 \\
\text { cRCTs) }\end{array}$ & $\begin{array}{l}\oplus \oplus \ominus \ominus \\
\text { Low }^{\mathrm{a}, \mathrm{e}}\end{array}$ & $\begin{array}{l}\text { May have reduced anaemia prevalence compared } \\
\text { to ITNs alone. }\end{array}$ \\
\hline
\end{tabular}

${ }^{*}$ The risk in the intervention arm (and its $95 \% \mathrm{Cl}$ ) is based on the assumed risk in the comparison arm and the relative effect of the intervention (and its $95 \% \mathrm{Cl}$ ). The assumed risk of the comparison arm is calculated from the total number of events/total number of participants in the control arms of the trials contributing to the metaanalysis.

CI: confidence interval; CRCT: cluster randomized controlled trial; EIR: entomological inoculation rate; IRS: indoor residual spraying; ITN: insecticide-treated net; RR: risk ratio.

\section{GRADE Working Group grades of evidence}


High certainty: we are very confident that the true effect lies close to that of the estimate of the effect.

Moderate certainty: we are moderately confident in the effect estimate: the true effect is likely to be close to the estimate of the effect, but there is a possibility that it is

substantially different.

Low certainty: our confidence in the effect estimate is limited: the true effect may be substantially different from the estimate of the effect.

Very low certainty: we have very little confidence in the effect estimate: the true effect is likely to be substantially different from the estimate of effect.

aDowngraded one level for serious imprecision: the Cls were wide and included both substantive increases and decreases in the outcome.

bDowngraded two levels for very serious inconsistency: there were two trials in the subgroup, reporting directly contrasting effects. This was represented by the $I^{2}$ value of $84 \%$ within the subgroup.

cDowngraded one level for serious inconsistency: three trials demonstrated an effect and one trial did not. Consequently, there was considerable qualitative heterogeneity with an $I^{2}$ value of $86 \%$ within the subgroup.

dDowngraded one level for serious inconsistency: large differences in effect estimates were reported in the three studies.

eDowngraded one level for serious inconsistency: there was moderate heterogeneity with an $I^{2}$ value of $41 \%$ within the subgroup. One study reported a substantial reduction in anaemia and another reported a moderate reduction. One comparison in the subgroup showed no effect by adding IRS, though it should be noted this comparison assessed the addition of IRS to pyrethroid-piperonyl butoxide nets.

fDowngraded two levels for very serious imprecision: where provided, the Cls for the mean EIR in the intervention arms were very wide, including values that would represent both large increases and reductions from the mean EIR in the control arms. The trial showing the greatest reduction in EIR did not report Cls for this outcome and it is, therefore, difficult to assess the precision (Protopopoff 2018).

\section{Summary of findings 2 . 'Summary of findings' table 2}

\section{Pyrethroid-like indoor residual spraying (IRS) + insecticide-treated nets (ITNs) versus ITNs alone for preventing malaria}

Patient or population: people at risk of malaria

Setting: sub-Saharan Africa (The Gambia, Sudan, Eritrea)

Intervention: combination of IRS + ITNs - using an insecticide for IRS that has the same target site as the pyrethroids used in ITNs

Comparison: ITNs alone

\begin{tabular}{|c|c|c|c|c|c|c|}
\hline \multirow[t]{2}{*}{ Outcomes } & \multicolumn{2}{|c|}{$\begin{array}{l}\text { Anticipated absolute effects* } \\
(95 \% \mathrm{Cl})\end{array}$} & \multirow[t]{2}{*}{$\begin{array}{l}\text { Relative effect } \\
(95 \% \mathrm{Cl})\end{array}$} & \multirow{2}{*}{$\begin{array}{l}\text { Number of partici- } \\
\text { pants } \\
\text { (studies) }\end{array}$} & \multirow{2}{*}{$\begin{array}{l}\text { Certainty of } \\
\text { the evidence } \\
\text { (GRADE) }\end{array}$} & \multirow{2}{*}{$\begin{array}{l}\text { Comments: } \\
\text { The combination of IRS and ITNs, when the in- } \\
\text { secticide used for IRS has the same target site as } \\
\text { the pyrethroids used in ITNs }\end{array}$} \\
\hline & $\begin{array}{l}\text { Risk with } \\
\text { ITNs alone }\end{array}$ & $\begin{array}{l}\text { Risk with IRS + } \\
\text { ITNs }\end{array}$ & & & & \\
\hline $\begin{array}{l}\text { Malaria inci- } \\
\text { dence }\end{array}$ & $\begin{array}{l}215 \text { cases per } \\
1000 \text { child- } \\
\text { years }\end{array}$ & $\begin{array}{l}230 \text { cases per } \\
1000 \text { child-years } \\
(172 \text { to } 307)\end{array}$ & $\begin{array}{l}\text { Rate ratio } 1.07 \\
(0.80 \text { to } 1.43)\end{array}$ & $\begin{array}{l}15,717 \text { child-years } \\
\text { ( } 2 \text { comparisons, } 2 \\
\text { cRCTs) }\end{array}$ & $\begin{array}{l}\oplus \oplus \oplus \ominus \\
\text { Moderate }^{a}\end{array}$ & $\begin{array}{l}\text { Probably had little or no effect on malaria inci- } \\
\text { dence compared to ITNs alone. }\end{array}$ \\
\hline
\end{tabular}




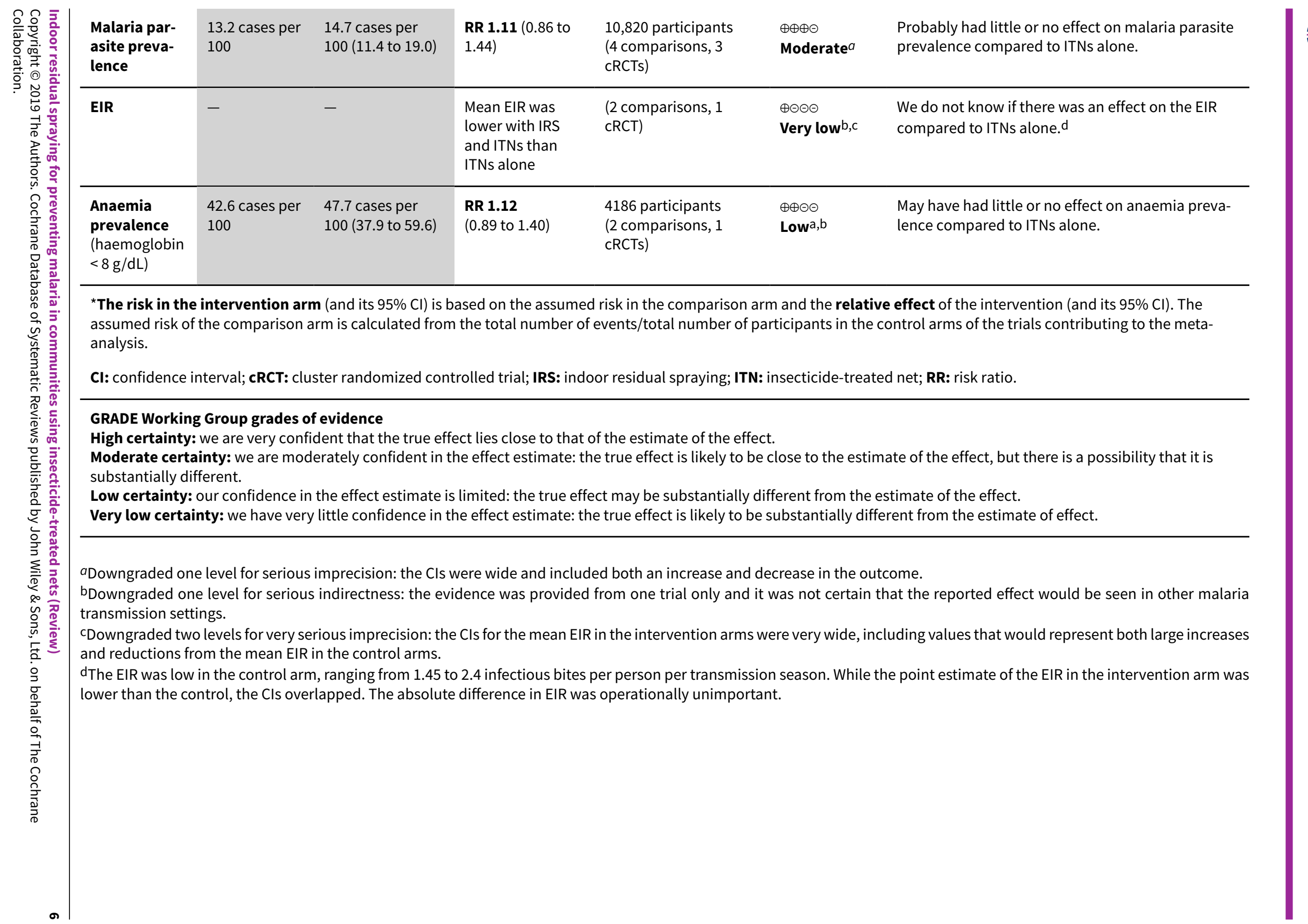




\section{B A C K G R O U N D}

\section{Description of the condition}

Between 2000 and 2015, malaria deaths halved globally. In this time, malaria control interventions were estimated to have averted 663 million cases of malaria, with much of the progress considered to be due to improved vector control (Bhatt 2015). Despite this decline, the disease is still a leading cause of mortality, responsible for 445,000 deaths worldwide in 2016 (WHO 2017a).

\section{Description of the intervention}

Vector control depends largely on insecticides, primarily delivered as indoor residual spraying (IRS) or insecticide-treated nets (ITNs). IRS is the regular spraying of insecticides to the indoor walls of houses. The insecticide lasts for at least four months, killing mosquitoes that land on it. ITNs are bed nets treated with insecticides, preventing mosquitoes from biting people and reducing the mosquito population. ITNs include long-lasting insecticidal nets (LLINs), where the insecticide lasts for up to three years, and conventionally treated nets, where the insecticide is active for up to 12 months. Up until 2018, only pyrethroid class insecticides were considered safe enough to be used for ITNs (Zaim 2000). However, the non-insecticide chemical piperonyl butoxide (PBO) can also be added to ITNs, making them more effective at killing mosquitoes in areas where the mosquito populations are highly resistant to pyrethroids (Gleave 2018). Insecticides used for IRS are less restricted, as people living in the households are considered less likely to come into contact with the treated walls than with the fabric of a bed net.

Pyrethroids target the mosquito voltage-gated sodium ion channels. If mosquito resistance to pyrethroids is leading to reduced effectiveness of ITNs, IRS using insecticides with different target sites ('non-pyrethroid-like' insecticides) may be less affected by the pyrethroid resistance and more likely to have an impact on malaria transmission. In contrast, IRS using insecticides that also target the voltage-gated sodium ion channels ('pyrethroid-like' insecticides) may be less likely to have an impact.

\section{How the intervention might work}

IRS with dichloro-diphenyl-trichlorethane (DDT) was the main intervention of the malaria eradication programmes in the mid-20th century (Pluess 2010). When malaria was eliminated from many parts of South America, Europe, and Asia, IRS was an integral part of the elimination strategies (Pluess 2010). However, many countries today choose to adopt ITNs rather than IRS, as they are logistically easier to implement than IRS and more acceptable to communities.

Theoretically, the simultaneous use of IRS and ITNs is better for malaria control than using ITNs alone for three reasons. First, we might expect an incremental effect of using two vector control interventions over one, particularly when the target vector species both feeds and rests indoors (endophagic and endophilic vectors). As with many vector control interventions, the reality is not simple and the success of the intervention will depend on both human and vector behaviour (Killeen 2006). Mosquito exophily can reduce the effectiveness of IRS and ITNs, as mosquitoes that rest outdoors more will have less contact with an indoor treated wall or net (Kitau 2012). Earlier biting times of Anopheles spp have also been observed, which can increase the likelihood of a mosquito encountering a human to bite and reduce the impact of ITNs (Ojuka 2015).

Second, implementing IRS in communities currently using ITNs may be beneficial for the management of mosquito resistance to insecticides. Malaria control programmes may additionally implement IRS as a reactive measure in response to high pyrethroid resistance in Anopheles mosquitoes. The addition of IRS, particularly with non-pyrethroid-like insecticides, could mitigate for this reduction in ITN effectiveness.

Third, policy-makers could also introduce a combination of the two interventions proactively, administering a non-pyrethroid-like IRS alongside ITNs as part of an insecticide resistance management (IRM) strategy to delay the emergence of pyrethroid resistance (WHO 2012).

\section{Why it is important to do this review}

The combination of IRS and ITNs can be logistically complicated to deliver. ITNs are advantageous because they can last for three to five years, and because net distribution campaigns can be conducted at a village central point or community health centre. In contrast, the current set of insecticides used for IRS will remain active for six months at best, and an effective spray campaign in a setting with perennial malaria transmission will therefore require several sprays per year (WHO 2015a). IRS is also logistically more demanding, requiring a visit to every individual household. IRS programmes typically take a substantially higher amount of financial commitment than an ITN distribution campaign, in part due to the sheer quantity of insecticide required at programmatic scales (Goodman 2001). Finally, IRS has experienced more problems with the acceptability of the intervention and its delivery than ITNs (Kleinschmidt 2009).

Advice has changed over time about whether or when the combination of IRS and ITNs should be used. In the past, the Global Technical Strategy has recommended combining ITNs with IRS for epidemic situations only (WHO 2015b). The current WHO Elimination Framework continues to recommend that elimination programmes using ITNs as a core strategy maintain a capacity to conduct IRS for the rapid clearance of transmission foci (WHO 2017b). However, it additionally recommends IRS is applied as a resistance management strategy in areas where ITNs are the primary intervention and vectors are resistant to pyrethroids. It is recommended that IRS is applied in a rotation of different classes of insecticide, though there is some ambiguity over when rotations should be carried out. The framework also guides that IRS should not be used to compensate for poor coverage of ITNs.

In the past few years, the effect of combining IRS with ITNs has been contentious, with inconsistent results reported across different trials. Modelling data has even suggested an antagonistic effect of combining IRS with ITNs when ITN coverage is poor (Yakob 2011). A greater understanding of the effect on malaria transmission is required to determine whether the additional logistical complexity of combining IRS with ITNs is worthwhile.

\section{O B J E C T IVES}

To summarize the effect on malaria of additionally implementing IRS, using non-pyrethroid-like or pyrethroid-like insecticides, in communities currently using ITNs. 


\section{METHODS}

\section{Criteria for considering studies for this review}

\section{Types of studies}

- Randomized controlled trials (RCTs) with: the unit of randomization being a cluster and at least two clusters per arm (CRCTs). As the two interventions were distributed at a community level, we did not expect to find trials with individual randomization.

- Controlled before-and-after studies (CBAs) with: a contemporaneous control arm and at least two sites per arm.

- Interrupted time series designs (ITS) with: a clearly defined point in time when the intervention occurred and at least three data points before and three after the intervention.

\section{Types of participants}

All people living in a rural or urban malarious area where ITNs are in use. We included participants living in all levels of endemicity, including both stable and unstable transmission.

\section{Types of interventions}

IRS using the World Health Organization (WHO)-recommended dosage (see Table 1; WHO 2015a). We individually evaluated the effects of IRS using:

- 'non-pyrethroid-like insecticides': those with alternative targets such as acetylcholinesterase, in contrast to ITNs.

- 'pyrethroid-like insecticides': those that target the voltagegated sodium ion channels, similarly to ITNs;

ITNs interventions were required to be the same in both intervention and control arms. Suitable ITNs included LLINs and pyrethroid-PBO nets, with either a full or preliminary recommendation by the WHO (Table 2), or conventionally treated nets, treated with insecticide at the WHO-recommended dosage (Table 3).

Any other malaria control measures were required to be the same in both intervention and control arms.

\section{Types of outcome measures}

\section{Primary outcomes}

Studies eligible for inclusion must have reported at least one of the following.

- Malaria incidence: measured as a count per person unit time of (a) infections or (b) new infections, following treatment to avoid measuring pre-existing infections. Infection was defined as any symptom, including fever, with confirmed parasitaemia (by blood smear microscopy or rapid diagnostic test (RDT)).

- Malaria parasite prevalence: the proportion of surveyed people with confirmed parasitaemia.

\section{Secondary outcomes}

\section{Entomological}

- Entomological inoculation rate (EIR): the estimated number of bites by infectious mosquitoes per person per unit of time. This was measured using the human biting rate (the number of mosquitoes biting a person over a stated period measured directly using human baits or indirectly using light traps, knockdown catches, baited huts, or other methods of biting rate determination) multiplied by the sporozoite rate.

- Sporozoite rate: the fraction of vector mosquitoes present and biting that were considered infectious, measured by a technique previously shown to be appropriate for the vector (microscopy, immunoassays, polymerase chain reaction-based assays or other methods)

- Adult mosquito density: measured by a technique previously shown to be appropriate for the vector (human baits, light traps, knock-down catches, baited huts, or other methods).

Epidemiological

- Malaria-related deaths.

- Anaemia prevalence defined as per WHO cut-offs (WHO 2011).

- Hospital admissions for malaria.

- Number of people with severe malaria: using site-specific definitions, provided they included (a) and either (b) or (c): (a) demonstration of parasitaemia by blood smear; (b) symptoms of cerebral malaria including coma, prostration or multiple seizures; (c) severe, life-threatening anaemia (WHO 2015c).

- Number of people with uncomplicated clinical malaria episodes: we will use site-specific definitions, provided they include: (a) demonstration of malaria parasites by blood smear or an RDT, or both; and (b) clinical symptoms including fever detected passively or actively.

\section{Mosquito insecticide resistance}

- Level of insecticide resistance, confirmed by WHO cylinder assays/Centers for Disease Control and Prevention (CDC) bottle bioassays or molecular techniques. This included resistance to either the class of insecticide used for IRS (that is, as an unwanted outcome of trials due to increased coverage of insecticidal interventions) or to pyrethroid insecticides (to monitor whether the addition of IRS prevented or reduced resistance to ITNs).

\section{Search methods for identification of studies}

We attempted to identify all relevant trials regardless of language or publication status (published, unpublished, in press, and in progress).

\section{Electronic searches}

We searched the following databases up to 18 March 2019 using the search terms and strategy described in Appendix 1: Cochrane Infectious Diseases Group Specialized Register; Cochrane Central Register of Controlled Trials (CENTRAL) Issue 3, April 2019, published in the Cochrane Library; MEDLINE (PubMed); Embase (Ovid); and LILACS (Bireme). We also checked the WHO International Clinical Trials Registry Platform (WHO ICTRP; www.who.int/ictrp/en/) and ClinicalTrials.gov (clinicaltrials.gov/ ct2/home) for ongoing trials, also on 18 March 2019, using the terms: indoor residual spraying; IRS; insecticide-treated nets; bednets; ITNs; LLIN.

\section{Searching other resources}

We contacted researchers working in the field for unpublished data. We also checked the reference lists of all trials identified by the above methods. 


\section{Data collection and analysis}

\section{Selection of studies}

Two review authors (LC and JP) independently assessed the titles and abstracts of trials identified by the searches. The same two review authors assessed full-text copies of potentially relevant trials for inclusion using an eligibility form based on the inclusion criteria. We compared the results of our assessments and resolved any disagreements by discussion and consensus, with arbitration by a third review author (PG) when necessary. We ensured that multiple publications of the same trial were included once. We listed excluded studies, together with their reasons for exclusion, in the Characteristics of excluded studies table. We illustrated the study selection process in a PRISMA diagram (Figure 1). 
Figure 1. Study flow diagram.

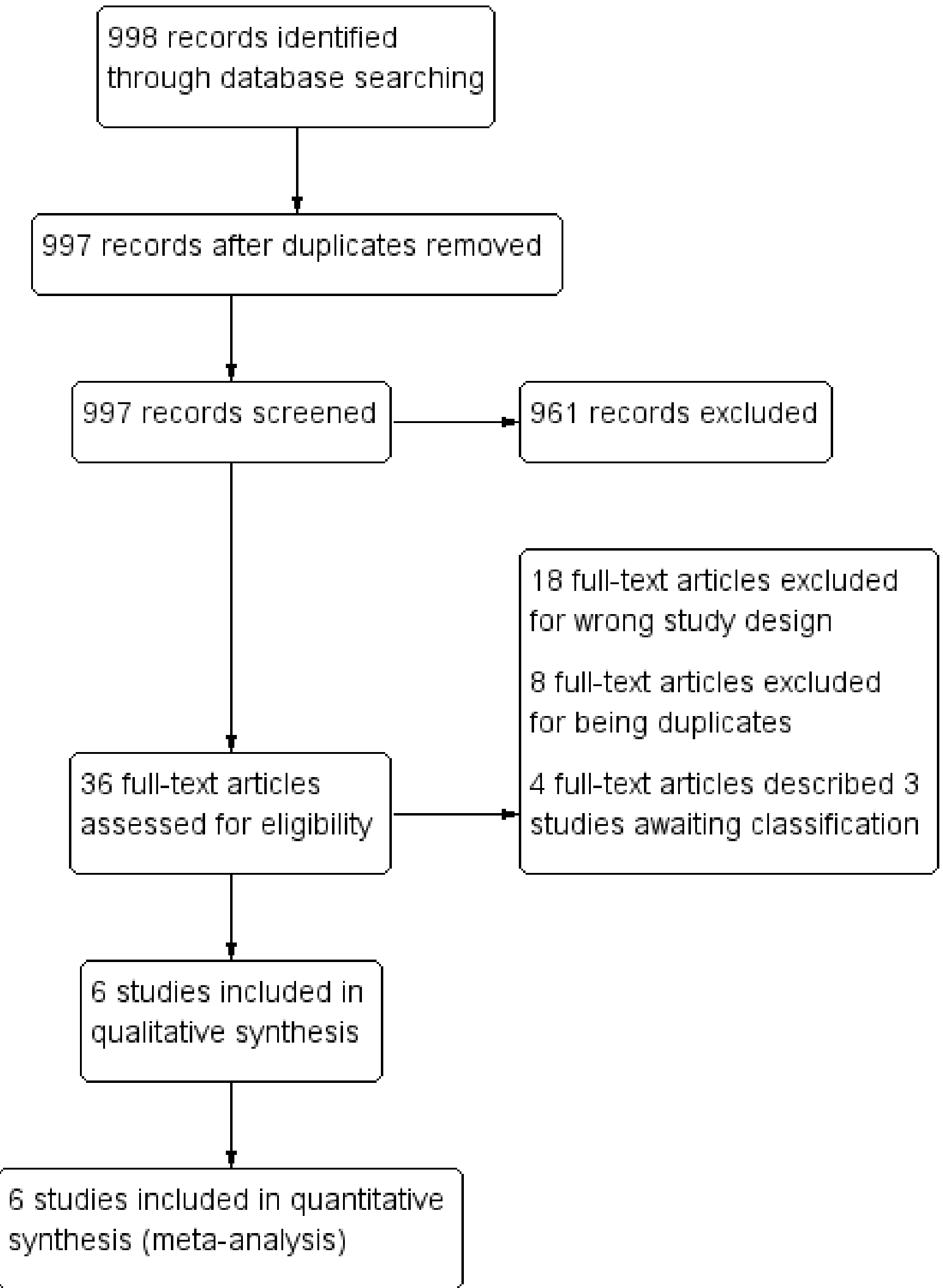




\section{Data extraction and management}

Two review authors (LC and JP) independently extracted information from the trials using prepiloted, electronic data extraction forms. In case of differences in extracted data, the two review authors discussed these differences to reach consensus. If unresolved, we consulted a third review author (PG). In case of missing data, we contacted the original study author(s) for clarification.

We extracted data on the following.

- Trial design: type of trial; method of participant selection; adjustment for clustering (for CRCTs); sample size; method of blinding of participants and personnel.

- Participants: trial settings and population characteristics; recruitment rates; withdrawal and loss to follow-up.

- Intervention: description of intervention and control (active ingredient, dose, formulation, method, frequency and timing of application, buffer zone between clusters); cointerventions; description of control; coverage of intervention, control, and cointerventions; compliance of intervention, control, and cointerventions.

- Outcomes: definition of outcome; diagnostic method or surveillance method; passive or active case detection; duration of follow-up; time points at which outcomes were assessed; number of events; number of participants or unit time; statistical power; unit of analysis; incomplete outcomes/missing data.

- Other:

* primary and secondary vector(s) species; vector(s) behaviour (nature, stability, adult habitat, peak biting times, exophilic/endophilic, exophagic/endophagic, anthropophilic/zoophilic); method of mosquito collection(s); phenotypic insecticide resistance (based on WHO definitions if supplementary WHO cylinder assays or CDC bottle bioassays, or both, were performed while the trial was running); genotypic insecticide resistance profile (either performed during the trial or if the trial referenced data from previous studies done on the same local vector population within the previous five years);

* malaria endemicity; eco-epidemiological setting; human population proximity to mosquito aquatic habitats, human population density per area; Plasmodium spp.

For dichotomous outcomes, we extracted the number of participants experiencing each outcome and the number of participants in each treatment arm. For count/rate data outcomes, we extracted the number of outcomes in the treatment and control arms, and the total person time at risk in each arm or the rate ratio, and a measure of variance (for example, standard error). For continuous outcomes, we extracted the mean and a measure of variance (standard deviation).

For CRCTs, we recorded the number of clusters randomized number of clusters analyzed; measure of effect (such as risk ratio (RR), odds ratio, or mean difference (MD)) with 95\% confidence intervals $(\mathrm{Cl})$ or standard deviations; number of participants; and the intracluster correlation coefficient (ICC) value. Where trials reported cluster-adjusted odds ratios, we converted these to RRs following the methodology stated in Section 12.5.4.4 of the Cochrane Handbook for Systematic Reviews of Interventions (Higgins 2011a).
For non-randomized studies, we extracted adjusted measures of intervention effects that attempted to control for confounding.

\section{Assessment of risk of bias in included studies}

Two review authors (LC and JP) independently assessed the risk of bias for each included CRCT using the Cochrane 'Risk of bias' tool and the five additional criteria listed in Section 16.3.2 of the Cochrane Handbook for Systematic Reviews of Interventions that relate specifically to cluster-randomized trials (Higgins 2011a; Higgins 2011b). If identified, we would have assessed non-RCTs and ITS trials for risk of bias using Cochrane EPOC's 'Risk of bias' tool. We resolved any discrepancies through discussion or by consulting a third review author (PG). We classified judgements of risk of bias as at low, high, or unclear risk of bias, and we used summary graphs ('Risk of bias' summary and 'Risk of bias' graph) to display results.

Due to the nature of the IRS application, blinding of participants and study personnel was not possible. When assessing the risk of performance bias, we considered that the primary outcomes of malaria incidence and malaria parasite prevalence were unlikely to be affected by participant knowledge of the intervention. Therefore, we did not associate the lack of participant blinding with a high risk of performance bias. When assessing the risk of detection bias, we considered that measurements of incidence that depended on self-reporting of fever may have been influenced by the participants' knowledge of the intervention. However, to meet the inclusion criteria for this review, such cases required confirmation of parasitaemia by blood smear microscopy or RDT, and the results of these objective tests were considered unlikely to be influenced by knowledge of the intervention arm. Therefore, where trials measured incidence using this method, we considered the lack of blinding to introduce an unclear risk of bias; this is consistent with the methods used by Pryce 2018.

\section{Measures of treatment effect}

We compared intervention and control data using RRs and for count/rate data, we used rate ratios. We used adjusted measures of effect to summarize treatment effect from non-randomized studies. We presented all results with their associated $95 \% \mathrm{Cls}$.

\section{Unit of analysis issues}

For CRCTs, or cluster non-randomized trials, we extracted adjusted measures of effect where possible. If included cRCTs had not adjusted for clustering in the analysis, we adjusted the data before combining it. We adjusted data by multiplying the standard errors by the square root of the design effect (Higgins 2011a), which was determined by the ICC. If the trial did not report the ICC value, we estimated the ICC value using a range of $0.01,0.05$, and 0.1 . When we estimated the ICC, we performed sensitivity analyses to investigate the robustness of our analyses.

If we identified studies for inclusion that had multiple intervention arms, we included data from these studies by either combining treatment arms, or by splitting the control arm so that we only included these participants in the meta-analysis once.

\section{Dealing with missing data}

In case of missing data, we applied available-case analysis, only including data on the known results. The denominator was the total number of participants who had data recorded for the specific outcome. For outcomes with no missing data, we planned to 
perform analyses on an intention-to-treat basis. We included all participants randomized to each arm in the analyses and analyzed participants in the arm to which they were randomized.

\section{Assessment of heterogeneity}

We inspected forest plots for overlapping $\mathrm{Cls}$ and assessed statistical heterogeneity in each meta-analysis using the $\mathrm{I}^{2}$ statistic and $\mathrm{Chi}^{2}$ statistic. We regarded heterogeneity as moderate if the $\mathrm{I}^{2}$ statistic was between $30 \%$ and $60 \%$; substantial if it was between $59 \%$ and $90 \%$; and considerable if it was between $75 \%$ and $100 \%$ (Deeks 2011). We regarded a $\mathrm{Chi}^{2}$ test statistic with a $\mathrm{P} \leq 0.10$ indicative of statistically significant heterogeneity. We explored clinical and methodological heterogeneity through consideration of the trial populations, methods, and interventions, and by visualization of trial results.

\section{Assessment of reporting biases}

If there were 10 or more trials included in each meta-analysis, we intended to investigate reporting biases (such as publication bias) using funnel plots. We would have assessed funnel plot asymmetry visually, and used formal tests for funnel plot asymmetry (Harbord 2006). If we detected asymmetry in any of these tests or by a visual assessment, we would have explored the reasons for asymmetry. As only six trials met the inclusion criteria, we did not investigate reporting bias using a funnel plot. Instead, we compared the outcomes reported against the trial protocols.

\section{Data synthesis}

We analyzed data using Review Manager 5 (Review Manager 2014). We used fixed-effect meta-analysis to combine data if heterogeneity was absent. For a meta-analysis of reported effect sizes, we used a generalized inverse variance model. Where raw data were used for a meta-analysis of RRs, we used a MantelHaenzel model. For meta-analysis of RRs and odds ratios, if considerable heterogeneity was present, we combined data using random-effects meta-analysis and reported a mean treatment effect. We decided whether to use fixed-effect or random-effects models based on the consideration of clinical and methodological heterogeneity between trials, as described previously.

\section{Certainty of the evidence}

We assessed the certainty of the evidence using the GRADE approach (Guyatt 2011). We rated each important outcome as described by Balshem 2011.

- High: we are very confident that the true effect lies close to that of the estimate of the effect.

- Moderate: we are moderately confident in the effect estimate. The true effect is likely to be close to the estimate of the effect.

- Low: our confidence in the effect estimate is limited. The true effect may be substantially different from the estimate of the effect.

- Very low: we have very little confidence in the effect estimate. The true effect is likely to be substantially different from the estimate of effect.

RCTs started as high-certainty evidence but were downgraded if there were valid reasons within the following five categories: risk of bias, imprecision, inconsistency, indirectness, and publication bias. Studies could also be upgraded if there was a large effect, a dose-response effect, and if all plausible residual confounding would reduce a demonstrated effect or would suggest a spurious effect if no effect was observed (Balshem 2011). We summarized our findings in Summary of findings for the main comparison and Summary of findings 2.

\section{Subgroup analysis and investigation of heterogeneity}

To explore reasons for substantial heterogeneity, we performed the following subgroup analysis.

- Use of ITNs, defined by individual use from the previous night:

* high ( $50 \%$ or more);

* low (less than 50\%).

We assessed differences between the subgroups using the $\mathrm{Chi}^{2}$ test, with a $P$ value less than 0.1 indicating statistically significant differences between subgroups.

\section{Sensitivity analysis}

We planned to perform sensitivity analysis on the primary outcome to see the effect of exclusion of trials at high risk of bias (for allocation concealment and incomplete outcome data) on the overall results. This was not required since all studies included were at low or unclear risk of bias for those specific domains. If the ICC value was estimated, we did sensitivity analyses to investigate the impact of varying the ICC value on meta-analysis results.

\section{RE S U L T S}

\section{Description of studies}

We provided descriptions of the included and excluded studies in the Characteristics of included studies and Characteristics of excluded studies tables. Studies awaiting classification were described in the Characteristics of studies awaiting classification table.

\section{Results of the search}

We identified 998 reports through the electronic search. We removed one duplicate and screened the remaining 997 abstracts against the review's inclusion criteria. Of these, we identified 36 unique reports for full-text screening (Figure 1).

\section{Included studies}

In total, six trials met the inclusion criteria, from which eight comparisons were drawn. All six trials were CRCTs. Three trials (providing four comparisons) used a non-pyrethroid-like IRS throughout the trial (Corbel 2012; Protopopoff 2018; West 2014), and two trials (providing two comparisons) used a pyrethroid-like IRS throughout (Keating 2011; Pinder 2015). One further trial used a pyrethroid-like insecticide in the first study year, but replaced it with a non-pyrethroid-like insecticide for the two subsequent years, and therefore provided two different comparisons (Kafy 2017).

\section{Comparison 1: IRS using non-pyrethroid-like insecticides}

The four trials evaluating the effect of non-pyrethroid-like IRS were conducted in sub-Saharan Africa; one in southern Benin (Corbel 2012); one in south-eastern Sudan (Kafy 2017), and two in north-west Tanzania (Protopopoff 2018; West 2014). The former two regions experience seasonal transmission, while north-west 
Tanzania has perennial transmission with two peak seasons. None of the trials were conducted in epidemic areas.

Two trials evaluated the effect of adding IRS to ITNs using a twoarmed study design (Kafy 2017; West 2014). Two trials had four arms. Corbel 2012 compared universal coverage of ITNs; universal coverage of ITNs plus carbamate-treated plastic sheeting; targeted ITNs (aiming only to cover pregnant women and children under six years old); and targeted ITNs plus IRS. The latter two arms provide the comparison for this review. Protopopoff 2018 used a $2 \times 2$ factorial design which compared standard LLINs; standard LLINs plus IRS; pyrethroid-PBO nets; and pyrethroid-PBO nets plus IRS.

\section{Interventions}

\section{Coverage}

IRS application coverage was described as $80 \%$ of households in the study area (Corbel 2012), consistently above $80 \%$ (Kafy 2017), $94 \%$ in both IRS intervention arms (Protopopoff 2018), and $89.3 \%$ to $92.1 \%$ (West 2014).

\section{Insecticide}

Two trials used a WP formulation of the carbamate bendiocarb, at a dose of $400 \mathrm{mg} / \mathrm{m}^{2}$ (Corbel 2012; West 2014), and in the second year of another trial (Kafy 2017). Protopopoff 2018 used Actellic 300CS (a commercial formulation of pirimiphos-methyl), at a dosage of $1 \mathrm{~g}$ / $\mathrm{m}^{2}$.

\section{Frequency}

The frequency of spraying varied depending on the ecoepidemiological conditions of each location. Two trials conducted two rounds, four months apart, preceding each of two annual transmission peaks (Kafy 2017; West 2014). Corbel 2012 repeated the IRS cycle every eight months, and Protopopoff 2018 conducted only one spraying round. Full characteristics of the interventions are summarized in Table 4.

\section{ITNs in intervention and control arms}

In each of the trials, ITN distribution was equal between the intervention and control arms. In two trials, the ITN distributed was the deltamethrin-based PermaNet 2.0 (Corbel 2012; Kafy 2017), while two trials involved distribution of the permethrin-based Olyset Net (Protopopoff 2018; West 2014). In the two arms that evaluated the efficacy of pyrethroid-PBO nets, Protopopoff 2018 used Olyset Plus instead of Olyset Net. A measure of ITN coverage and compliance for each study is summarized in Table 5.

\section{Cointerventions}

The four trials did not report on any cointerventions.

\section{Outcomes}

\section{Epidemiological}

All four trials measured clinical outcomes in children only; one in those under six years of age (Corbel 2012), one in children aged one to 10 years of age (Kafy 2017) and two between six months and 14 years (Protopopoff 2018; West 2014). Of the two primary outcomes, malaria incidence was measured in two studies (Corbel 2012; Kafy 2017), and malaria parasite prevalence was measured in all four trials. Two trials also reported the prevalence of childhood anaemia (Protopopoff 2018; West 2014). Protopopoff 2018 limited their analysis of anaemia to children aged six months to four years. We extracted the nine-month postintervention crosssectional survey results only, as IRS was not conducted beyond this time point, which acted as their main endpoint for assessing the efficacy of IRS (Protopopoff 2018).

\section{Entomological}

Three trials reported estimated EIR, adult mosquito density, and the sporozoite rate (Corbel 2012; Protopopoff 2018; West 2014).

\section{Mosquito insecticide resistance}

One trial additionally reported the prevalence in malaria vectors of alleles associated with resistance to pyrethroids (1014F kdr) and carbamates (G119S ace1) (Corbel 2012). Kafy 2017 reported the level of phenotypic resistance to pyrethroids.

\section{Comparison 2: IRS using pyrethroid-like insecticides}

The three CRCTs evaluating pyrethroid-like IRS were all conducted in sub-Saharan Africa; in the west lowlands of Eritrea (Keating 2011), the upper river region of The Gambia (Pinder 2015), and in south-eastern Sudan (Kafy 2017). The regions each experience seasonal transmission, and none were in epidemic areas.

\section{Interventions}

\section{Coverage}

IRS application coverage was described as consistently above $80 \%$ (Kafy 2017), 84.8\% (Keating 2011), and 83\% to 86\% (Pinder 2015).

\section{Insecticide}

Two trials used a wettable powder (WP) formulation of DDT, at a dose of $1 \mathrm{~g} / \mathrm{m}^{2}$ to $2 \mathrm{~g} / \mathrm{m}^{2}$ (Keating 2011; Pinder 2015). One trial used the pyrethroid deltamethrin at a dose of $25 \mathrm{mg} / \mathrm{m}^{2}$ in the first study year (Kafy 2017).

\section{Frequency}

The frequency of spraying varied depending on the ecoepidemiological conditions of each location. One trial conducted IRS once per year to coincide with the start of the transmission season (Pinder 2015). One trial conducted two rounds, four months apart, preceding each of two annual transmission peaks (Kafy 2017). One trial conducted only one spraying round (Keating 2011). Full characteristics of the interventions have been summarized in Table 4.

\section{ITNs in intervention and control arms}

In each of the three trials, ITN distribution was equal between the intervention and control arms. In one trial, the ITN distributed was the deltamethrin-based PermaNet 2.0 (Kafy 2017), while one trial involved distribution of the permethrin-based Olyset Net (Pinder 2015). One trial did not distribute ITNs as the region already had a high coverage; any LLIN, or ITN that had been treated at least once in the last 11 months, was considered acceptable when measuring net coverage in this study (Keating 2011). A measure of ITN coverage and compliance for each study is summarized in Table 5.

\section{Cointerventions}

One trial listed larval habitat management and continued case management as cointerventions that were conducted in both intervention and control arms during the study period (Keating 2011). The remaining trials did not report on any cointerventions. 


\section{Outcomes}

\section{Epidemiological}

Two trials measured clinical outcomes in children only; one in children aged one to 10 years of age (Kafy 2017), and one in children aged between six months and 14 years (Pinder 2015). The third trial measured outcomes in participants of all ages (Keating 2011). Of the two primary outcomes, two studies measured malaria incidence (Kafy 2017; Pinder 2015), and all three trials measured malaria parasite prevalence. One trial also reported the prevalence of childhood anaemia (Pinder 2015). For malaria parasite prevalence and anaemia prevalence, Pinder 2015 reported separately adjusted effect estimates for both years of the study, 2010 and 2011, so we included both estimates in the analysis separately.

\section{Entomological}

One trial reported the estimated EIR, sporozoite rate, and adult mosquito density measured as the number of adult An gambiae s.l. collected per trap per night (Pinder 2015).

\section{Mosquito insecticide resistance}

One trial measured the prevalence of alleles associated with pyrethroid resistance only (Kafy 2017).

\section{Excluded studies}

We excluded 26 full-text articles for the following reasons:

- study design did not meet the inclusion criteria (18 full-text articles);

- duplicate articles (eight full-text articles).

Full details are provided in the Characteristics of excluded studies tables.

\section{Studies awaiting classification}

Four full-text articles describing three studies are currently reported in the 'Characteristics of studies awaiting classification' table. One is a stepped wedge design and the results presented are not in a form that can be used in this analysis; we have requested additional data from the study authors (Hamainza 2016). The other two trials have been completed and we are awaiting publication of the results (Chaccour 2018; Deressa 2016).

\section{Risk of bias in included studies}

Trials overall were well designed with few concerns over risk of bias (Figure 2). Details of the assessment are included in the 'Risk of bias' table of the Characteristics of included studies table. 
Figure 2. Risk of bias summary: review authors' judgements about each risk of bias item for each included study.

\begin{tabular}{|c|c|c|c|c|c|c|c|c|c|c|c|c|c|c|}
\hline & 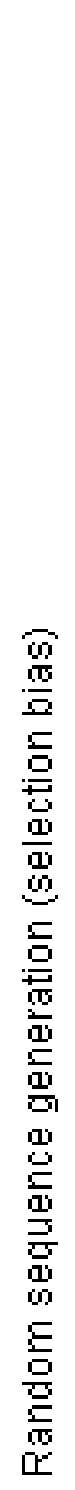 & 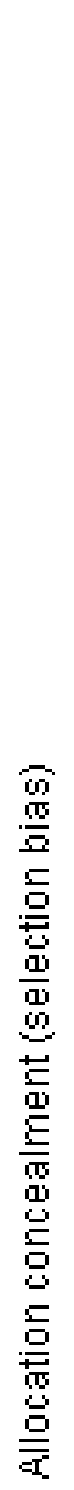 & 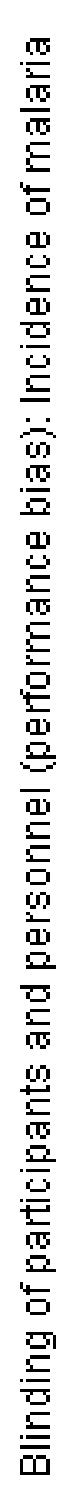 & 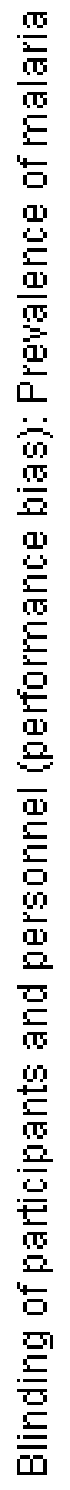 & 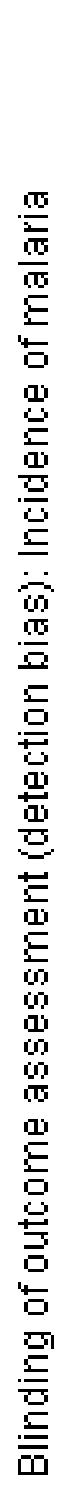 & 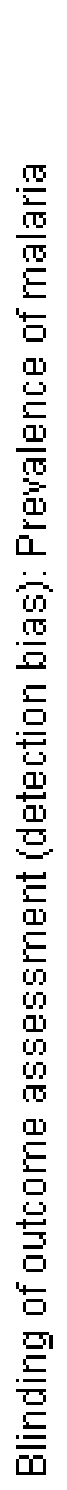 & 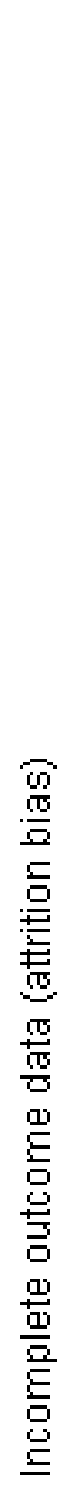 & 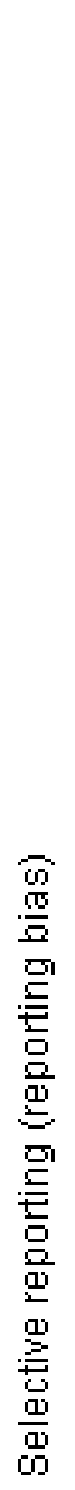 & 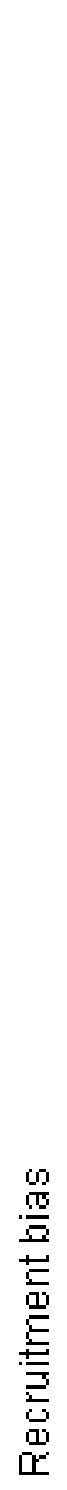 & 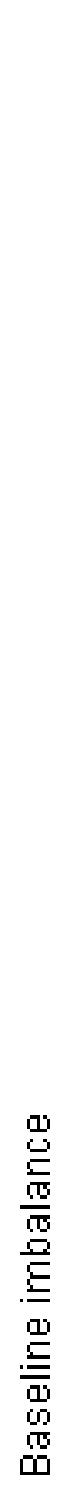 & 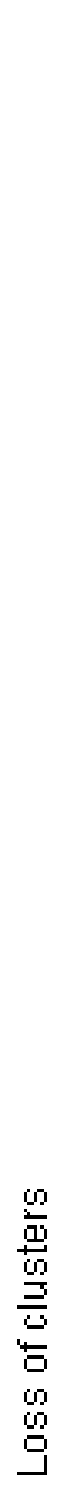 & 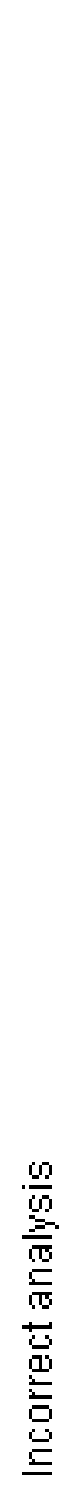 & 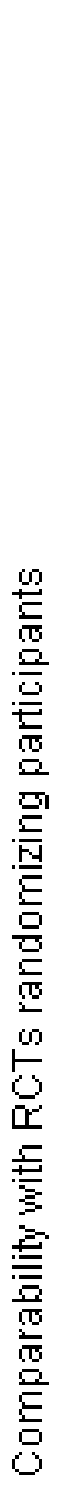 & 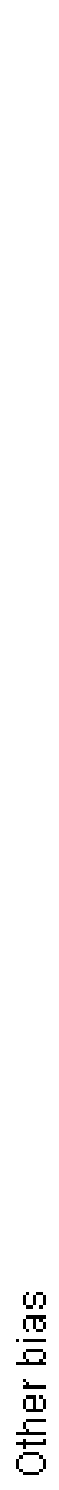 \\
\hline \multicolumn{15}{|l|}{ Corbel 2012} \\
\hline Kafy 2017 & + & 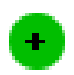 & + & + & & & $?$ & + & + & + & & + & + & \\
\hline Keating 2011 & $?$ & $?$ & + & + & 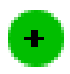 & $\uparrow$ & + & + & + & $?$ & + & + & + & \\
\hline Pinder 2015 & + & + & + & + & $?$ & & & & + & + & & 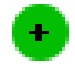 & & \\
\hline Protopopoff 2018 & $\oplus$ & + & + & + & & + & + & + & + & + & + & + & & \\
\hline West 2014 & + & + & + & S & + & + & + & + & 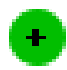 & & & + & & \\
\hline
\end{tabular}




\section{Allocation}

We assessed five trials at low risk of bias for random sequence generation and allocation concealment, as allocation was decided using a computerized randomization algorithm (Corbel 2012; Kafy 2017; Pinder 2015; Protopopoff 2018; West 2014). One trial was at unclear risk of bias because the randomization procedure was not described (Keating 2011).

\section{Blinding}

Due to the nature of the IRS application, blinding of participants and study personnel was not possible. Participant and personnel knowledge of intervention arm was not expected to have an influence on the outcomes included in this review.

One trial blinded microscopists (Pinder 2015). However, all six trials measured prevalence using either a RDT or blood smear examination. As these tests are objective, all six trials were at low risk of detection bias. Two trials that measured malaria incidence depended on self-reporting of fever, and as such the detection of this outcome may have been influenced by the participants' knowledge of the intervention (Corbel 2012; Pinder 2015). However, both cases confirmed parasitaemia using objective tests. Therefore, the trials were at unclear risk of bias. The remaining trial used active case detection with RDTs to measure incidence and was, therefore, considered at low risk of performance bias.

\section{Incomplete outcome data}

One trial reported a difference of more than $10 \%$ between the intervention and control arms in person-days that were lost to follow-up (Corbel 2012). This was judged at high risk of bias. The remaining five trials were at low (Keating 2011; Pinder 2015; Protopopoff 2018; West 2014) or unclear risk of bias (Kafy 2017).

\section{Selective reporting}

The trials reported on each of their intended outcomes as specified in their registered protocols.

\section{Other potential sources of bias}

None of the trials were considered at risk of recruitment bias as the study participants were randomly selected. One trial was at unclear risk of baseline imbalance, as the baseline data for prevalence were not reported (Keating 2011). No trials were at high or unclear risk of bias from loss of clusters, incorrect analyses, or other biases.

\section{Effects of interventions}

See: Summary of findings for the main comparison 'Summary of findings' table 1; Summary of findings 2 'Summary of findings' table 2

\section{Comparison 1: adding IRS using non-pyrethroid-like insecticides to ITNs}

See Summary of findings for the main comparison.

\section{Malaria incidence}

Two trials reported malaria incidence (Corbel 2012; Kafy 2017). One trial reported a substantial benefit of IRS, while the other reported a higher malaria incidence in the intervention arm. This lack of consistency was reflected in the considerable heterogeneity $\left(\mathrm{I}^{2}=\right.$ $84 \%)$. As there are only two trials, a subgroup analysis by ITN usage would not be informative. Overall, the pooled analysis gave a mean effect between the two results (rate ratio $0.93,95 \% \mathrm{Cl} 0.46$ to 1.86 ; 2 CRCTs, 566 child-years; Analysis 1.1; very low-certainty evidence).

The results from Kafy 2017 were noteworthy: the data from different years of the trial appeared in both Comparison 1 and Comparison 2. The first year had shown the addition of IRS using a pyrethroid-like insecticide had no effect on malaria incidence (RR 1.00, 95\% Cl 0.36 to 2.78); in the second and third years, when a non-pyrethroid-like insecticide was used for IRS, there was a lower malaria incidence (RR $0.65,95 \% \mathrm{Cl} 0.44$ to 0.96 ).

\section{Malaria parasite prevalence}

All four trials assessed the effect on malaria parasite prevalence. One trial provided two comparisons to the analysis, one comparing standard ITNs plus IRS versus standard ITNs alone, and a second comparing pyrethroid-PBO nets plus IRS versus pyrethroid-PBO nets alone (Protopopoff 2018). In the comparison involving standard ITNs, the addition of IRS was associated with a large reduction in malaria parasite prevalence (RR $0.52,95 \% \mathrm{Cl} 0.18$ to 1.52). However, the effect was much less pronounced in the comparison involving pyrethroid-PBO nets (RR 0.85, 95\% Cl 0.34 to 2.11). This may be explained by the improved effectiveness of pyrethroid-PBO nets over standard ITNs seen in the study. Even in the absence of IRS, the pyrethroid-PBO net arm had a prevalence of $31 \%$, compared to $55 \%$ in the standard ITN arm.

Across the included studies, the pooled analysis showed the malaria parasite prevalence was lower when IRS was added (RR $0.67,95 \% \mathrm{Cl} 0.35$ to 1.28 ; 4 cRCTs, 10,440 participants; Analysis 1.2; low-certainty evidence). Most studies showed a benefit of IRS with substantial reductions in prevalence, but one study again reported a higher prevalence in the intervention arm (Corbel 2012). This lack of consistency is reflected in the considerable heterogeneity $\left(1^{2}=86 \%\right)$. We conducted a subgroup analysis by percentage of the trial population sleeping under an ITN (Analysis 1.3). Two trials were conducted with ITN use below 50\% (Corbel 2012; West 2014), and two were conducted with ITN use of $50 \%$ or more (Kafy 2017; Protopopoff 2018). This analysis did not explain the heterogeneity.

The results from Kafy 2017 were noteworthy: the data from different years of the trial appeared in both Comparison 1 and Comparison 2. In the first year, following IRS implementation using a pyrethroid-like insecticide, there was an increase in malaria parasite prevalence in the intervention arm (RR 1.96, 95\% Cl 0.86 to 4.46). However, in the second and third years, when a nonpyrethroid-like insecticide was used for IRS, there was a large reduction in prevalence ( $\mathrm{RR} 0.41,95 \% \mathrm{Cl} 0.28$ to 0.61 ).

\section{Entomological inoculation rate}

Three trials reported estimates of the EIR (Corbel 2012; Protopopoff 2018; West 2014). Due to considerable differences between trials in the way the EIR was defined, estimated, and in the effect sizes reported, it was not possible to conduct a meta-analysis. We presented the results of each trial in Table 6.

In summary, the EIR was lower when IRS was added in one of the three trials. The results correlated with the reported epidemiological outcomes in two of the three trials.

- Corbel 2012 reported a slightly lower mean value for the number of infected bites per person per year when IRS was added (7.3\%, 
$95 \% \mathrm{Cl} 3.8$ to 14.2$)$ compared to the control arm $(9.4,95 \% \mathrm{Cl}$ 5.1 to 17.1). This was concordant with the results the trial report for epidemiological outcomes, where there was no evidence of a lower malaria incidence or parasite prevalence in the combined arm.

- In both comparisons of Protopopoff 2018, there was a much lower mean EIR when IRS was added to nets. Similarly to the above epidemiological outcomes, the lower EIR was more marked in the comparison with the standard ITNs; whereas the EIR in the ITN-only arm was much lower with the pyrethroid-PBO net arm. We could not calculate $\mathrm{Cls}$ as the standard errors were not given for the means.

- West 2014 reported no reduction in the mean number of infected bites per household per month when IRS was added to ITNs $(1.1,95 \% \mathrm{Cl} 0.4$ to 2.8 in the ITN-only arm and $1.3,95 \% \mathrm{Cl} 0.4$ to 4.4 in the IRS plus ITNs arm). This finding was inconsistent with the epidemiological outcomes, where the trial reported a large reduction in both malaria parasite prevalence and anaemia prevalence.

\section{Sporozoite rate}

Two trials reported the effect on the sporozoite rate (Protopopoff 2018; West 2014). Both defined this outcome as the proportion of An gambiae s.l. caught from light traps with sporozoites.

- In both comparisons of Protopopoff 2018, the sporozoite rate was lower when IRS was added. In the IRS plus standard ITNs arm the proportion was $0.4 \%$ versus $2.8 \%$ in the standard ITNs alone comparison. In the IRS plus pyrethroid-PBO net arm the proportion was $0 \%$ versus $0.7 \%$ in the pyrethroid-PBO net alone comparison. The trial did not report $95 \% \mathrm{Cls}$ for these measurements or an overall effect estimate.

- West 2014 reported a $28 \%$ reduction in the odds of a mosquito being infected with sporozoites in the intervention arm compared to the control arm, but the $\mathrm{Cl}$ included no effect (OR $0.72,95 \% \mathrm{Cl} 0.21$ to 2.53 ).

Table 7 summarizes the characteristics and effects of all trials reporting the sporozoite rate included in this review.

\section{Adult mosquito density}

One trial measured adult mosquito density as a biting rate (Corbel 2012), and as the number of adult mosquitoes caught per trap per night in both trials conducted in Tanzania (Protopopoff 2018; West 2014). The differences in the reporting of these outcomes precluded a quantitative synthesis. In summary, all three trials reported a reduction in adult mosquito density when IRS was added.

- Corbel 2012 reported a reduction of bites by $31 \%$ in the intervention arm compared to the control arm, but the $\mathrm{Cls}$ were wide and included no effect (rate ratio $0.69,95 \% \mathrm{Cl} 0.38$ to 1.25 ).

- In the IRS plus standard ITNs versus standard ITNs alone comparison, Protopopoff 2018 reported a mean number of 2.37 vectors caught per night per household in the intervention arm and 2.83 vectors per night per household in the control arm. In the IRS plus pyrethroid-PBO nets the mean number was 1.85 versus 1.84 in the pyrethroid-PBO nets alone comparison. As with the above EIR outcome, the trial did not report $95 \% \mathrm{Cls}$ for these measurements or an overall effect estimate.
- West 2014 reported a $77 \%$ reduction of adult mosquitoes in the intervention arm compared to the control arm, but the Cls included no effect (rate ratio $0.23,95 \% \mathrm{Cl} 0.04$ to 1.32 ).

Table 8 summarizes the characteristics and effects of all trials reporting adult mosquito density included in this review.

\section{Anaemia prevalence}

Two trials assessed the effect on anaemia prevalence. One trial provided two comparisons to the analysis, one comparing standard ITNs plus IRS versus standard ITNs alone, and a second comparing pyrethroid-PBO nets plus IRS versus pyrethroid-PBO nets alone. Similarly to the previous outcomes, the introduction of IRS with a standard ITN was associated with a reduction in the prevalence of anaemia compared to a standard ITN alone (RR $0.17,95 \% \mathrm{Cl} 0.04$ to 0.67 ), but the combination of IRS plus pyrethroid-PBO net was not favourable to a pyrethroid-PBO net alone (RR 1.18, 95\% Cl 0.09 to 15.08).

Across the included studies, the pooled analysis showed that the prevalence of anaemia was lower when IRS was added to communities using ITNs (RR 0.46, 95\% Cl 0.18 to 1.20 ; 2 cRCTs, 2026 participants; Analysis 1.4; low-certainty evidence), and the metaanalysis showed moderate heterogeneity between trials $\left(I^{2}=41 \%\right)$. As there are only two trials, a subgroup analysis by ITN usage was not considered to be useful.

\section{Insecticide resistance}

Corbel 2012 reported the allelic frequency of $1014 \mathrm{~F} k d r$, a genetic marker associated with resistance to pyrethroid insecticide in mosquitoes. There was no difference detected in the frequency of $1014 \mathrm{~F} k d r$ in the IRS plus ITNs arm $(86 \%, 95 \% \mathrm{Cl} 80 \%$ to $92 \%)$ compared to the ITN-only arm $(86 \%, 95 \% \mathrm{Cl} 79 \%$ to $93 \%)$. The trial did not report the individual frequency in each intervention arm of G119S ace1, a genetic marker associated with resistance to carbamate insecticides. However, it commented that the allele was almost absent across the study area during the trial (less than 5\%, 2123 participants).

Kafy 2017 reported that there was less phenotypic pyrethroid resistance in the IRS plus ITNs arm, with $68 \%$ mosquito mortality after exposure to deltamethrin ( $95 \% \mathrm{Cl} 60.0 \%$ to $76.0 \%)$ compared to $56.1 \%$ mortality in the ITN-only arm ( $95 \% \mathrm{Cl} 47.1 \%$ to $64.9 \%)$.

\section{Comparison 2: adding IRS with pyrethroid-like insecticides to} ITNs

See Summary of findings 2.

\section{Malaria incidence}

The two trials that reported the effect on malaria incidence did not detect an effect of IRS in communities that were using ITNs (rate ratio $1.07,95 \% \mathrm{Cl} 0.80$ to $1.43 ; 2$ cRCTs, 15,717 child-years; Analysis 2.1; moderate-certainty evidence).

\section{Malaria parasite prevalence}

The three trials that reported the effect on malaria parasite prevalence did not detect an effect of IRS in communities that were using ITNs, with no heterogeneity between the studies (RR 1.11, $95 \% \mathrm{Cl} 0.86$ to 1.44 ; 10,820 participants; Analysis 2.2; moderatecertainty evidence). 


\section{Entomological inoculation rate}

One trial reported the effect on the estimated EIR (Pinder 2015). The authors defined the estimated EIR as the mean number of infected bites per person per transmission season. In the first year, the trial reported a difference in the estimated EIR of $2.44(95 \% \mathrm{Cl} 0.69$ to 6.39) without IRS and 1.08 ( $95 \% \mathrm{Cl} 0.16$ to 4.02$)$ when IRS was added, but the $\mathrm{Cls}$ overlapped. The pattern in the point estimates was the same in the second year, with an estimated EIR of $1.45(95 \%$ $\mathrm{Cl} 0.15$ to 5.69$)$ without IRS and $0.29(95 \% \mathrm{Cl} 0.00$ to 2.66$)$ when IRS was added. While the point estimates were not consistent with the human data, the wide Cls make no inference possible. Table 6 summarizes the characteristics and effects of all trials reporting the EIR included in this review.

\section{Sporozoite rate}

One trial reported the effect on the sporozoite rate (Pinder 2015). The authors defined this as the proportion of An gambiae s.l. caught using light traps, with sporozoites. The actual number of infected mosquitoes detected was small (19 in both arms across the two years). In the first year of assessment, $0.19 \%$ (4/2131) of An gambiae s.l. were positive in the intervention arm, and $0.32 \%$ (9/2829) were positive in the control arm. The risk of a mosquito being infected with sporozoites was $41 \%$ lower in the intervention arm compared to the control arm, but the analysis was underpowered (RR 0.59, $95 \% \mathrm{Cl} 0.18$ to 1.91 ). In the second year of assessment, $0.65 \%$ (5/773) of An gambiae s.l. were positive in the intervention arm and $0.09 \%(1 / 1131)$ in the control arm. The risk of a mosquito being infected with sporozoites was more than seven times higher in the intervention arm compared to the control arm, but again this was underpowered (RR $7.32,95 \% \mathrm{Cl} 0.86$ to 62.5 ). Table 7 summarizes the characteristics and effects of all trials reporting the sporozoite rate included in this review.

\section{Adult mosquito density}

One trial reported the effect on adult mosquito density (Pinder 2015). The authors defined this outcome as the number of $A n$ gambiae s.l. per trap per night. The trial used both light and exit traps. There were no clear differences between the arms, and the Cls were wide (2010 using light traps: $\mathrm{MD}-1.22,95 \% \mathrm{Cl}-3.58$ to 1.14; 2010 using exit traps: $\mathrm{MD}-0.13,95 \% \mathrm{Cl}-0.54$ to $0.28 ; 2011$ using light traps: $\mathrm{MD}-0.69,95 \% \mathrm{Cl}-2.15$ to 0.77 ; and 2011 using exit traps: $M D-0.40,95 \% \mathrm{Cl}-1.05$ to 0.25$)$. Table 8 summarizes the characteristics and effects of all trials reporting adult mosquito density included in this review.

\section{Anaemia prevalence}

The one trial that reported the prevalence of anaemia did not detect an effect of IRS in communities that were using ITNs (RR 1.12, 95\% $\mathrm{Cl} 0.89$ to 1.40 ; 4186 participants, 1 CRCT; Analysis 2.3; low-certainty evidence).

\section{Insecticide resistance}

No trials reported level of insecticide resistance in such a way that an effect size could be calculated. However, Kafy 2017 reported that in the first year of the trial there was no difference in mosquito deltamethrin mortality when IRS was added $(65 \%, 95 \% \mathrm{Cl} 49 \%$ to $81 \%)$ compared to the control arm $(60 \%, 95 \% \mathrm{Cl} 44 \%$ to $76 \%)$.

\section{DISCUSSION}

\section{Summary of main results}

See Summary of findings for the main comparison and Summary of findings 2 .

Adding IRS using a non-pyrethroid-like insecticide to ITNs gave mixed results and we could not explain why there were such differences between the trials. There was some indication of an added effect on malaria and anaemia prevalence in some of the trials.

Adding IRS using a pyrethroid-like insecticide to ITNs did not provide any improvement in malaria outcomes in the two trials to date.

For both comparisons included in this review, entomological outcomes were reported inconsistently, and qualitative comparisons with the human malaria outcomes showed poor correlation in relation to the presence or absence of an effect.

\section{Certainty of the evidence}

Details of the downgrading for GRADE are contained in the 'Summary of findings' tables. There was a large amount of qualitative heterogeneity, with some studies reporting large effects, and some studies reporting little or no effect in the primary outcomes. This decreased the certainty of the evidence and raised doubts about the generalizability to other settings.

\section{Overall completeness and applicability of evidence}

Given the wide geographical variety of malaria endemicities, transmission patterns, and insecticide resistance, we need to be cautious with inferences to policy from the limited number of trials conducted to date. The review included six trials, which were divided into two main comparisons. With so few trials, showing variable results, it was difficult to confidently draw conclusions about the impact of adding IRS to ITNs. Applicability of vector control interventions in different settings is always a concern. This is because only a few trials are conducted in very specific contexts. The ecology, behaviour, and insecticide-resistance profiles of Anopheles mosquitoes can vary massively between and within species. The included studies in this review are all conducted in Sub-Saharan Africa, between 2008 and 2016, with primary vectors all belonging to the An gambiae s.l. species complex (Table 4). The effect of combining IRS with ITNs in the trials reported here will not necessarily apply to other target species in other settings, particularly those which are more exophilic and exophagic (Okumu 2011).

The rationale for adding IRS to ITNs can be framed in three contexts, and the applicability of the evidence to each of these is discussed below.

First, where the maximum reduction of malaria that is feasibly possible has already been achieved with one intervention, an incremental impact may be expected by adding a second intervention that also targets endophilic and endophagic mosquitoes (Okumu 2011). Though current WHO policy does not recommend the addition of IRS where ITN compliance is low, instead favouring the target of universal coverage of one core intervention, suggestions have been made that rolling out IRS in 
an area with low ITN compliance would compensate for the poor usage of ITNs (WHO 2014a). Our review presented findings from two trials conducted in areas of low ITN compliance, with one in Benin and the other in Tanzania, but the two trials had conflicting results (Corbel 2012; West 2014).

A second rationale is that the addition of IRS may be useful in an area where high pyrethroid resistance is causing ITNs to fail. When the trials included in this review were conducted, only pyrethroids were approved for use on ITNs, whereas four classes of insecticides (including pyrethroids) could be used for IRS (WHO 2014b; WHO 2014c; WHO 2015a). By adding a non-pyrethroidlike IRS to a pyrethroid ITN, one would expect the reduction in efficacy due to pyrethroid resistance to be compensated for (WHO 2012). Our review attempted to explore this by presenting separate analyses dependent on the target site of the insecticides used for IRS. The rationale behind this was that if pyrethroid resistance is causing ITNs to fail, introducing a pyrethroid-like IRS will be unlikely to have a benefit. The included trials that used pyrethroid-like insecticides followed this rationale, showing no effect on epidemiological outcomes. In contrast, introducing an non-pyrethroid-like IRS should improve malaria disease outcomes. The findings of Kafy 2017 in particular support this conclusion, reporting reductions in malaria prevalence and incidence only in the second and third years of the trial when the insecticide used for IRS was changed to one with a non-pyrethroid target site. Several trials using non-pyrethroid-like insecticides showed a clear benefit of IRS with large reductions in prevalence, but one study had higher malaria prevalence in the intervention arm (Corbel 2012). To further investigate this unexpected result, we re-examined the manuscript of Corbel 2012, which is reported in meticulous detail. Though the trial was considered at high risk of attrition bias, this was due to the number of theoretical child days lost to follow up being higher in the intervention arm than in the control arm. This potential bias would therefore be unlikely to overestimate the malaria prevalence in the intervention arm. The trial was conducted in an area of moderate allelic frequency of $1014 \mathrm{~F} k d r$, associated with resistance to pyrethroids. There was high coverage of IRS, and though ITN use during the trial was low, this was not lower than another trial in the subgroup that reported a significant effect (West 2014). This suggests their findings of no clear evidence of benefit are valid and not related to problems implementing the intervention. As a result, there remains considerable unexplained heterogeneity between trials for this comparison. More research will be needed to understand this heterogeneity in order to predict when and where the combination of IRS and ITNs will have an impact.

The findings of Protopopoff 2018 may help to indirectly assess the relative importance of the above two concepts. In the trial, the combination of IRS with pyrethroid-PBO nets provided no additional benefit compared to pyrethroid-PBO nets alone, suggesting that the majority of the benefit seen when IRS was combined with a standard ITN was due to the addition of an insecticide that is effective against pyrethroid-resistant mosquitoes, rather than due to the incremental impact of adding a second core intervention.

Third, one potential justification for combining a non-pyrethroidlike IRS with ITNs is to restore susceptibility to pyrethroids in the vector, or to prevent the emergence of resistance in the first place. By this rationale, waiting to implement the combination of IRS with ITNs until incremental impact is demonstrated over ITNs alone may mean doing so far too late (Killeen 2018). While many studies characterized insecticide resistance (either phenotypically, genotypically, or both) at the start of the follow-up period, only two trials continued to monitor the changes in insecticide resistance postintervention rollout. The reporting of such outcomes was heterogeneous, and we were unable to adequately explore the effect that mass rollout of both core interventions would have on insecticide resistance. While standardized methods of measuring and reporting insecticide resistance would help to compare these results between studies, it remains a matter of conjecture whether a considerable change in resistance would be detected within the period of a typical RCT.

\section{Potential biases in the review process}

We did not anticipate in our protocol separating the analyses by whether the insecticide used for IRS had a pyrethroid-like or nonpyrethroid-like target site (Choi 2017). However, because policy makers and specialists in the field considered this to be critical to decision making - to the extent that it would be unusual for anyone to recommend pyrethroid-like insecticides for use in IRS we separated the analysis to be policy-relevant.

\section{Agreements and disagreements with other studies or reviews}

There has been no other systematic review conducted on this topic. A narrative review published by the WHO included the studies by Corbel 2012; Pinder 2015; and West 2014 (WHO 2014d). The review suggested that West 2014 differed from the other studies, showing a reduction in malaria epidemiological outcomes favouring the intervention because the study area had low ITN usage. However, our review includes new trials that show a reduction in epidemiological outcomes even in areas with high ITN usage. Whether or not the IRS was conducted using a pyrethroidlike appears to be a better predictor for success or failure of the intervention, although there remains some heterogeneity when a non-pyrethroid-like insecticide is used. Where we have conducted subgroup analysis to explore this heterogeneity, ITN usage was not shown to be an effect modifier.

\section{AUTHORS' CONCLUSIONS}

\section{Implications for practice}

Four trials tested adding IRS using a non-pyrethroid-like insecticide to ITNs, and gave mixed results. Three trials tested adding indoor residual spraying (IRS) using a pyrethroid-like insecticide to insecticide-treated nets (ITNs), and did not detect an improvement in malaria outcomes. Thus, given the current evidence assessed in this review, adding IRS in either set of circumstances is difficult to justify on the basis that it will improve malaria control. The evidence from these trials was also insufficient to evaluate whether adding IRS in communities using ITNs would be an effective strategy to prevent pyrethroid resistance emerging.

\section{Implications for research}

In some trials assessing the combination of non-pyrethroid-like IRS with ITNs, the effects were substantial, but this effect was absent in one trial. This creates uncertainty and needs further studies to unravel these conflicting results. Researchers and policy makers may wish to consider programme implementation using quasiexperimental methods, such as stepped wedge designs. Improved 
and standardized methods for measuring and reporting pyrethroid resistance will help comparisons between studies.

\section{ACKNOWLEDGEMENTS}

The Academic Editor is Dr Jimee Hwang, and the Sign-off Editor is Dr Hellen Gelband.

We are grateful to Vittoria Lutje, Information Specialist with the Cochrane Infectious Diseases Group (CIDG), for help with the literature search strategy.

Leslie Choi, Joseph Pryce, and Paul Garner are supported by the Research, Evidence and Development Initiative (READ-It). READ-It and the CIDG editorial base are funded by UK aid from the UK government for the benefit of low- and middle-income countries (project number 300342-104). The views expressed do not necessarily reflect the UK government's official policies.

Leslie Choi is supported by PIIVeC, the Partnership for Increasing the Impact of Vector Control. PIIVeC is funded by the Medical Research Council of the UK (grant number MR/P027873/1) through the Global Challenges Research Fund.

This work was partly supported through a grant from the Global Malaria Programme, WHO (WHO Global Malaria Programme Agreement for Performance of Work (APW) Grant 2017 (number 709319)). The views expressed in this review have not been influenced by, or necessarily reflect, WHO policy. 


\section{RE F E R E N C E S}

\section{References to studies included in this review}

\section{Corbel 2012 \{published data only\}}

Corbel V, Akogbeto M, Damien GB, Djenontin A, Chandre F, Rogier C, et al. Combination of malaria vector control interventions in pyrethroid resistance area in Benin: a cluster randomised controlled trial. Lancet Infectious Diseases 2012;12(8):617-26.

\section{Kafy 2017 \{published data only\}}

Kafy HT, Ismail BA, Mnzava AP, Lines J, Abdin MS, Eltaher JS, et al. Impact of insecticide resistance in Anopheles arabiensis on malaria incidence and prevalence in Sudan and the costs of mitigation. Proceedings of the National Academy of Sciences of the United States of America 2017;114(52):E11267-75. [DOI: 10.1073/pnas.1713814114]

\section{Keating 2011 \{published data only\}}

Keating J, Locatelli A, Gebremichael A, Ghebremeskel T, Mufunda J, Mihreteab S, et al. Evaluating indoor residual spray for reducing malaria infection prevalence in Eritrea: results from a community randomized control trial. Acta Tropica 2011;119(2):107-13.

\section{Pinder 2015 \{published data only\}}

Pinder M, Jawara M, Jarju LB, Salami K, Jeffries D, Adiamoh M, et al. Efficacy of indoor residual spraying with dichlorodiphenyltrichloroethane against malaria in Gambian communities with high usage of long-lasting insecticidal mosquito nets: a cluster-randomised controlled trial. Lancet 2015;385(9976):1436-46.

\section{Protopopoff 2018 \{published data only\}}

Protopopoff N, Mosha JF, Lukole E, Charlwood JD, Wright A, Mwalimu CD, et al. Effectiveness of a long-lasting piperonyl butoxide-treated insecticidal net and indoor residual spray interventions, separately and together, against malaria transmitted by pyrethroid-resistant mosquitoes: a cluster, randomised controlled, two-by-two factorial design trial. Lancet 2018:391(10130):1577-88.

\section{West 2014 \{published data only\}}

West PA, Protopopoff N, Wright A, Kivaju Z, Tigererwa R, Mosha FW, et al. Indoor residual spraying in combination with insecticide-treated nets compared to insecticide-treated nets alone for protection against malaria: a cluster randomised trial in Tanzania. PLoS Medicine 2014;11(4):e1001630.

\section{References to studies excluded from this review}

\section{Abeku 2014 \{published data only\}}

Abeku TA, Helinski M, Ssekitooleko J, Kirby MJ, Kyomuhangi I, Magumba G, et al. Variations in malaria epidemiology in relation to vector control coverage in nine districts of Uganda. 63 rd Annual Meeting of the American Society of Tropical Medicine and Hygiene; 2014 Nov 2-6; New Orleans (LA). 2014.
Bekele 2012 \{published data only\}

Bekele D, Belyhun Y, Petros B, Deressa W. Assessment of the effect of insecticide-treated nets and indoor residual spraying for malaria control in three rural kebeles of Adami Tulu District, South Central Ethiopia. Malaria Journal 2012;11(1):127.

Diallo 2015 \{published data only\}

* Diallo A, Cisse B, Tairou F, Ba E, Gomis J, Sy O, et al. A clusterrandomized trial of targeted control to eliminate malaria in central Senegal: main results in year 2. American Journal of Tropical Medicine and Hygiene 2015;93(4):81.

Diallo A, Cisse B, Tairou F, Ba EH, Sy O, Gomis J, et al. A clusterrandomized trial of targeted control to eliminate malaria in central Senegal: study design and acceptability of the interventions. American Journal of Tropical Medicine and Hygiene 2014;91(5 (Suppl 1)):198.

Sy O, Cisse B, Diallo A, Tairou F, Ba EK, Ndiaye JL, et al. Efficacy of Actellic (R) 300 CS (pirimiphos-methyl) after two years of indoor residual spraying in Senegal. American Journal of Tropical Medicine and Hygiene 2015;93(4):81-2.

Tairou F, Ba EH, Diallo A, Sy O, Cisse B, Gomis JF, et al. The costs and cost-effectiveness of two spatially targeted, multicomponent malaria elimination strategies: results of a large three-arm cluster-randomized trial in rural Senegal. American Journal of Tropical Medicine and Hygiene 2015;93(4):81.

Fullman 2013 \{published data only\}

Fullman N, Burstein R, Lim SS, Medlin C, Gakidou E. Nets, spray or both? The effectiveness of insecticide-treated nets and indoor residual spraying in reducing malaria morbidity and child mortality in sub-Saharan Africa. Malaria Journal 2013;12(1):62.

\section{Gari 2016 \{published data only\}}

Gari T, Kenea O, Loha E, Deressa W, Hailu A, Balkew M, et al. Malaria incidence and entomological findings in an area targeted for a cluster-randomized controlled trial to prevent malaria in Ethiopia: results from a pilot study. Malaria Journal 2016;15(1):145.

\section{Gimnig 2016 \{published data only\}}

Gimnig JE, Otieno P, Were V, Marwanga D, Abong'o D, Wiegand $R$, et al. The effect of indoor residual spraying on the prevalence of malaria parasite infection, clinical malaria and anemia in an area of perennial transmission and moderate coverage of insecticide treated nets in Western Kenya. PloS One 2016;11(1):e0145282.

\section{Hamel 2011 \{published data only\}}

Hamel MJ, Otieno P, Bayoh N, Kariuki S, Were V, Marwanga D, et al. The combination of indoor residual spraying and insecticidetreated nets provides added protection against malaria compared with insecticide-treated nets alone. American Journal of Tropical Medicine and Hygiene 2011;85(6):1080-6. 
Katureebe 2016 \{published data only\}

Katureebe A, Zinszer K, Arinaitwe E, Rek J, Kakande E, Charland $\mathrm{K}$, et al. Measures of malaria burden after long-lasting insecticidal net distribution and indoor residual spraying at three sites in Uganda: a prospective observational study. PLOS Medicine 2016;13(11):e1002167.

\section{Kitau 2015 \{published data only\}}

* Kitau J, Protopopoff N, Wright A, West P, Mosha FW, Kisinza W, et al. Anopheles arabiensis is not successfully controlled by indoor residual spraying in Northwest Tanzania: implication for malaria vector control in the area. Tropical Medicine \& International Health 2015;20:19-20.

Protopopoff N, Kitau J, Wright A, West P, Mosha FW, Kisinza W, et al. Anopheles arabiensis is not successfully controlled by indoor residual spraying in northwest Tanzania: Implication for malaria vector control in the area. American Journal of Tropical Medicine and Hygiene 2014;91(5 (Suppl 1)):415.

\section{Lyimo 1991 \{published data only\}}

Lyimo EO, Msuya FH, Rwegoshora RT, Nicholson EA, Mnzava AE, Lines JD, et al. Trial of pyrethroid impregnated bednets in an area of Tanzania holoendemic for malaria. Part 3. Effects on the prevalence of malaria parasitaemia and fever. Acta Tropica 1991;49(3):157-63.

\section{Matowo 2015 \{published data only\}}

Matowo J, Kitau J, Kaaya R, Kavishe R, Wright A, Kisinza W, et al. Trends in the selection of insecticide resistance in Anopheles gambiae sl mosquitoes in northwest Tanzania during a community randomized trial of longlasting insecticidal nets and indoor residual spraying. Medical and Veterinary Entomology 2015;29(1):51-9.

\section{Pinder 2011 \{published data only\}}

Pinder M, Jawara M, Jarju LB, Kandeh B, Jeffries D, Lluberas MF, et al. To assess whether indoor residual spraying can provide additional protection against clinical malaria over current best practice of long-lasting insecticidal mosquito nets in The Gambia: study protocol for a two-armed cluster-randomised trial. Trials 2011;12(1):147.

\section{Pinder 2012 \{published data only\}}

Pinder M, Jawara MS, Jarju LB, Kandeh B, Jeffries D, Bojang KA, et al. To assess whether indoor residual spraying can provide additional protection against clinical malaria over current best practice of long-lasting insecticidal mosquito nets in the Gambia: a two-armed cluster-randomized study. American Journal of Tropical Medicine and Hygiene 2012;87(5 (Suppl 1)):139.

\section{Protopopoff 2007a \{published data only\}}

Protopopoff N, Van Bortel W, Marcotty T, Van Herp M, Maes P, Baza D, et al. Spatial targeted vector control in the highlands of Burundi and its impact on malaria transmission. Malaria Journal 2007;6(1):158.

\section{Protopopoff 2007b \{published data only\}}

Protopopoff N, Van Herp M, Maes P, Reid T, Baza D, D'Alessandro $U$, et al. Vector control in a malaria epidemic occurring within a complex emergency situation in Burundi: a case study. Malaria Journal 2007;6(1):93.

Protopopoff 2015a \{published data only\}

Protopopoff N, Charlwood D, Mosha J, Wright A, Kisinza W, Mosha F, et al. Evaluation of a novel long lasting insecticidal net to indoor residual spray product, separately to together, against malaria transmitted by pyrethroid resistant mosquitoes in northwest Tanzania: a cluster randomized controlled trial. American Journal of Tropical Medicine and Hygiene 2015;93(4):572.

\section{Protopopoff 2015b \{published data only\}}

* Protopopoff N, Wright A, West PA, Tigererwa R, Mosha FW, Kisinza W, et al. Combination of insecticide treated nets and indoor residual spraying in northern Tanzania provides additional reduction in vector population density and malaria transmission rates compared to insecticide treated nets alone: a randomised control trial. PloS One 2015;10(11):e0142671.

Protopopoff N, Wright A, West PA, Tigererwa R, Mosha FW, Kisinza W, et al. Correction: Combination of insecticide treated nets and indoor residual spraying in Northern Tanzania provides additional reduction in vector population density and Malaria transmission rates compared to insecticide treated nets alone: a randomised control trial. PloS One 2016;11(1):e0146629.

\section{West 2012 \{published data only\}}

West PA, Protopopoff N, Rowland M, Wright A, Kivaju Z, Kirby M, et al. Comparison of long-lasting insecticidal nets versus longlasting insecticidal nets in combination with indoor residual house spraying for malaria vector control: results of a cluster randomized trial. American Journal of Tropical Medicine and Hygiene 2012;87(5 (Suppl 1)):3.

\section{West 2015 \{published data only\}}

West PA, Protopopoff N, Wright A, Kivaju Z, Tigererwa R, Mosha FW, et al. Enhanced protection against malaria by indoor residual spraying in addition to insecticide treated nets: is it dependent on transmission intensity or net usage?. PloS One 2015;10(3):e0115661.

\section{Zhou 2013 \{published data only\}}

* Zhou G, Afrane YA, Dixit A, Atieli HE, Lee MC, Wanjala CL, et al. Modest additive effects of integrated vector control measures on malaria prevalence and transmission in western Kenya. Malaria Journal 2013;12(1):256.

Zhou G, Githeko AK, Minakawa N, Yan G. Community-wide benefits of targeted indoor residual spray for malaria control in the western Kenya highland. Malaria Journal 2010;9(1):67.

\section{References to studies awaiting assessment}

\section{Chaccour 2018 \{published data only\}}

Chaccour CJ, Alonso S, Zulliger R, Wagman J, Saifodine A, Candrinho $B$, et al. Combination of indoor residual spraying with long-lasting insecticide-treated nets for malaria control in Zambezia, Mozambique: a cluster randomised trial 
and cost-effectiveness study protocol. BMJ Global Health 2018;3(1):e000610.

\section{Deressa 2016 \{published data only\}}

* Deressa W, Loha E, Balkew M, Hailu A, Gari T, Kenea O, et al. Combining long-lasting insecticidal nets and indoor residual spraying for malaria prevention in Ethiopia: study protocol for a cluster randomized controlled trial. Trials 2016;17(1):20.

Loha E, Deressa W, Gari T, Balkew M, Kenea O, Solomon T, et al. Combining long-lasting insecticidal nets and indoor residual spraying for malaria prevention in Ethiopia: a cluster randomized controlled trial. American Journal of Tropical Medicine and Hygiene 2017;97:602-3.

\section{Hamainza 2016 \{published data only\}}

Hamainza B, Sikaala CH, Moonga HB, Chanda J, Chinula D, Mwenda $\mathrm{M}$, et al. Incremental impact upon malaria transmission of supplementing pyrethroid-impregnated longlasting insecticidal nets with indoor residual spraying using pyrethroids or the organophosphate, pirimiphos methyl. Malaria Journal 2016;15(1):100.

\section{Additional references}

\section{Balshem 2011}

Balshem $\mathrm{H}$, Helfand $M$, Schünemann $\mathrm{HJ}$, Oxman AD, Kunz R, Brozek J, et al. GRADE guidelines: 3 . Rating the quality of evidence. Journal of Clinical Epidemiology 2011;64(4):401-6. [DOI: 10.1016/j.jclinepi.2010.07.015]

\section{Bhatt 2015}

Bhatt S, Weiss DJ, Cameron E, Bisanzio D, Mappin B, Dalrymple $U$, et al. The effect of malaria control on Plasmodium falciparum in Africa between 2000 and 2015. Nature 2015;526(7572):207-11. [DOI: 10.1038/nature15535]

\section{Deeks 2011}

Deeks JJ, Higgins JP, Altman DG, on behalf of the Cochrane Statistical Methods Group. Chapter 9: Analysing data and undertaking meta-analyses. In: Higgins JP, Green S, editor(s). Cochrane Handbook for Systematic Reviews of Interventions Version 5.1.0 (updated March 2011). The Cochrane Collaboration, 2011. Available from handbook.cochrane.org.

\section{Gleave 2018}

Gleave K, Lissenden N, Richardson M, Choi L, Ranson H. Piperonyl butoxide (PBO) combined with pyrethroids in insecticide-treated nets to prevent malaria in Africa. Cochrane Database of Systematic Reviews 2018, Issue 11. [DOI: 10.1002/14651858.CD012776.pub2]

\section{Goodman 2001}

Goodman CA, Mnzava AE, Dlamini SS, Sharp BL, Mthembu DJ, Gumede JK. Comparison of the cost and cost-effectiveness of insecticide-treated bednets and residual house-spraying in KwaZulu-Natal, South Africa. Tropical Medicine \& International Health 2001;6(4):280-95.

\section{Guyatt 2011}

Guyatt GH, Oxman AD, Schünemann HJ, Tugwell P, Knottnerus A. GRADE guidelines: a new series of articles in the Journal of Clinical Epidemiology. Journal of Clinical Epidemiology 2011;64(4):380-2. [DOI: 10.1016/ j.jclinepi.2010.09.011]

\section{Harbord 2006}

Harbord RM, Egger M, Sterne JA. A modified test for smallstudy effects in meta-analyses of controlled trials with binary endpoints. Statistics in Medicine 2006;25(20):3443-57.

\section{Higgins 2011a}

Higgins JP, Deeks JJ, Altman DG, on behalf of the Cochrane Statistical Methods Group. Chapter 16: Special topics in statistics. In: Higgins JP, Green S, editor(s). Cochrane Handbook for Systematic Reviews of Interventions Version 5.1.0 (updated March 2011). The Cochrane Collaboration, 2011. Available from handbook.cochrane.org.

\section{Higgins 2011b}

Higgins JP, Altman DG, Gøtzsche PC, Jüni P, Moher D, Oxman AD, et al. The Cochrane Collaboration's tool for assessing risk of bias in randomised trials. BMJ 2011;343:d5928. [DOI: 10.1136/bmj.d5928]

\section{Killeen 2006}

Killeen GF, Kihonda J, Lyimo E, Oketch FR, Kotas ME, Mathenge $E$, et al. Quantifying behavioural interactions between humans and mosquitoes: evaluating the protective efficacy of insecticidal nets against malaria transmission in rural Tanzania. BMC Infectious Diseases 2006;6:161.

\section{Killeen 2018}

Killeen GF, Ranson H. Insecticide-resistant malaria vectors must be tackled. Lancet 2018;391(10130):551-2.

\section{Kitau 2012}

Kitau J, Oxborough RM, Tungu PK, Matowo J, Malima RC, Magesa SM, et al. Species shifts in the Anopheles gambiae complex: do LLINs successfully control Anopheles arabiensis?. PloS One 2012;7(3):e31481. [DOI: 10.1371/ journal.pone.0031481]

\section{Kleinschmidt 2009}

Kleinschmidt I, Schwabe C, Shiva M, Segura JL, Sima V, Mabunda SJ, et al. Combining indoor residual spraying and insecticide-treated net interventions. American Journal of Tropical Medicine and Hygiene 2009;81(3):519-24.

\section{Ojuka 2015}

Ojuka P, Boum Y 2nd, Denoeud-Ndam L, Nabasumba C, Muller Y, Okia M, et al. Early biting and insecticide resistance in the malaria vector Anopheles might compromise the effectiveness of vector control intervention in Southwestern Uganda. Malaria Journal 2015;14:148. [DOI: 10.1186/s12936-015-0653-z]

\section{Okumu 2011}

Okumu FO, Moore SJ. Combining indoor residual spraying and insecticide-treated nets for malaria control in Africa: a review of 
possible outcomes and an outline of suggestions for the future. Malaria Journal 2011;10(1):208.

\section{Pluess 2010}

Pluess B, Tanser FC, Lengeler C, Sharp BL. Indoor residual spraying for preventing malaria. Cochrane Database of Systematic Reviews 2010, Issue 4. [DOI: 10.1002/14651858.CD006657.pub2]

\section{Pryce 2018}

Pryce J, Richardson M, Lengeler C. Insecticide-treated nets for preventing malaria. Cochrane Database of Systematic Reviews 2018, Issue 11. [DOI: 10.1002/14651858.CD000363.pub3]

\section{Review Manager 2014 [Computer program]}

Nordic Cochrane Centre, The Cochrane Collaboration. Review Manager 5 (RevMan 5). Version 5.3. Copenhagen: Nordic Cochrane Centre, The Cochrane Collaboration, 2014.

\section{Shililu 2004}

Shililu J, Ghebremeskel T, Seulu FE, Mengistu S, Fekadu HE, Zerom M, et al. Seasonal abundance, vector behavior, and malaria parasite transmission in Eritrea. Journal of the American Mosquito Control Association 2004;20(2):155-64.

\section{WHO 2011}

World Health Organization. Vitamin and Mineral Nutrition Information System. Haemoglobin concentrations for the diagnosis of anaemia and assessment of severity. 2011. www.who.int/vmnis/indicators/haemoglobin/en/index.html (accessed 5 June 2017).

\section{WHO 2012}

World Health Organization. Global plan for insecticide resistance management in malaria vectors. 2012. apps.who.int/ iris/bitstream/10665/44846/1/9789241564472_eng.pdf (accessed 5 June 2017).

\section{WHO 2014a}

World Health Organization. WHO guidance for countries on combining indoor residual spraying and long-lasting insecticidal nets. 2014. www.who.int/malaria/publications/ atoz/who-guidance-combining-irs_llins-mar2014.pdf (accessed 3 March 2018).

\section{WHO 2014b}

World Health Organization. WHO recommended longlasting insecticidal nets. 2014. www.who.int/whopes/ Long_lasting_insecticidal_nets_06_Feb_2014.pdf (accessed 3 March 2018).

\section{WHO 2014c}

World Health Organization. WHO recommended insecticide products for treatment of mosquito nets for malaria vector control. 2014. www.who.int/whopes/ Insecticides_ITN_Malaria_Nov2014.pdf (accessed 3 March 2018).

\section{WHO 2014d}

World Health Organization. WHO guidance for countries on combining indoor residual spraying and long-lasting insecticidal nets. www.who.int/malaria/publications/atoz/whoguidance-combining-irs-llins/en/ (accessed 29 June 2018).

\section{WHO 2015a}

World Health Organization. Indoor residual spraying: an operational manual for indoor residual spraying (IRS) for malaria transmission control and elimination. 2nd edition. apps.who.int/iris/ bitstream/10665/177242/1/9789241508940_eng.pdf? ua=1\&ua=1 (accessed 5 June 2017).

\section{WHO 2015b}

World Health Organization. Global Technical Strategy for Malaria 2016-2030. apps.who.int/iris/ bitstream/10665/176712/1/9789241564991_eng.pdf? ua=1\&ua=1. Geneva, Switzerland: WHO, (accessed 5 June 2017).

\section{WHO 2015c}

World Health Organization. Guidelines for the treatment of malaria. 3rd edition. 2015. apps.who.int/iris/ bitstream/10665/162441/1/9789241549127_eng.pdf? ua=1\&ua=1. Geneva, Switzerland: WHO, (accessed 5 June 2017).

\section{WHO 2017a}

World Health Organization. World Malaria Report 2017. apps.who.int/iris/bitstream/ handle/10665/259492/9789241565523eng.pdf;jsessionid=CFDD7D24C7A2D9B507E0087E32B9EA6B? sequence $=1$ (accessed 25 Oct 2018).

\section{WHO 2017b}

World Health Organization. A framework for malaria elimination. apps.who.int/iris/ bitstream/10665/254761/1/9789241511988-eng.pdf?ua=1. Geneva, Switzerland: WHO, (accessed 5 June 2017).

\section{Yakob 2011}

Yakob L, Dunning R, Yan G. Indoor residual spray and insecticide-treated bednets for malaria control: theoretical synergisms and antagonisms. Journal of the Royal Society Interface 2011;8(59):799-806. [DOI: 10.1098/rsif.2010.0537]

\section{Zaim 2000}

Zaim M, Aitio A, Nakashima N. Safety of pyrethroidtreated mosquito nets. Medical and Veterinary Entomology 2000;14(1):1-5.

\section{References to other published versions of this review Choi 2017}

Choi L, Pryce J, Garner P. The combination of indoor residual spraying with insecticide-treated nets versus insecticide-treated nets alone for preventing malaria. Cochrane Database of Systematic Reviews 2017, Issue 6. [DOI: 10.1002/14651858.CD012688]

* Indicates the major publication for the study 


\section{CHARACTERISTICS OF STUDIES}

Characteristics of included studies [ordered by study ID]

Corbel 2012

Methods

Study design: CRCT with 4 intervention arms

- LLIN targeted to pregnant women and children aged $<6$ years (TLLIN)

- TLLIN + full coverage of carbamate IRS (TLLIN + IRS)

- ULLIN

- ULLIN + CTPS

Unit of allocation: clusters (villages)

Number of units: 28 villages randomized into 4 arms equally

Outcome assessment/surveillance type: 60 children randomly selected from each village to participate in the study.

- Active case detection for malaria episodes was done on the cohort of children during 12 periods of 6 consecutive days at 6-weekly intervals. Thick blood films were taken from every sick child.

- Cross-sectional surveys were done at each period of clinical monitoring on every asymptomatic child who showed an axillary temperature $<37.5^{\circ} \mathrm{C}$. A thick film sample was taken on the fourth day to ensure that asymptomatic children were not sick in preceding days.

- From 14 January to 24 December 2009, mosquitoes were collected through 8 surveys of 2 consecutive days every 6 weeks. This collection occurred 2 weeks before medical surveys. Sporozoite rate was detected using ELISA of heads and thoraces for $P$ falciparum CSP.

Length of follow-up: 18 months (23 June 2008 to 24 December 2009)

Adjustment for clustering: yes

Participants

Number of participants: 3018 (429) TLLIN, 1996 (420) ULLIN, 2251 (415) ULLIN + CTPS, 2660 (413) TLLIN + IRS

\section{Population characteristics:}

- TLLIN arm coverage to pregnant women and children aged $<6$ years

- Moderate level of pyrethroid resistance in malaria vectors ( $>40 \% k d r$ allelic frequency)

- Population size of 250-500 inhabitants with non-isolated habitations

- Absence of a local health centre

- Inclusion criteria for children were age (0-71 months) and their effective domiciliation in these village

Withdrawal and loss to follow-up: in every arm, about $20 \%$ of the recordings were not taken into account because of loss to follow-up (17\%), death of children (1.5\%), and refusal (1.5\%)

Interventions

Relevant comparison for this review: TLLIN versus TLLIN + IRS

IRS:

Active ingredient and dosage: bendiocarb $400 \mathrm{mg} / \mathrm{m}^{2}$

Formulation: wettable powder

Frequency of spraying: every 8 months

Coverage: aimed for $80 \%$ coverage as per WHO recommendations

Buffer size between clusters: minimum $2 \mathrm{~km}$ between villages

ITN: 
Corbel 2012 (Continued)

Active ingredient and dosage: deltamethrin $55 \mathrm{mg}$ (PermaNet 2.0)

Coverage: for TLLIN coverage, 1 LLIN was provided per sleeping unit of children $<6$ years or pregnant women, or both, whereas 1 net was given to every sleeping unit for ULLIN coverage. Overall, this corresponded to a mean of 1 LLIN every 4 people for TLLIN and 1 net for every 2 people for ULLIN (census showed that the mean number of people per house was 4). Coverage was defined as the total number of hung nets relative to the total number of sleeping units. Mean coverage was low: $38 \%$ in the control arm and $45 \%$ in the intervention arm.

Compliance: defined as proportion of children aged $<6$ years sleeping under the net the night preceding the visit. Mean compliance was low: $58 \%$ in the control arm and $45 \%$ in the intervention arm.

Control: ITN only as above

Cointerventions: none reported

Outcomes

Incidence density rates of $P$ falciparum clinical malaria in children aged $<6$ years (defined as malaria symptoms + a parasite density $>2000$ parasites $/ \mu \mathrm{L}$ )

Prevalence of asymptomatic infections in children aged $<6$ years

Parasite density of asymptomatic infections in children aged $<6$ years

EIR (as defined by the number of infected bites per person per year)

Prevalence of pyrethroid-resistant 1014F kdr allele and carbamate-resistant G119S ace1 allele in malaria vectors

Geometric mean of $P$ falciparum parasites $/ \mu \mathrm{L}$

Location profile

Study location: Ouidah-Kpomasse-Tori Bossito health district, southern Benin

Malaria endemicity: mesoendemic

EIR: control arm reported an annual mean of 9.4 infected bites/person/year (range 5.1-17.1)

Population proximity/density: density $/ \mathrm{km}^{2}$

TLLIN: 449

ULLIN: 462

ULLIN + CTPS: 577

TLLIN + IRS: 579

Plasmodium spp: $P$ falciparum

Vector profile

Primary (and secondary) vector species: An gambiae s.l. and An funestus s.l.

Vector behaviour (nature, stability, adult habitat, peak biting times, exophilic/endophilic, exophagic/endophagic, anthropophilic/zoophilic): not measured

Phenotypic resistance profile: not measured

Genotypic resistance profile: moderate $k d r$ allelic frequency and virtually no ace 1 allelic frequency

Method of mosquito collection: adult female mosquitoes were caught using human landing catches technique both indoors and outdoors at 4 sites per village from 10 p.m. to 6 a.m. and for 2 consecutive nights per survey (that is, 16 person-nights per village per survey). Independent staff regularly checked quality of the mosquito collections on a randomly selected sample representing $12 \%$ of the total nightcollection. 
Corbel 2012 (Continued)

Risk of bias

\begin{tabular}{lll}
\hline Bias & Authors' judgement & Support for judgement \\
\hline $\begin{array}{ll}\text { Random sequence genera- } \\
\text { tion (selection bias) }\end{array}$ & Low risk & $\begin{array}{l}\text { Quote: "In each village, we randomly selected } 60 \text { children aged < } 6 \text { years from } \\
\text { the census list of the inhabitants to participate using computer-generated ran- } \\
\text { dom numbers. The allocation sequence and randomization of the blocks and } \\
\text { children were prepared by the study statistician at IRD-CREC." }\end{array}$
\end{tabular}

\begin{tabular}{ll}
\hline $\begin{array}{l}\text { Allocation concealment } \\
\text { (selection bias) }\end{array}$ & Low risk
\end{tabular}$\quad \begin{aligned} & \text { Children and study investigators were not blinded to treatment allocation but } \\
& \text { allocation sequence and randomization of the blocks and children were pre- } \\
& \text { pared by the study statistician at IRD-CREC. }\end{aligned}$

Blinding of participants Low risk

Participants and personnel were not blinded to intervention.

and personnel (perfor-

mance bias)

Incidence of malaria

\begin{tabular}{|c|c|c|}
\hline $\begin{array}{l}\text { Blinding of participants } \\
\text { and personnel (perfor- }\end{array}$ & Low risk & $\begin{array}{l}\text { Participants and personnel were not blinded to intervention. Low risk of bias } \\
\text { for prevalence as all cohort members had their blood taken. }\end{array}$ \\
\hline
\end{tabular}

mance bias)

Prevalence of malaria

\begin{tabular}{|c|c|c|}
\hline $\begin{array}{l}\text { Blinding of outcome as- } \\
\text { sessment (detection bias) } \\
\text { Incidence of malaria }\end{array}$ & Unclear risk & $\begin{array}{l}\text { Participants and personnel were not blinded to intervention. Unclear risk of } \\
\text { bias for incidence due to self-reporting of sickness before confirmation by mi- } \\
\text { croscopy, an objective assessment. }\end{array}$ \\
\hline
\end{tabular}

\begin{tabular}{|c|c|c|}
\hline $\begin{array}{l}\text { Blinding of outcome as- } \\
\text { sessment (detection bias) } \\
\text { Prevalence of malaria }\end{array}$ & Low risk & $\begin{array}{l}\text { Participants and personnel were not blinded to intervention. Low risk of bias } \\
\text { for prevalence as all cohort members had their blood taken. }\end{array}$ \\
\hline $\begin{array}{l}\text { Incomplete outcome data } \\
\text { (attrition bias) } \\
\text { All outcomes }\end{array}$ & High risk & $\begin{array}{l}\text { Loss to follow-up performed but over } 10 \% \text { difference in children-days between } \\
\text { the } 2 \text { arms: } 5224 \text { theoretical children-days missing in control arm, } 6688 \text { chil- } \\
\text { dren-days missing in intervention arm. }\end{array}$ \\
\hline
\end{tabular}

\begin{tabular}{|c|c|c|}
\hline $\begin{array}{l}\text { Selective reporting (re- } \\
\text { porting bias) }\end{array}$ & Low risk & $\begin{array}{l}\text { All children-days were analyzed. The study protocol reported } 1 \text { each outcome } \\
\text { as stated in the clinical trials register (note: retrospectively registered). }\end{array}$ \\
\hline Recruitment bias & Low risk & Cohort of children were randomly selected. \\
\hline Baseline imbalance & Low risk & $\begin{array}{l}\text { Baseline data were displayed. No significant differences at baseline between } \\
\text { intervention arms for incidence }(P=0.78) \text {. The prevalence was significantly } \\
\text { higher in the TTLIN + IRS arm }(P=0.01) \text {. Entomological outcomes were not } \\
\text { provided at baseline. }\end{array}$ \\
\hline
\end{tabular}

\begin{tabular}{lll}
\hline Loss of clusters & Low risk & No clusters were lost. \\
\hline Incorrect analysis & Low risk & Adjustment for clustering was done. \\
\hline $\begin{array}{l}\text { Comparability with RCTs } \\
\text { randomizing participants }\end{array}$ & Low risk & $\begin{array}{l}\text { Because the intervention is expected to have community level impact as well } \\
\text { as individual impact, cRCTs are the most appropriate study design to capture } \\
\text { this. }\end{array}$ \\
\hline Other bias & Low risk & No other biases. \\
\hline
\end{tabular}


Unit of allocation: clusters (villages)

Number of units: 26 villages randomized into 2 arms equally. Each cluster consisting of $\geq 500$ households

Outcome assessment/surveillance type: 60 children randomly selected from each village to participate in the study

- Active case detection for malaria episodes was done on the cohort of children aged 0.5-10 years weekly during the peak of the malaria season (September to November) and fortnightly during the remainder of the year, for a total of 30 annual visits. during 12 periods of 6 consecutive days at 6-weekly intervals. Malaria was confirmed by RDT (SD BIOLINE-Malaria Ag P.f/P.v.; Standard Diagnostics, Inc.), or microscopy, or both.

- Prevalence of infection was measured once each year, during September to October. Cohort of children were tested for $P$ falciparum infection using RDTs (SD BIOLINE-Malaria Ag P.f/P.v.; Standard Diagnostics, Inc.) irrespective of symptoms.

Length of follow-up: 1 June 2012 to 31 May 2015

Adjustment for clustering: yes

Participants

Number of participants: total population in study area in 2011 was 139,566. Over the 3-year study period, 7529 children were recruited who were followed up cumulatively for 17,284 person-years.

Population characteristics: a baseline household census estimated that the area comprised approximately 119,000 households in 197 villages with 600,000 inhabitants who were predominantly dependent on rain-fed agriculture. Mean age of cohort children were similar across all study arms (about 5-6 years old)

Withdrawal and loss to follow-up: not reported

\section{Comparison: IRS + ITN versus ITN alone}

\section{IRS:}

Active ingredient, dosage, and formulation: deltamethrin $25 \mathrm{mg} / \mathrm{m}^{2}$ in 2012 (formulation not reported, Chema Industries), bendiocarb $200 \mathrm{mg} / \mathrm{m}^{2}$ in 2013 and 2014 (Ficam 80\%, wettable powder, Bayer)

Frequency of spraying: IRS was conducted in August and late December of each year

Coverage: $99 \%$ in 2012, $82 \%$ in 2013, and $83 \%$ in 2014

Buffer size between clusters: minimum $3 \mathrm{~km}$ between the edges of adjoining clusters

ITN:

Active ingredient and dosage: deltamethrin $55 \mathrm{mg}$ (PermaNet 2.0)

Coverage: an annual intervention assessment survey showed that household net ownership was $99.6 \%$ in $2012,82.1 \%$ in 2013 , and $98.6 \%$ in 2014 .

Compliance: defined as the proportion of affirmative responses to the question "Did this child sleep under an LLIN last night?" In 2012, this was 79\% in both arms. In 2013, it was $74 \%$ in the LLIN-only arm and $75 \%$ in the LLIN + IRS arm. In 2014, it was $82 \%$ in both study arms.

Control: ITN only as above

Cointerventions: none reported 
Kafy 2017 (Continued)

- Deltamethrin susceptibility using WHO discriminating dose tests

- Prevalence of pyrethroid-resistant 1014F kdr allele

- Cost and cost-effectiveness

Location profile

Study location: Galabat, south-eastern Sudan, located around $80 \mathrm{~km}$ from Gedarif town and borders Ethiopia

Malaria endemicity: highly seasonal

EIR: not reported

Population proximity/density: not reported

Plasmodium spp: $P$ falciparum accounts for $95 \%$ of the malaria burden

Vector behaviour (nature, stability, adult habitat, peak biting times, exophilic/endophilic, exophagic/endophagic, anthropophilic/zoophilic): not reported

Phenotypic resistance profile: mean percentage mortality in the LLIN arm $(65.0 \%, 95 \% \mathrm{Cl} 44.6 \%$ to $85.3 \%)$ was not significantly different from that of the LLIN + IRS arm (60\%, 95\% Cl 38.2\% to $82.2 \%)$ during 2012 ( $t=0.425$; degrees of freedom 9; $P=0.68$ ).

Genotypic resistance profile: Vgsc-1014F allelic frequency was around $60 \%$ in mosquitoes sampled from both study arms in 2012

Method of mosquito collection: Anopheles larvae and pupae were collected annually during the rainy season. Adults were collected using pyrethrum spray catches. 24 An arabiensis females per cluster were selected at random for Vgsc-1014F genotyping to estimate a cluster-specific resistance marker frequency.

Notes

\section{Risk of bias}

Bias Authors' judgement Support for judgement

Random sequence genera- Low risk tion (selection bias)

Clusters were randomly allocated using a restricted randomization computerized procedure. Balance criteria were prevalence of $P$ falciparum infection, ITN use, $k d r$ frequency in An arabiensis and cluster population size. Out of 200,000 random allocations, 8000 yielded balance between study arms on these criteria, from which 1 sequence was randomly selected.

\section{Allocation concealment Low risk} (selection bias)
The 26 clusters in Gedarif, Sudan were randomized to receive LLIN + IRS or LLINs alone, using restricted randomization to ensure balance between study arms.

Balance criteria were: prevalence of $P$ falciparum infection and ITN use as determined in a baseline survey, $\mathrm{kdr}$ frequency in An arabiensis from a survey of mosquito collections carried out in each cluster, and cluster population size. Out of 200,000 random allocations of the 26 clusters, 8000 yielded balance between study arms on these criteria. Of these, 1 allocation was randomly chosen, after verifying that the imposed restriction did not introduce undue dependence between clusters.

Blinding of participants Low risk
and personnel (perfor-
mance bias)
Incidence of malaria

Participants and personnel were not blinded to intervention. Low risk of bias for both incidence and prevalence. RDTs and microscopy were used to confirm malaria infection. 
Kafy 2017 (Continued)

\begin{tabular}{|c|c|c|}
\hline $\begin{array}{l}\text { Blinding of participants } \\
\text { and personnel (perfor- } \\
\text { mance bias) }\end{array}$ & Low risk & $\begin{array}{l}\text { Participants and personnel were not blinded to intervention. Low risk of bias } \\
\text { for both incidence and prevalence. RDTs and microscopy were used to confirm } \\
\text { malaria infection. }\end{array}$ \\
\hline
\end{tabular}

mance bias)

Prevalence of malaria for both incidence and prevalence. RDTs and microscopy were used to confirm

\begin{tabular}{|c|c|c|}
\hline $\begin{array}{l}\text { Blinding of outcome as- } \\
\text { sessment (detection bias) } \\
\text { Incidence of malaria }\end{array}$ & Low risk & $\begin{array}{l}\text { Participants and personnel were not blinded to intervention. Low risk of bias } \\
\text { for both incidence and prevalence. RDTs and microscopy were used to confirm } \\
\text { malaria infection. }\end{array}$ \\
\hline
\end{tabular}

\begin{tabular}{|c|c|c|}
\hline $\begin{array}{l}\text { Blinding of outcome as- } \\
\text { sessment (detection bias) } \\
\text { Prevalence of malaria }\end{array}$ & Low risk & $\begin{array}{l}\text { Participants and personnel were not blinded to intervention. Low risk of bias } \\
\text { for both incidence and prevalence. RDTs and microscopy were used to confirm } \\
\text { malaria infection. }\end{array}$ \\
\hline
\end{tabular}

Incomplete outcome data $\quad$ Unclear risk $\quad$ No report of withdrawals.
(attrition bias)

All outcomes

\begin{tabular}{|c|c|c|}
\hline $\begin{array}{l}\text { Selective reporting (re- } \\
\text { porting bias) }\end{array}$ & Low risk & $\begin{array}{l}\text { All children-days were analyzed. The study protocol reports } 1 \text { each outcome as } \\
\text { stated in the clinical trials register (note: retrospectively registered) }\end{array}$ \\
\hline Recruitment bias & Low risk & Cohort of children were randomly selected \\
\hline Baseline imbalance & Low risk & $\begin{array}{l}\text { Although baseline information was not available, key effect modifiers such as } \\
\text { age and LLIN usage were measured during the study and there were no signifi- } \\
\text { cant differences. }\end{array}$ \\
\hline Loss of clusters & Low risk & No clusters were lost. \\
\hline Incorrect analysis & Low risk & Adjustment for clustering was done. \\
\hline $\begin{array}{l}\text { Comparability with RCTs } \\
\text { randomizing participants }\end{array}$ & Low risk & $\begin{array}{l}\text { Because the intervention is expected to have community level impact as well } \\
\text { as individual impact, CRCTs are the most appropriate study design to capture } \\
\text { this. }\end{array}$ \\
\hline Other bias & Low risk & No other biases. \\
\hline
\end{tabular}

Keating 2011

Study design: CRCT with 2 intervention arms
Unit of allocation: clusters (villages)
Number of units: 58 randomized villages in each arm
Outcome assessment/surveillance type: 15 houses within each village were randomly selected to
serve as ultimate sampling units, giving 870 houses in each arm of the study. Household residents were
given a questionnaire and took a RDT (Carestart) for malaria infection. Positive tests were confirmed by
blood smear microscopy.

Length of follow-up: 3-4 months post spraying (6-15 October 2009)

Adjustment for clustering: yes

Participants Number of participants: 7273 resided in participating houses. In the paper, 5508 total from Table 2 but 5502 stated in results

Population characteristics: the distribution of participants living in houses located in treatment and control villages was similar on sex, age, employment status of the respondent, and education level 
Keating 2011 (Continued)

Withdrawal and loss to follow-up: test refusal rates differed between treatment $(8.5 \%)$ and control $(12.7 \%)$ arms $(P<0.05)$

Interventions

\section{Comparison: IRS + ITN versus ITN alone}

IRS:

Active ingredient and dosage: DDT $1-2 \mathrm{~g} / \mathrm{m}^{2}$

Formulation: wettable powder

Frequency of spraying: once, June-July 2009

Coverage: minimum $80 \%$ target ( $84.8 \%$ of households sampled sprayed within 12 months)

Buffer size between clusters: $>5 \mathrm{~km}$ between intervention and control villages. in 2 instances whereby a treatment village was too close $(<5 \mathrm{~km})$ to a control village, the closest village $>5 \mathrm{~km}$ was selected into the control arm.

ITN: any ITN that was treated at least once in last 11 months, or was an LLIN

Coverage: measured as people living in household owning $\geq 1$ ITN: $75.8 \%$ (range $74.2 \%$ to $77.4 \%$ )

Compliance: measured as individuals using ITN in the previous night: $50.7 \%$ (range $48.6 \%$ to $52.8 \%$ )

Control: ITN only as above

Coverage: measured as people living in household owning $\geq 1$ ITN: $72.0 \%$ (range $70.2 \%$ to $73.7 \%$ )

Compliance: measured as people using ITN in the previous night: $46.2 \%$ (range $43.9 \%$ to $48.6 \%$ )

Cointerventions: larval habitat management and continued case management

Outcomes

Location profile
Malaria prevalence: parasite infection and febrile illness data from all household residents $>1$ month old requiring a positive RDT (Carestart) and a positive thick blood film

Study location: Gash Barka, West lowlands of Eritrea, mostly rural and agricultural. Altitudes were 1500-3000 m above sea level. 30\% of the country's population lived here. Approximately $200 \mathrm{~mm}$ per year precipitation. Temperatures were extremely hot and dry climatic conditions with seasonal precipitation, concentrated in the summer months.

Malaria endemicity: season with peak transmission occurring September-November. Smaller malaria season March-April

EIR: study references an estimated annual range of 0-70.6 (Shililu 2004).

Population proximity/density: not reported

Plasmodium spp: $P$ falciparum with rare reports of $P$ vivax

Vector profile

Primary (and secondary) vector species: An arabiensis and An gambiae s.S.

Vector behaviour (nature, stability, adult habitat, peak biting times, exophilic/endophilic, exophagic/endophagic, anthropophilic/zoophilic): not reported

Phenotypic resistance profile: not reported

Genotypic resistance profile: not reported

Method of mosquito collection: no entomological data collected

Notes 
Keating 2011 (Continued)

\begin{tabular}{lll} 
Bias & Authors' judgement & Support for judgement \\
\hline $\begin{array}{l}\text { Random sequence genera- } \\
\text { tion (selection bias) }\end{array}$ & Unclear risk & Quote: "Fifty-eight (58) v \\
& & Comment: however rand \\
\hline $\begin{array}{l}\text { Allocation concealment } \\
\text { (selection bias) }\end{array}$ & Unclear risk & Not stated. \\
\hline $\begin{array}{l}\text { Blinding of participants } \\
\text { and personnel (perfor- } \\
\text { mance bias) } \\
\text { Incidence of malaria }\end{array}$ & Low risk & Outcome not reported. \\
\hline
\end{tabular}

\begin{tabular}{ll}
\hline $\begin{array}{l}\text { Blinding of participants } \\
\text { and personnel (perfor- } \\
\text { mance bias) }\end{array}$ & $\begin{array}{l}\text { Participants and personnel were not blinded to the intervention status; how- } \\
\text { ever, the outcome would not be affected by this knowledge. }\end{array}$ \\
Prevalence of malaria &
\end{tabular}

\begin{tabular}{|c|c|c|}
\hline $\begin{array}{l}\text { Blinding of outcome as- } \\
\text { sessment (detection bias) } \\
\text { Incidence of malaria }\end{array}$ & Low risk & Outcome not reported. \\
\hline $\begin{array}{l}\text { Blinding of outcome as- } \\
\text { sessment (detection bias) } \\
\text { Prevalence of malaria }\end{array}$ & Low risk & $\begin{array}{l}\text { Outcome assessors were not blinded to the intervention status; however, the } \\
\text { outcome was measured using an objective tool (Carestart RDT) and would not } \\
\text { be affected by this knowledge. }\end{array}$ \\
\hline $\begin{array}{l}\text { Incomplete outcome data } \\
\text { (attrition bias) } \\
\text { All outcomes }\end{array}$ & Low risk & Only one time point used, inapplicable \\
\hline $\begin{array}{l}\text { Selective reporting (re- } \\
\text { porting bias) }\end{array}$ & Low risk & $\begin{array}{l}\text { The study only intended to report the relationship between IRS and parasite } \\
\text { prevalence and this outcome was provided. Numbers appeared correct, as- } \\
\text { sumed typographical error in table } 2 \text {, should read } 5502 \text {. }\end{array}$ \\
\hline Recruitment bias & Low risk & Households for survey were randomly selected. \\
\hline Baseline imbalance & Unclear risk & $\begin{array}{l}\text { Baseline data were not displayed but due to randomization this should be ac- } \\
\text { counted for. }\end{array}$ \\
\hline Loss of clusters & Low risk & No mention of lost clusters. \\
\hline Incorrect analysis & Low risk & Adjustment for clustering was done. \\
\hline $\begin{array}{l}\text { Comparability with RCTs } \\
\text { randomizing participants }\end{array}$ & Low risk & $\begin{array}{l}\text { Because the intervention is expected to have community level impact as well } \\
\text { as individual impact, cRCTs are the most appropriate study design to capture } \\
\text { this. }\end{array}$ \\
\hline Other bias & Low risk & No other biases. \\
\hline
\end{tabular}

\title{
Pinder 2015
}

\section{Methods}

\author{
Study design: CRCT with 2 intervention arms
}

Unit of allocation: clusters of villages, each cluster consisted of 1-3 neighbouring villages (97 villages in total) 
Number of units: 35 randomized clusters in each arm. A subset of 16 clusters per arm was used for entomological assessment

\section{Outcome assessment/surveillance type:}

- Children in the study villages aged 6 months to 14 years were sampled according to cluster size and enrolled into a study cohort

- Incidence rates monitored through passive case detection at local health facilities

- Prevalence and parasite rates were measured at the end of each transmission season

- Mosquito density was assessed using light traps and exit traps in 6 sentinel sites in each of 32 clusters, 1 night per month

Length of follow-up: 2 years (2010-2011), 2 transmission seasons (June-December 2010 and 2011)

Adjustment for clustering: cluster adjusted measures were presented for some outcomes.

Participants

Number of participants: control: 3949 enrolled children, intervention: 3896

Population characteristics: cohort of children aged $<14$ years. Ethnic origin varied with more Mandin$k a$ and lower Fula people in the LLIN arm than in the IRS + LLIN arm.

Withdrawal and loss to follow-up: separate analysis was done per survey, each time a survey was done, cohorts would be replenished.

Interventions

\section{Comparison: IRS + ITN versus ITN alone}

IRS:

Active ingredient and dosage: DDT target dose $2 \mathrm{~g} / \mathrm{m}^{2}$ (2010 mean: $1.69 \mathrm{~g} / \mathrm{m}^{2}, 2011: 3.27 \mathrm{~g} / \mathrm{m}^{2}$ )

Formulation: $75 \%$ wettable powder

Frequency of spraying: once per transmission season (15-28 July 2010, and 20 July to 9 August 2011)

Coverage: per cluster in 2010 (\%): 86 (range 82.84-90.16); per cluster in 2011 (\%): 83 (range 79.27-86.28)

Buffer size between clusters: $>2 \mathrm{~km}$

ITN:

Active ingredient and dosage: permethrin $2 \% \mathrm{w} / \mathrm{w}$ (Olyset Net)

Coverage: nets were provided to cover all sleeping spaces as determined by a baseline survey. $59 \%$ coverage in June 2010. 89\% coverage in January 2011. 93\% in January 2012.

Compliance: not reported

Control: ITN only as above

Coverage: 2010: 62\%; 2011: 92\%; 2012: 96\%.

Compliance: not reported

Cointerventions: none reported

Outcomes Primary:

Incidence of clinical malaria assessed by passive case detection Number of An gambiae s.l. collected per light trap per night

Secondary:

Haemoglobin concentration 
Pinder 2015 (Continued)

Proportion of children with moderate anaemia $(<80 \mathrm{~g} / \mathrm{L})$ and severe anaemia $(<50 \mathrm{~g} / \mathrm{L})$

Presence of malaria parasites

Parasite density

Proportion of children with high parasitaemia (> 5000 parasites $/ \mu \mathrm{L}$ )

Prevalence of children with enlarged spleens measured at the end of the transmission season each year

Sporozoite rate estimates in trapped mosquitoes

Estimated EIR (mean number of infective mosquito bites per person per season)

Location profile

Study location: Upper River Region of The Gambia, > 110 children aged 6 months to 14 years on 1 June 2010

Malaria endemicity: moderate seasonal malaria transmission

EIR: estimated seasonal mean from the control arm of the study measured 2.44 (range $0.69-6.39$ ) in the first year and $0.29(0.003-2.66)$ in the second year

Population proximity/density: not reported

Plasmodium spp: $P$ falciparum

Vector profile

Primary (and secondary) vector species: An gambiae s.l.

Vector behaviour (nature, stability, adult habitat, peak biting times, exophilic/endophilic, exophagic/endophagic, anthropophilic/zoophilic): not reported

Phenotypic resistance profile: not reported

Genotypic resistance profile: not reported

Method of mosquito collection: light and exit traps indoors in 6 rooms in 6 different randomly selected compounds per cluster, 1 night per month

\footnotetext{
Notes
}

\section{Risk of bias}

\begin{tabular}{lll}
\hline Bias & Authors' judgement & Support for judgement \\
\hline $\begin{array}{l}\text { Random sequence genera- } \\
\text { tion (selection bias) }\end{array}$ & Low risk & Villages were randomly assigned using a computerized algorithm. \\
\hline $\begin{array}{l}\text { Allocation concealment } \\
\text { (selection bias) }\end{array}$ & Low risk & Villages were randomly assigned using a computerized algorithm. \\
\hline $\begin{array}{l}\text { Blinding of participants } \\
\text { and personnel (perfor- } \\
\text { mance bias) } \\
\text { Incidence of malaria }\end{array}$ & Low risk & Participants and personnel were not blinded to intervention. \\
\hline $\begin{array}{l}\text { Blinding of participants } \\
\text { and personnel (perfor- } \\
\text { mance bias) }\end{array}$ & Low risk & For prevalence, risk of bias is low as every participant had their blood taken. \\
$\begin{array}{l}\text { Prevalence of malaria } \\
\end{array}$ & \\
\hline
\end{tabular}


Pinder 2015 (Continued)

Blinding of outcome as- Unclear risk Unclear risk of bias for incidence due to self-reporting of sickness before consessment (detection bias) firmation by microscopy, an objective assessment.

Incidence of malaria

$\begin{array}{ll}\begin{array}{l}\text { Blinding of outcome as- } \\ \text { sessment (detection bias) }\end{array} & \text { Low risk } \\ \begin{array}{l}\text { Prevalence of malaria } \\ \text { For prevalence, risk of bias was low as every participant had their blood tak- } \\ \text { en. Observer bias was reduced where feasible. Slide microscopists and their } \\ \text { supervisors were blinded to the identity and intervention status of the partici- } \\ \text { pants. }\end{array}\end{array}$

\begin{tabular}{lll}
\hline $\begin{array}{l}\text { Incomplete outcome data } \\
\text { (attrition bias) } \\
\text { All outcomes }\end{array}$ & Low risk & $\begin{array}{l}\text { Incomplete outcome data were minimal and similar between intervention } \\
\text { arms. Attrition between 2010 and 2011 accounted for by topping up cohort } \\
\text { with newborn children (312 in LLIN + IRS arm; 324 in LLIN-only arm). }\end{array}$ \\
\hline $\begin{array}{l}\text { Selective reporting (re- } \\
\text { porting bias) }\end{array}$ & Low risk & $\begin{array}{l}\text { The study protocol reported on each outcome as stated in the clinical trials } \\
\text { register (note: retrospectively registered). }\end{array}$ \\
\hline Recruitment bias & Low risk & Cohort of children were randomly selected. \\
\hline $\begin{array}{l}\text { Baseline imbalance } \\
\text { Loss of clusters }\end{array}$ & Low risk & Baseline data were displayed and similar. \\
\hline $\begin{array}{l}\text { Incorrect analysis } \\
\text { Comparability with RCTs } \\
\text { randomizing participants }\end{array}$ & Low risk & No clusters were lost. \\
\hline \begin{tabular}{l} 
Other bias \\
\hline
\end{tabular} & Low risk & $\begin{array}{l}\text { Adjustment for clustering was done. } \\
\text { Because the intervention was expected to have community level impact as } \\
\text { ture this. }\end{array}$ \\
\hline
\end{tabular}

Study design: CRCT with 4 intervention arms using a $2 \times 2$ factorial design
- $\operatorname{arm~1:~standard~LLIN~(Olyset~Net)~}$
- $\operatorname{arm~2:~standard~LLIN~(Olyset~Net)~+~IRS~}$
- $\operatorname{arm~3:~pyrethroid~net~+~synergist~PBO~(Olyset~Plus)~}$
arm 4: pyrethroid net + synergist PBO (Olyset Plus) + IRS

\section{Therefore, there were 2 comparisons for this review: arm 1 versus arm 2, and arm 3 versus arm 4}

Unit of allocation: clusters comprised from 40 villages

Number of units: 48 clusters randomized into 4 arms equally

Outcome assessment/surveillance type: cross-sectional surveys of children aged 0.5-14 years were done to determine the prevalence of Plasmodium spp infection. The main endpoint for assessment of the IRS was 9 months postintervention. Up to 3 children from 55 households with eligible participants per cluster were randomly selected for each survey.

Length of follow-up: originally planned for 18 months (1 January 2015 to 30 June 2016) but was subsequently extended to 24 months (1 January 2014 to 31 December 2016)

Adjustment for clustering: yes

Participants

Number of participants: at the primary endpoint for assessment of the IRS, the number of children recruited were 933 in arm 1, 877 in arm 2, 883 in arm 3, and 969 in arm 4 Population characteristics: 
- total population in core and buffer areas ranged from 31,138 to 38,081

- total population in the core area of the clusters between 14,845 and 16,358

Withdrawal and loss to follow-up: a fresh cohort was recruited for each cross-sectional survey and ITT analysis was conducted.

Interventions
IRS:

Active ingredient and dosage: pirimiphos-methyl at the recommended dosage $1 \mathrm{~g} / \mathrm{m}^{2}$

Formulation: $30 \%$ capsule suspension (Actellic 300CS)

Frequency of spraying: once in February 2015

Coverage: per cluster (\%): $94 \%(95 \% \mathrm{Cl} 92 \%$ to $96 \%)$ in arm 2 and $94 \%(95 \% \mathrm{Cl} 87 \%$ to $97 \%)$ in arm 4

Buffer size between clusters: minimum outer buffer zone of $300 \mathrm{~m}$. Only the inner core area was used for the measurement of study outcomes

\section{ITN:}

Active ingredient and dosage: permethrin $2 \% \mathrm{w} / \mathrm{w}$ (Olyset Net) and permethrin $2 \%$ (Olyset Plus) and PBO $1 \% \mathrm{w} / \mathrm{w}$

Coverage: 9 months postintervention, coverage defined as household owning $\geq 1$ LLIN (study LLIN or any other LLIN) was 98\% (95\% CI 96\% to 99\%) in arm 2 and 98\% (95\% CI 95\% to 99\%) in arm 4

Compliance: at 9 months postintervention, compliance defined as residents declaring to use an LLIN the previous night (study LLIN or any other LLIN) was 76\% (95\% CI $70 \%$ to $80 \%$ ) in arm 2 and $77 \%$ (95\% $\mathrm{Cl} 70 \%$ to $83 \%)$ in arm 4

Control: ITN only as above

Coverage: at 9 months postintervention, coverage defined as household owning $\geq 1$ LLIN (study LLIN or any other LLIN) was 97\% (95\% CI 93\% to 99\%) in arm 1 and 98\% (95\% Cl 97\% to 99\%) in arm 3

Compliance: at 9 months postintervention, compliance defined as residents declaring to use a LLIN the previous night (study LLIN or any other LLIN) was $80 \%(95 \% \mathrm{CI} 75 \%$ to $85 \%)$ in arm 1 and $78 \%(95 \% \mathrm{CI}$ $73 \%$ to $82 \%$ ) in arm 3

Cointerventions: none reported
Location profile
- Prevalence of Plasmodium spp infection

- Proportion of children with moderate-to-severe anaemia (defined as haemoglobin $<8 \mathrm{~g} / \mathrm{dL}$ )

- EIR defined as the mean number of infective mosquito bites per household per month

- Adult mosquito density per night per household
Study location: Northwest Tanzania, Muleba Distract, Kagera Region, the study area comprised 29,365 households and a population of 135,900 people

Malaria endemicity: perennial with peaks after the rainy season. Rainfall occurs in 2 seasons: the "short rains" in October-December (mean monthly rainfall $160 \mathrm{~mm}$ ) and the "long rains" in March-May (mean monthly rainfall $300 \mathrm{~mm}$ )

EIR: not measured at baseline

Population proximity/density: not reported

Plasmodium spp: $P$ falciparum 
Vector behaviour (nature, stability, adult habitat, peak biting times, exophilic/endophilic, exophagic/endophagic, anthropophilic/zoophilic): not reported

Phenotypic resistance profile: An gambiae s.l. had high levels of resistance to pyrethroids.

Genotypic resistance profile: the Vgsc gene mutation was found in all tested An gambiae s.l. with cooccurrence of Vgsc-1014F and Vgsc-1014S in 22 (9\%) of 234 An gambiae s.l. mosquitoes. No mutation was found in the 247 An arabiensis tested.

Method of mosquito collection: mosquito surveillance was done from March 2015 to December 2016, in each cluster by a project field assistant for 1 night per month in 7 randomly selected houses per cluster using CDC Miniature Light Trap Model 512 (John W Hock Company, USA).

\section{Notes}

\section{Risk of bias}

\begin{tabular}{lll}
\hline Bias & Authors' judgement & Support for judgement \\
\hline $\begin{array}{l}\text { Random sequence genera- } \\
\text { tion (selection bias) }\end{array}$ & Low risk & $\begin{array}{l}\text { During each survey, we randomly sampled } 55 \text { households with children aged } 6 \\
\text { months to } 14 \text { years from the core area of each cluster using the census lists. }\end{array}$
\end{tabular}

Allocation concealment Low risk
(selection bias)

(selection bias)

\begin{abstract}
The inhabitants of each cluster to the type of LLINs received. The 2 types of nets were of similar colour and shape, and only distinguishable by label codes and coloured thread inserted during manufacture. Additionally, field staff who took blood samples in the cross-sectional surveys were masked to the study arms the clusters were assigned to.
\end{abstract}

It was not possible to blind either the investigators or the participants to the treatment allocation of IRS but we do not feel this would impact the outcome.

\begin{tabular}{|c|c|c|}
\hline $\begin{array}{l}\text { Blinding of participants } \\
\text { and personnel (perfor- } \\
\text { mance bias) } \\
\text { Incidence of malaria }\end{array}$ & Low risk & This outcome was not measured. \\
\hline $\begin{array}{l}\text { Blinding of participants } \\
\text { and personnel (perfor- } \\
\text { mance bias) }\end{array}$ & Low risk & $\begin{array}{l}\text { Field staff who took blood samples in the cross-sectional surveys were masked } \\
\text { to the study arms the clusters were assigned to. }\end{array}$ \\
\hline Prevalence of malaria & & $\begin{array}{l}\text { It was not possible to mask either the investigators who assessed the blood } \\
\text { samples or the participants to the treatment allocation of IRS but we do not } \\
\text { consider this would impact the outcome which was assessed by RDT (an objec- } \\
\text { tive test). }\end{array}$ \\
\hline
\end{tabular}

\begin{tabular}{lll}
\hline $\begin{array}{l}\text { Blinding of outcome as- } \\
\text { sessment (detection bias) } \\
\text { Incidence of malaria }\end{array}$ & Low risk & This outcome was not measured. \\
\hline $\begin{array}{l}\text { Blinding of outcome as- } \\
\text { sessment (detection bias) }\end{array}$ & Low risk & $\begin{array}{l}\text { Field staff who took blood samples in the cross-sectional surveys were masked } \\
\text { to the study arms the clusters were assigned to. }\end{array}$ \\
$\begin{array}{l}\text { It was not possible to blind either the investigators or the participants to the } \\
\text { treatment allocation of IRS but we do not feel this would impact the outcome } \\
\text { which was assessed by RDT (an objective test). }\end{array}$
\end{tabular}

Incomplete outcome data Low risk A new cohort of children was used for each cross-sectional survey.
(attrition bias)

All outcomes
Field staff who took blood samples in the cross-sectional surveys were masked samples or the participants to the treatment allocation of IRS but we do not consider this would impact the outcome which was assessed by RDT (an objec- 
Protopopoff 2018 (Continued)

Selective reporting (re- Low risk The study protocol reported each outcome as stated in the clinical trials regisporting bias) ter (note: retrospectively registered).

\begin{tabular}{lll}
\hline Recruitment bias & Low risk & Cohort of children were randomly selected. \\
\hline Baseline imbalance & Low risk & $\begin{array}{l}\text { Baseline data was displayed. No significant differences at baseline for out- } \\
\text { comes the study assessed. }\end{array}$ \\
\hline Loss of clusters & Low risk & No clusters were lost. \\
\hline Incorrect analysis & Low risk & Adjustment for clustering was done. \\
\hline $\begin{array}{l}\text { Comparability with RCTs } \\
\text { randomizing participants }\end{array}$ & Low risk & $\begin{array}{l}\text { Because the intervention is expected to have community level impact as well } \\
\text { as individual impact, cRCTs are the most appropriate study design to capture } \\
\text { this. }\end{array}$ \\
\hline Other bias & Low risk & No other biases. \\
\hline
\end{tabular}

\section{West 2014}

\section{Methods}

Study design: CRCT with 2 intervention arms

Unit of allocation: clusters (villages)

Number of units: 25 randomized villages in each arm. A subset of 20 villages per arm was used for entomological assessment

Outcome assessment/surveillance type: see below in 'Outcomes' section

Length of follow-up: 3 postintervention cross-sectional household surveys were undertaken in 2012. Survey A ( 23 February to 31 March) was after the short rainy season and 2 months after the first spray round. Survey B ( 25 June to 31 July) was after the long rainy season, 6 months after the first spray round, and 2 months after the second spray round. Survey C ( 25 October to 4 December) was 6 months after the second spray round and 10 months after the first. Baseline surveys were conducted in 2011 during the same periods as surveys $A$ and $B$.

\section{Adjustment for clustering: yes}

Participants

Number of participants: for each of the survey, a different number of participants were used in each cohort

- Survey A: 2192 children in control arm, 2348 in intervention arm

- Survey B: 2045 children in control arm, 2207 in intervention arm

- Survey C: 2101 children in control arm, 2303 in intervention arm

Population characteristics: cohort of children aged $0.5-14$ years, villages had to be sprayed with IRS in the baseline year.

Withdrawal and loss to follow-up: $82.2 \%$ to $84.4 \%$ of intervention participants tested in each survey. $78.3 \%$ to $80.8 \%$ of control participants tested

IRS:

Active ingredient and dosage: bendiocarb $400 \mathrm{mg} / \mathrm{m}^{2}$

Formulation: $80 \%$ wettable powder

Frequency of spraying: 2 rounds of spraying (December 2011 to January 2012) and (April 2012 to May 2012), timed to precede the peak in malaria cases that normally occurs at the end of each rainy season. 
West 2014 (Continued)

Coverage: survey A: $92.1 \%$ (88.4\% to $94.7 \%)$ (1215); survey B: $89.5 \%$ (84.0\% to $93.2 \%)$ (1138); survey C: $89.3 \%(83.6 \%$ to $93.2 \%)(1209)$

Buffer size between clusters: each village was divided into a core surveillance area consisting of $\geq 200$ houses and approximately $1 \mathrm{~km}$ radius, where the surveys were conducted, and an outer buffer zone of approximately $1 \mathrm{~km}$ width which also received treatment but in which no outcome monitoring was done.

\section{ITN:}

Active ingredient and dosage: permethrin $2 \% \mathrm{w} / \mathrm{w}$ (Olyset Net)

Coverage measured as \% of households with $\geq 1$ ITN per sleeping space: survey A: 57.2 (range 53.660.7) (1215); survey B: 57.4 (range 54.0-60.9) (1142); survey C: 56.8 (range 51.7-61.8) (1211)

Coverage measured as $\%$ of households with $\geq 1$ ITN: survey A: 89.0 (range 87.1-90.6) (1216); survey B: 88.2 (range 85.7-90.3) (1142); survey C: 83.8 (range 79.9-87.1) (1211)

Compliance measured as \% of study children that reported sleeping under an ITN the night previous to the survey:

survey A: 53.0 (range 47.5-58.3) (2349); survey B: 44.1 (range 39.2-49.2) (2207); survey C: 36.1 (range 31.0-41.5) (2303)

Control: ITN only as above

Coverage measured as $\%$ of households with $\geq 1$ ITN per sleeping space: survey A: 52.2 (range 47.856.5) (1178); survey B: 51.6 (range 47.0-56.0) (1094); survey C: 52.8 (range 47.6-58.0) (1168)

Coverage measured as $\%$ of households with $\geq 1$ ITN: survey A: 85.8 (range 83.7-87.7) (1177); survey B: 82.5 (range 78.7-85.7) (1096); survey C: 78.2 (range 74.3-81.6) (1170)

Compliance measured as \% of study children that reported sleeping under an ITN the night previous to the survey: survey A: 46.6 (range 41.7-51.6) (2193); survey B: 40.7 (range 34.7-47.0) (2045); survey C: 36.0 (range 29.8-42.6) (2101)

Cointerventions: none reported

P falciparum parasite rate in children aged $0.5-14$ years, 80 households in each cluster. Up to 3 children per household selected. Aimed for a mean of 80 children per cluster. Tested with RDT (Carestart (Pan) Malaria, DiaSys)

Anaemia in children aged $<5$ years

Mean haemoglobin in children aged $<5$ years. Tested with HemoCue Hb 201+ (Aktiebolaget Leo Diagnostics)

EIR: 20/25 clusters per arm were monitored for 1 night each month from April 2011 to December 2012. 8 randomly selected houses in each cluster

Sporozoite rate

Location profile

Study location: Northwest Tanzania, Muleba Distract, Kagera Region, the study area included 68,108 households at an altitude of 1100-1600 m above sea level. Rainfall occurred in 2 seasons: the 'short rains' in October-December (mean monthly rainfall $160 \mathrm{~mm}$ ) and the 'long rains' in March-May (mean monthly rainfall $300 \mathrm{~mm}$ ).

Malaria endemicity: perennial with peaks after the rainy season

EIR: baseline characteristics measured by the study reported a mean per month in the control arm of 1.1 (range $0.4-2.8$ ) and 1.3 (range $0.4-4.4$ ) in the intervention arm

Population proximity/density: not reported 
West 2014 (Continued)

Plasmodium spp: $P$ falciparum

Vector profile $\quad$ Primary (and secondary) vector species: An gambiae S.S. and An arabiensis

Vector behaviour (nature, stability, adult habitat, peak biting times, exophilic/endophilic, exophagic/endophagic, anthropophilic/zoophilic): not reported

Phenotypic resistance profile: resistance to pyrethroids in An gambiae s.s.

Genotypic resistance profile: not reported

Method of mosquito collection: CDC light traps indoors

\section{Notes}

\section{Risk of bias}

\begin{tabular}{lll}
\hline Bias & Authors' judgement & Support for judgement \\
\hline $\begin{array}{l}\text { Random sequence genera- } \\
\text { tion (selection bias) }\end{array}$ & Low risk & Quote: "Twenty-five clusters were randomly allocated to receive IRS..." \\
& $\begin{array}{l}\text { Comment: } 200,000 \text { random allocations were generated. } 1 \text { allocation was ran- } \\
\text { domly selected from the list of these with no intracluster dependence on key } \\
\text { variables. }\end{array}$ \\
\hline
\end{tabular}

\begin{tabular}{|c|c|c|}
\hline $\begin{array}{l}\text { Allocation concealment } \\
\text { (selection bias) }\end{array}$ & Low risk & $\begin{array}{l}\text { Allocation concealment was a low risk of bias considering the computer-ran- } \\
\text { domized allocation. }\end{array}$ \\
\hline
\end{tabular}

\begin{tabular}{|c|c|c|}
\hline $\begin{array}{l}\text { Blinding of participants } \\
\text { and personnel (perfor- } \\
\text { mance bias) } \\
\text { Incidence of malaria }\end{array}$ & Low risk & Outcome not reported. \\
\hline $\begin{array}{l}\text { Blinding of participants } \\
\text { and personnel (perfor- } \\
\text { mance bias) } \\
\text { Prevalence of malaria }\end{array}$ & Low risk & $\begin{array}{l}\text { Participants could not be blinded to the control and intervention. However, } \\
\text { the outcomes recorded were objective and at low risk of being affected by in- } \\
\text { tervention arm knowledge. }\end{array}$ \\
\hline
\end{tabular}

\begin{tabular}{|c|c|c|}
\hline $\begin{array}{l}\text { Blinding of outcome as- } \\
\text { sessment (detection bias) } \\
\text { Incidence of malaria }\end{array}$ & Low risk & Outcome not reported. \\
\hline $\begin{array}{l}\text { Blinding of outcome as- } \\
\text { sessment (detection bias) } \\
\text { Prevalence of malaria }\end{array}$ & Low risk & $\begin{array}{l}\text { Outcome assessors were not blinded to the control and intervention. How- } \\
\text { ever, the outcomes recorded were objective measurements (using RDTs, and } \\
\text { standardized mosquito traps). }\end{array}$ \\
\hline $\begin{array}{l}\text { Incomplete outcome data } \\
\text { (attrition bias) } \\
\text { All outcomes }\end{array}$ & Low risk & ITT was done, balanced numbers in both arms. \\
\hline $\begin{array}{l}\text { Selective reporting (re- } \\
\text { porting bias) }\end{array}$ & Low risk & $\begin{array}{l}\text { Outcomes reported match those in the registered protocol, but children aged } \\
6 \text { months to } 10 \text { years rather than } 14 \text { years was reported in the trial protocol. }\end{array}$ \\
\hline Recruitment bias & Low risk & Cohort of children were randomly selected. \\
\hline Baseline imbalance & Low risk & $\begin{array}{l}\text { Baseline characteristics were presented for both study arms and showed simi- } \\
\text { larity across key characteristics. }\end{array}$ \\
\hline
\end{tabular}


West 2014 (Continued)

$\begin{array}{ll}\text { Loss of clusters } \quad \text { Low risk } & 1 \text { cluster was assigned the wrong intervention and then dropped. Sensitivity } \\ \text { analysis was done to show this did not impact the outcome. }\end{array}$

\begin{tabular}{lll}
\hline Incorrect analysis & Low risk & Adjustment for clustering was done. \\
\hline $\begin{array}{ll}\text { Comparability with RCTs } \\
\text { randomizing participants }\end{array}$ & Low risk & $\begin{array}{l}\text { Because the intervention is expected to have community level impact as well } \\
\text { as individual impact, cRCTs are the most appropriate study design to capture } \\
\text { this. }\end{array}$
\end{tabular}

Other bias Low risk No other biases.

Abbreviations: Anopheles arabiensis: An arabiensis; An funestus: Anopheles funestus;An gambiae: Anopheles gambiae; cRCT: cluster randomized controlled trial; CSP: circumsporozoite protein; CTPS: carbamate-treated plastic sheeting; DDT: dichloro-diphenyltrichlorethane; EIR: entomological inoculation rate; ELISA: enzyme-linked immunosorbent assay; IRD-CREC: Institut de Recherche pour le Développement Centre de Recherches Entomologiques de Cotonou; IRS: indoor residual spraying; ITN: insecticide-treated net; ITT: intention to treat; LLIN: long-lasting insecticidal mosquito net; $P$ falciparum:Plasmodium falciparum; $P$ vivax:Plasmodium vivax; RCT: randomized controlled trial; RDT: rapid diagnostic test; TLLIN: targeted long-lasting insecticidal mosquito nets; ULLIN: universal longlasting insecticidal mosquito nets; WHO: World Health Organization.

\section{Characteristics of excluded studies [ordered by study ID]}

\begin{tabular}{|c|c|}
\hline Study & Reason for exclusion \\
\hline Abeku 2014 & Study design did not meet inclusion criteria \\
\hline Bekele 2012 & Study design did not meet inclusion criteria \\
\hline Diallo 2015 & Study design did not meet inclusion criteria \\
\hline Fullman 2013 & Study design did not meet inclusion criteria \\
\hline Gari 2016 & Study design did not meet inclusion criteria \\
\hline Gimnig 2016 & Study design did not meet inclusion criteria \\
\hline Hamel 2011 & Study design did not meet inclusion criteria \\
\hline Katureebe 2016 & Study design did not meet inclusion criteria \\
\hline Kitau 2015 & Duplicate (data from West 2014) \\
\hline Lyimo 1991 & Study design did not meet inclusion criteria \\
\hline Matowo 2015 & Study design did not meet inclusion criteria \\
\hline Pinder 2011 & Duplicate (study protocol of Pinder 2015) \\
\hline Pinder 2012 & Duplicate (conference abstract of Pinder 2015) \\
\hline Protopopoff $2007 a$ & Study design did not meet inclusion criteria \\
\hline Protopopoff 2007b & Study design did not meet inclusion criteria \\
\hline Protopopoff 2015a & Duplicate (conference abstract of West 2014) \\
\hline
\end{tabular}




\begin{tabular}{ll}
\hline Study & Reason for exclusion \\
\hline Protopopoff 2015b & Duplicate (data from West 2014) \\
\hline West 2012 & Duplicate (conference abstract of West 2014) \\
\hline West 2015 & Study design did not meet inclusion criteria \\
\hline Zhou 2013 & Study design did not meet inclusion criteria \\
\hline
\end{tabular}

Characteristics of studies awaiting assessment [ordered by study ID]

Chaccour 2018

Study design: CRCT with 2 intervention arms
Study status: ongoing
Unit of allocation: villages
Number of units: 43 clusters per arm
Outcome assessment/surveillance type:
- Community malaria incidence measured through active monthly parasitological surveys in par-
ticipating households. 18 children from each cluster aged 6-59 months at time of enumeration
recruited. Parasitaemia confirmed with RDT;
- Incidence rates at the health facility level measured via passive surveillance.

Length of follow-up: September 2016 to December 2018

Adjustment for clustering: yes

Participants

Number of participants: cohort of 784 children per arm aged 6-59 months were recruited for monthly active case detection. For each cross-sectional survey, an independent sample of 770 participants (385 children aged 6-71 months and 385 children aged $\geq 60$ months) were included.

Population characteristics: 162,188 participants, with 31, 927 (19.7\%) under 5 years of age.

Withdrawal and loss to follow-up: not reported

Active ingredient and dosage: pirimiphos-methyl at the recommended dosage of $1 \mathrm{~g} / \mathrm{m}^{2}$

Formulation: $30 \%$ capsule suspension (Actellic 300CS)

Frequency of spraying: yearly

Coverage: aimed for universal coverage

Buffer size between clusters: each cluster had an internal buffer zone of $\geq 1 \mathrm{~km}$ defined around each cluster's core area, and cohort members were only selected from core areas.

ITN:

Active ingredient and dosage: nets used at the time from mass distribution campaigns.

Coverage: not reported

Compliance: not reported 
Cointerventions: none reported

\section{Primary:}

Malaria cases averted in children aged 6-59 months at the community level by adding IRS (community incidence)

Cost per malaria case averted in children aged 6-59 months at the community level by adding IRS

Malaria case averted in children aged 6-59 months at the health facility level by adding IRS (health facility incidence)

Cost per malaria case averted in children aged 6-59 months at the health facility level by adding IRS

\section{Secondary:}

Vector densities, human biting rates, sporozoite rates, indoor and outdoor feeding behaviours, prevalence and intensity of resistance to pyrethroids, and estimates of EIR as measured or estimated through entomological surveillance

Changes in community-based parasite prevalence

Incremental impact of combining IRS with LLINs, including assessment of the impact of new nets in year 2

Correlation between incidence at community and health facility levels

Correlation between incidence (community and health facility) and prevalence

Changes in malaria prevention methods including net use and in health-seeking behaviour

Location profile

Study location: Mopeia is a district in Zambezia, 1 of the most impoverished provinces of Mozambique. Carried out in all of Mopeia's villages.

Malaria endemicity: highly endemic

EIR: not reported

Population proximity/density: not reported

Plasmodium spp: $P$ falciparum

Vector profile

Primary (and secondary) vector species: An gambiae s.s. and An funestus s.s. although An arabiensis is present as well

Vector behaviour (nature, stability, adult habitat, peak biting times, exophilic/endophilic, exophagic/endophagic, anthropophilic/zoophilic): not reported

Phenotypic resistance profile: data from January 2015 in the neighbouring districts of Mocuba and Morrumbala show pyrethroid resistance (mortality 24 hours after deltamethrin WHO tube test: $52 \%$ in Mocuba and 34\% in Morrumbala; mortality after lambda-cyhalothrin: $40 \%$ in Mocuba and $33 \%$ in Morrumbala) in the localAn gambiae s.l. population.

Genotypic resistance profile: not reported

Method of mosquito collection: 8 households in each cluster from a subset of 5 villages per arm used light traps and human landing catches. Monitoring took place on 3 consecutive nights every month leading to 240 collections per month. 
- $L L I N+I R S$

- LLINs alone

- IRS alone

- control

Study status: ongoing

Unit of allocation: villages

Number of units: 44 clusters per arm, with each cluster comprised of approximately 35 households (about 175 people)

Outcome assessment/surveillance type: malaria incidence based on the results of the RDTs in people with a fever or history of fever attending health posts by passive case detection. Community-based surveys were conducted each year to assess anaemia among children aged 5-59 months. In addition, community-based malaria prevalence surveys were conducted each year on a representative sample of households during the main transmission season.

Length of follow-up: 119 weeks from September 2014 to January 2017

Adjustment for clustering: not reported

Participants

Number of participants: 34,548 total

Population characteristics: not reported

Withdrawal and loss to follow-up: not reported

Interventions

The relevant comparison for this review is LLIN + IRS versus LLINs alone

IRS:

Active ingredient and dosage: propoxur $2 \mathrm{~g} / \mathrm{m}^{2}$

Formulation: 50\% water-dispersible powder

Frequency of spraying: yearly

Coverage: aimed for $80 \%$ coverage as per WHO recommendations

Buffer size between clusters: not reported

ITN:

Active ingredient and dosage: deltamethrin $55 \mathrm{mg}$ (PermaNet 2.0)

Coverage: not reported

Compliance: not reported

Control: ITN only as above

Cointerventions: none reported

Malaria incidence

\section{Secondary:}


Deressa 2016 (Continued)

\author{
Anaemia in children \\ Malaria prevalence \\ Mosquito adult density \\ Sporozoite rate \\ Changes in insecticide resistance, both phenotype and genotype
}

Location profile

Study location: study was carried out in the Adami Tullu part of the Adami Tullu-Jiddo-Kombolcha woreda in the East Shewa Zone of the Oromia Regional State in Ethiopia. The capital of the district, Zeway (or Batu), has a latitude and longitude of $7^{\circ} 56^{\prime} \mathrm{N} 38^{\circ} 42^{\prime} \mathrm{E}$ with an elevation of $1640 \mathrm{~m}$ above sea level. It is located approximately $160 \mathrm{~km}$ south of Addis Ababa. The district is set in the Great Rift Valley in south-central Ethiopia, with altitudes ranging from $1500 \mathrm{~m}$ to $2300 \mathrm{~m}$. For villages to be included in the trial, they had to have a relatively easy access, relatively higher malaria transmission, and located within $5 \mathrm{~km}$ from Lake Zeway.

Malaria endemicity: seasonal and unstable. The main malaria transmission season occurs between September and December each year following the heavy rainfall between July and August, whereas the smaller peak occurs during May and June each year following small rains during March and April

EIR: not reported

Population proximity/density: not reported

Plasmodium spp: $P$ falciparum and $P$ vivax

Vector profile

Primary (and secondary) vector species: An arabiensis and An pharoensis

Vector behaviour (nature, stability, adult habitat, peak biting times, exophilic/endophilic, exophagic/endophagic, anthropophilic/zoophilic): not reported

Phenotypic resistance profile: not reported

Genotypic resistance profile: not reported

Method of mosquito collection: 16 villages (4 per arm) were randomly selected for entomological study, in which indoor host-seeking mosquitoes were collected by CDC light traps from 4 houses per arm, indoor resting mosquitoes from 16 houses per arm using pyrethrum spray collection and outdoor resting mosquitoes from 4 artificial pit shelters per arm of the study.

Phenotypic insecticide resistance was monitored annually throughout the study period using standard WHO tube tests. Insecticides used in this test were pyrethroids (deltamethrin, alphacypermethrin, permethrin, and lambdacyhalothrin) and the carbamates (bendiocarb and propoxur). Resistance intensity was quantified to assess any change in resistance. Molecular and biochemical analyses were used to identify potential insecticide resistance mechanisms.

Notes insecticide formulations

Study status: completed

Unit of allocation: village or groups of villages

Number of units: 14 units with mixed interventions 


\section{Outcome assessment/surveillance type:}

- Active monthly parasitological surveys in participating households. Participants were encouraged to seek care through passively offered diagnosis and treatment services in-between surveys. Parasitaemia confirmed with RDT (ICT Malaria P.f. cassette test)

- Entomological observations were made in 15 households in each cluster. Additionally, human landing catches were conducted both indoors and outdoor

Length of follow-up: 29 months in Luangwa and 26 months in Nyimba, starting from January Adjustment for clustering: yes

Participants

Number of participants: 25,354 at the start of the study stated in population characteristics; however, figure 2 suggested 84,275

Population characteristics: out of these participants, 29\% (7412) were children under the age of 5 years. The overall cluster populations ranged from 1158 to 3429 .

Withdrawal and loss to follow-up: Figure 2 in the paper suggested many participants withdrew, no ITT analysis stated.

Interventions

IRS:

Active ingredient, dosage, formulation and coverage:

- deltamethrin, wettable granule formulation, $82 \%$

- lambdacyhalothrin, capsule suspension, $61 \%$

- pirimiphos methyl, emulsifiable concentrate, $53 \%$

- pirimiphos methyl, capsule suspension, $69 \%$

Frequency of spraying:

- October 2010: deltamethrin (clusters 4, 5, 6, and 7). Control (1, 2, 3, 8, 9, 10, 11, 12, 13, and 14)

- October 2011: pirimiphos EC (2, 4, 5, 9, 11, and 13); lambdacyhalothrin (6, 7). Control (1, 3, 8, 10, and 12)

- November 2012: pirimiphos CS (8, 9, 10, 12, and 14); February 2013: pirimiphos EC (2, 4, and 5); Lambdacyhalothrin (6 and 7). Control (1, 2, 3, 11, and 13)

Coverage: in the first 1-6 months' post IRS implementation (range 0-100\%; mean 29.4\%)

Buffer size between clusters: not reported

ITN: no mass distribution took place as part of the study; however, ITN use was already high (LLIN use in the first 1-6 months' post IRS implementation across all clusters in both arms (range 6.6$100 \%$, mean $68.2 \%)$ ).

Control: ITN as above and areas that had not yet received spraying during the study period and those for which the last spray round began more than 12 months ago.

Cointerventions: intermittent preventive therapy

Outcomes Primary:

Diagnostic positivity for malaria infection, expressed as the proportion of RDT-tested people who were found to be positive

\section{Secondary:}

Indoor-outdoor distribution of human exposure to An funestus bites measured as bites per person perhour

Location profile

Study location: Luangwa located in Lusaka and Nyimba located in Eastern provinces, of the Republic of Zambia. Predominantly rural 
Hamainza 2016 (Continued)

\title{
Malaria endemicity: perennial
}

EIR: 70 (for non-users of LLINs)

Population proximity/density: not reported

Plasmodium spp: $P$ falciparum

Vector profile

\begin{abstract}
Primary (and secondary) vector species: An funestus
Vector behaviour (nature, stability, adult habitat, peak biting times, exophilic/endophilic, exophagic/endophagic, anthropophilic/zoophilic): not reported
\end{abstract}

Phenotypic resistance profile: $\mathrm{F} 1$ generation from wild-caught mosquitoes were exposed to standard WHO susceptibility tests using insecticide impregnated papers for the duration of the study (2010-2013). Throughout the study period, An funestus were consistently susceptible to both malathion and DDT (100\% mortality) in both Luangwa and Nyimba. Moderate resistance to deltamethrin that increased to high resistance in both sites during the study period. Lambdacyhalothrin showed a similar pattern but was only measured in Luangwa.

Genotypic resistance profile: not reported

Method of mosquito collection: light traps and Ifakara tent traps. Each house was visited once per month for mosquito trapping. Light traps were placed at the foot end of an occupied sleeping space covered with an LLIN, hanging approximately $1.5 \mathrm{~m}$ above the floor. A tent trap was placed immediately outside, approximately $5 \mathrm{~m}$ away from the house. Traps were set up in the evenings and collection of the captured mosquitoes was done in the early morning by aspiration. Additionally, human landing catches were conducted both indoors and outdoors from 18.00 to 06.00 hours.

Notes

Abbreviations: An: Anopheles; CDC: Centers for Disease Control and Prevention; CRCT: cluster randomized controlled trial; DDT: dichlorodiphenyl-trichlorethane; EIR; entomological inoculation rate; ICT: immunochromatographic diagnostic test; IRS: indoor residual spraying; ITN: insecticide-treated net; ITT: intention to treat; LLIN: long-lasting insecticidal mosquito net; RCT: randomized controlled trial; RDT: rapid diagnostic test; WHO: World Health Organization.

\section{DATA AND ANALYSES}

\section{Comparison 1. Non-pyrethroid-like indoor residual spraying (IRS) plus insecticide-treated nets (ITNs) versus ITNs} alone

\begin{tabular}{lllll}
\hline Outcome or subgroup title & $\begin{array}{l}\text { No. of } \\
\text { studies }\end{array}$ & $\begin{array}{l}\text { No. of } \\
\text { partici- } \\
\text { pants }\end{array}$ & Statistical method & Effect size \\
\hline 1 Malaria incidence & 2 & Rate ratio (Random, 95\% Cl) & $0.93[0.46,1.86]$ \\
\hline 2 Malaria parasite prevalence & 4 & Risk Ratio (Random, 95\% Cl) & $0.67[0.35,1.28]$ \\
\hline $\begin{array}{l}\text { 3 Malaria parasite prevalence (net } \\
\text { usage subgroup analysis) }\end{array}$ & 4 & Risk Ratio (Random, 95\% Cl) & $0.67[0.35,1.28]$ \\
\hline 3.1 Net usage $\geq 50 \%$ & 2 & Risk Ratio (Random, 95\% Cl) & $0.47[0.33,0.67]$ \\
\hline 3.2 Net usage < 50\% & 2 & Risk Ratio (Random, 95\% Cl) & $0.87[0.34,2.22]$ \\
\hline 4 Anaemia prevalence & 2 & Risk Ratio (Random, 95\% Cl) & $0.46[0.18,1.20]$ \\
\hline \hline
\end{tabular}

Indoor residual spraying for preventing malaria in communities using insecticide-treated nets (Review) 


\begin{tabular}{lllll}
\hline Outcome or subgroup title & $\begin{array}{l}\text { No. of } \\
\text { studies }\end{array}$ & $\begin{array}{l}\text { No. of } \\
\text { partici- } \\
\text { pants }\end{array}$ & Statistical method & Effect size \\
\hline 5 kdr allelic frequency & 1 & & Risk Ratio (M-H, Fixed, 95\% Cl) & Subtotals only \\
\hline $\begin{array}{l}5.1 \text { Sensitivity analysis with an esti- } \\
\text { mated intracluster correlation coef- } \\
\text { ficient (ICC) of } 0.01\end{array}$ & 1 & 107 & Risk Ratio (M-H, Fixed, 95\% Cl) & $1.01[0.86,1.18]$ \\
\hline $\begin{array}{l}5.2 \text { Sensitivity analysis with an esti- } \\
\text { mated ICC of } 0.05\end{array}$ & 1 & 84 & Risk Ratio (M-H, Fixed, 95\% Cl) & $0.99[0.83,1.18]$ \\
\hline $\begin{array}{l}5.3 \text { Sensitivity analysis with an esti- } \\
\text { mated ICC of } 0.1\end{array}$ & 1 & 67 & Risk Ratio (M-H, Fixed, 95\% Cl) & $1.01[0.83,1.22]$ \\
\hline
\end{tabular}

Analysis 1.1. Comparison 1 Non-pyrethroid-like indoor residual spraying (IRS) plus insecticide-treated nets (ITNs) versus ITNs alone, Outcome 1 Malaria incidence.

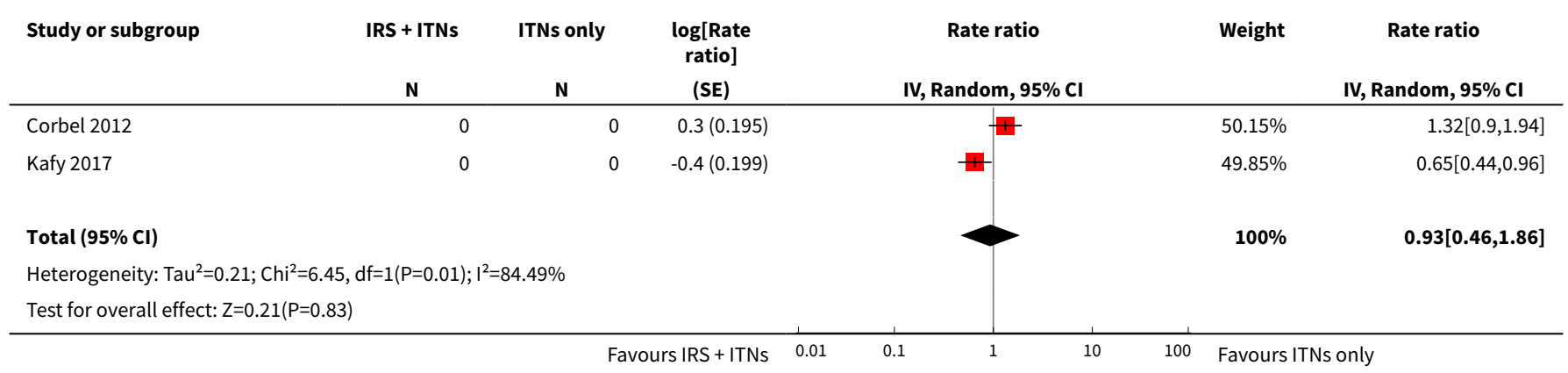

Analysis 1.2. Comparison 1 Non-pyrethroid-like indoor residual spraying (IRS) plus insecticide-treated nets (ITNs) versus ITNs alone, Outcome 2 Malaria parasite prevalence.

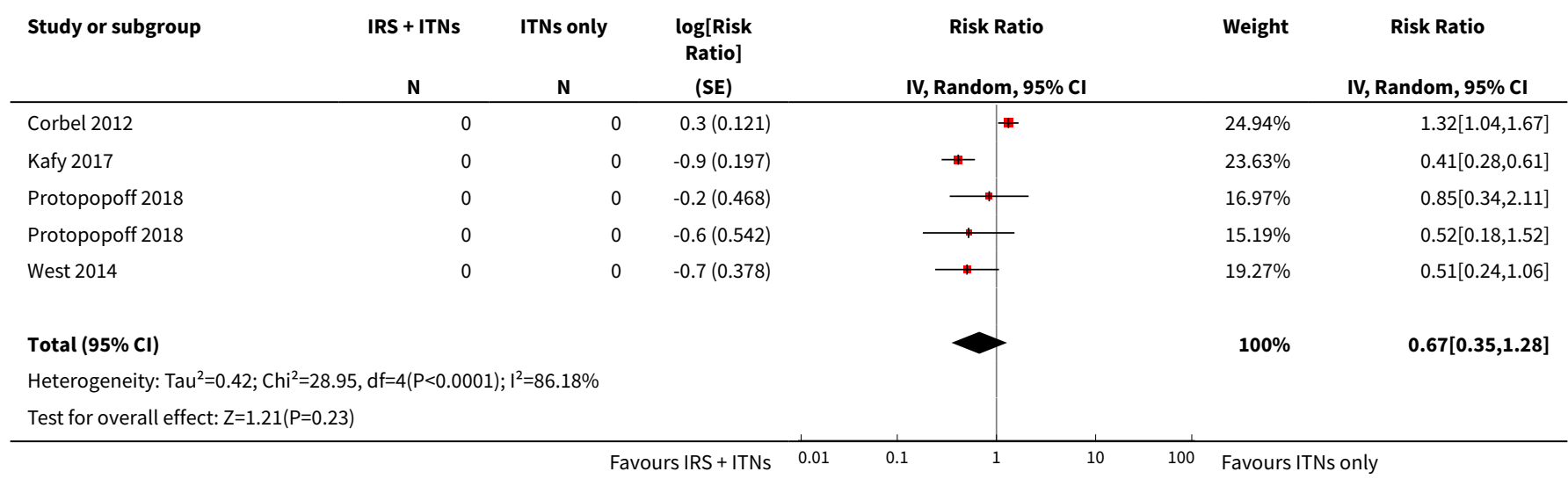


Analysis 1.3. Comparison 1 Non-pyrethroid-like indoor residual spraying (IRS) plus insecticide-treated nets (ITNs) versus ITNs alone, Outcome 3 Malaria parasite prevalence (net usage subgroup analysis).

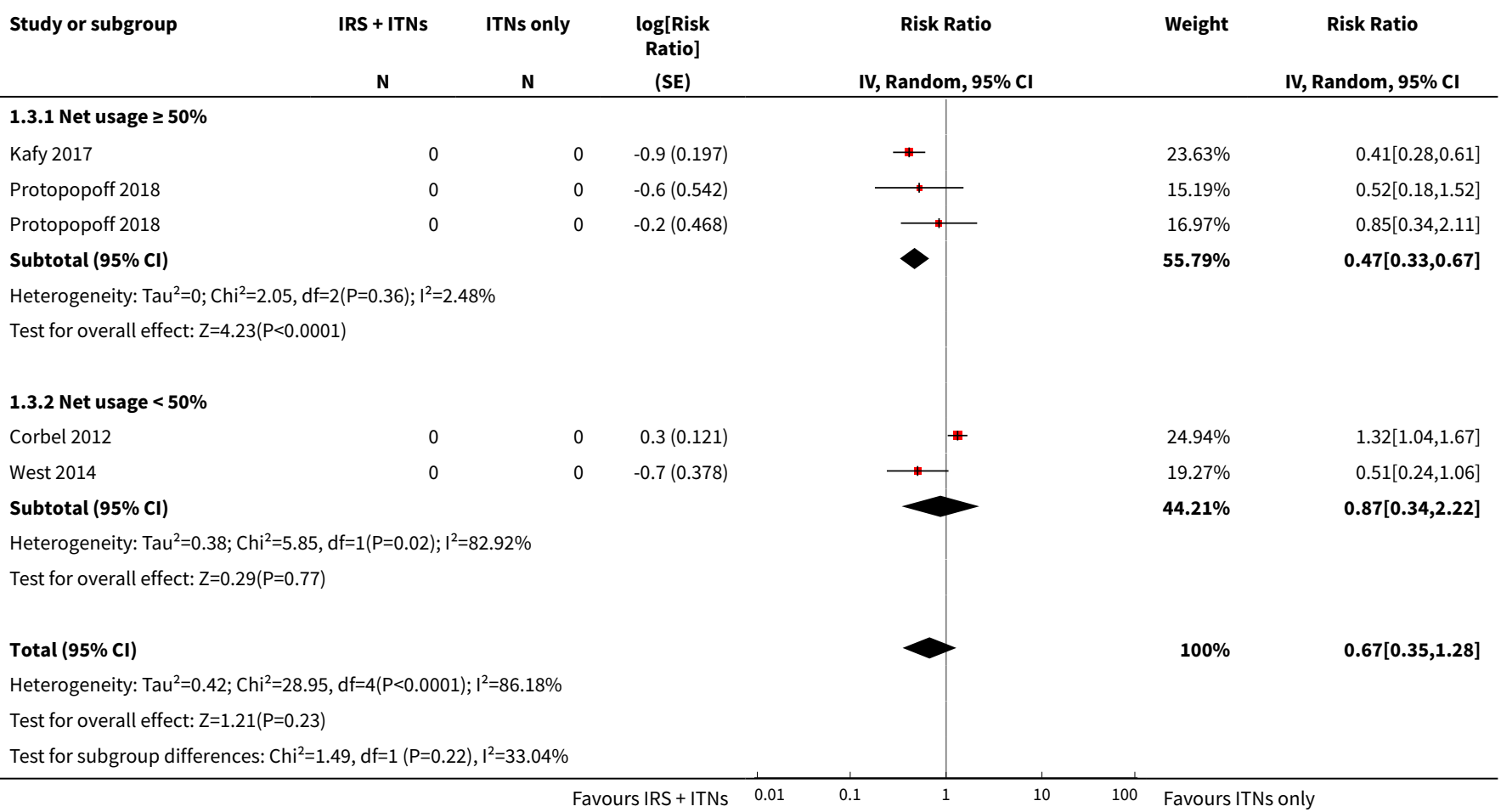

Analysis 1.4. Comparison 1 Non-pyrethroid-like indoor residual spraying (IRS) plus insecticide-treated nets (ITNs) versus ITNs alone, Outcome 4 Anaemia prevalence.

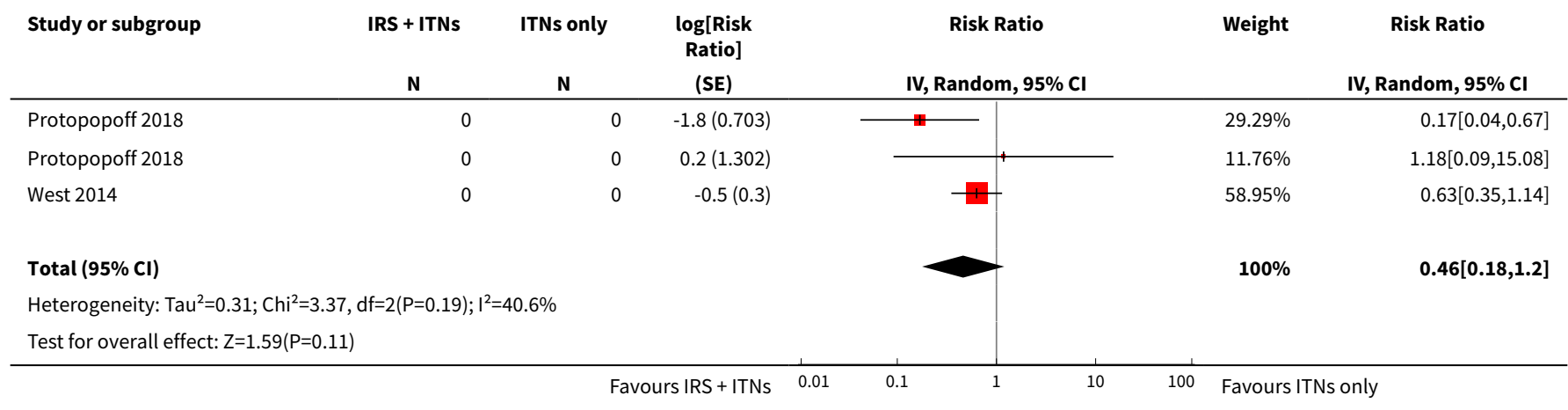

Analysis 1.5. Comparison 1 Non-pyrethroid-like indoor residual spraying (IRS) plus insecticide-treated nets (ITNs) versus ITNs alone, Outcome 5 kdr allelic frequency.

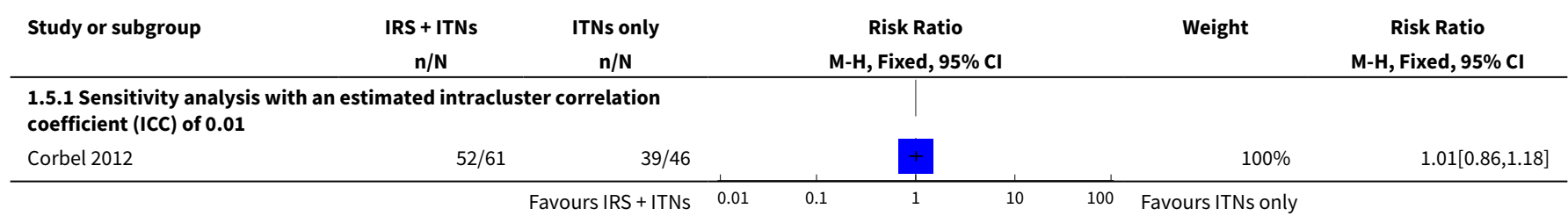




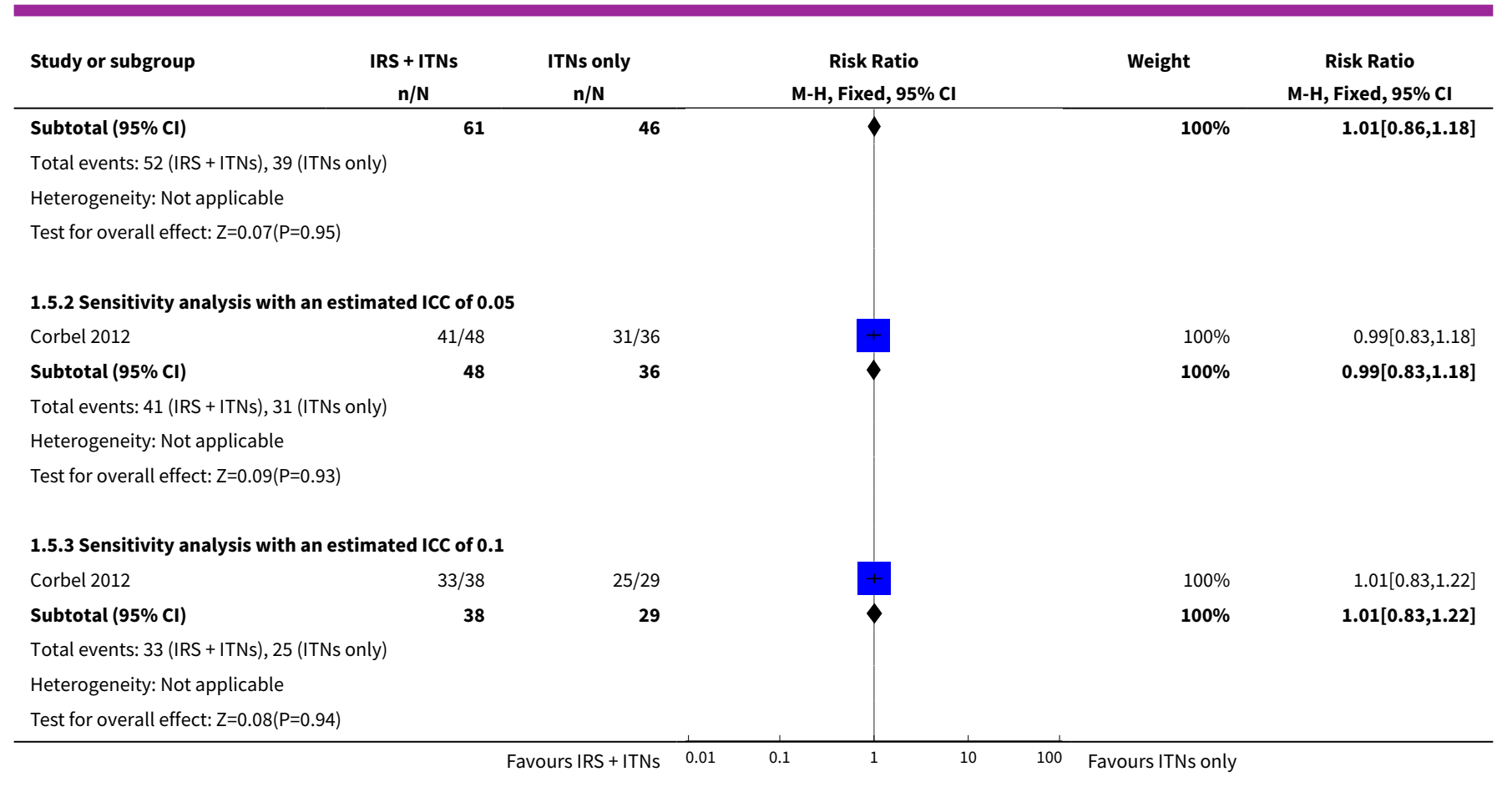

Comparison 2. Pyrethroid-like indoor residual spraying (IRS) plus insecticide-treated nets (ITNs) versus ITNs alone

\begin{tabular}{lllll}
\hline Outcome or subgroup title & $\begin{array}{l}\text { No. of } \\
\text { studies }\end{array}$ & $\begin{array}{l}\text { No. of } \\
\text { partici- } \\
\text { pants }\end{array}$ & Statistical method & Effect size \\
\hline 1 Malaria incidence & 2 & Rate ratio (Random, 95\% Cl) & $1.07[0.80,1.43]$ \\
\hline 2 Malaria parasite prevalence & 3 & Risk Ratio (Random, 95\% Cl) & $1.11[0.86,1.44]$ \\
\hline 3 Anaemia prevalence & 1 & Risk Ratio (Random, 95\% Cl) & $1.12[0.89,1.40]$ \\
\hline
\end{tabular}

Analysis 2.1. Comparison 2 Pyrethroid-like indoor residual spraying (IRS) plus insecticide-treated nets (ITNs) versus ITNs alone, Outcome 1 Malaria incidence.

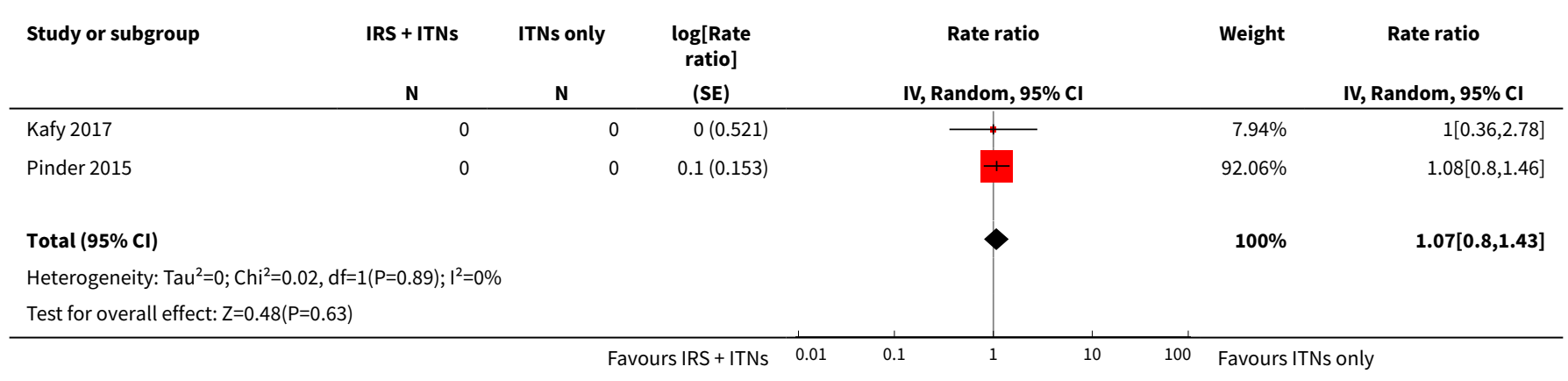


Analysis 2.2. Comparison 2 Pyrethroid-like indoor residual spraying (IRS) plus insecticide-treated nets (ITNs) versus ITNs alone, Outcome 2 Malaria parasite prevalence.

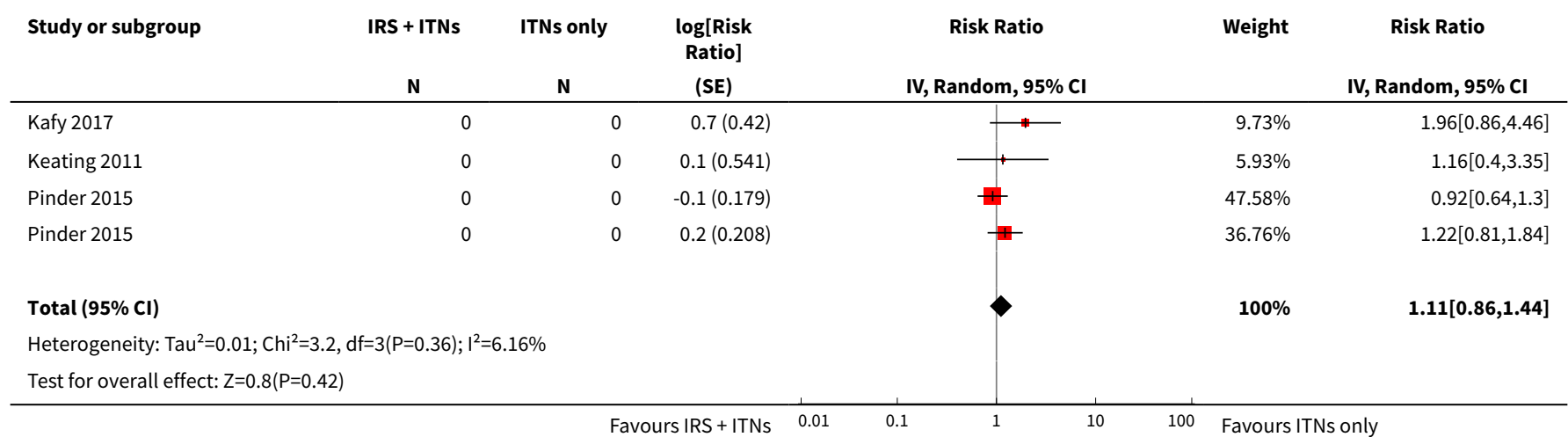

Analysis 2.3. Comparison 2 Pyrethroid-like indoor residual spraying (IRS) plus insecticide-treated nets (ITNs) versus ITNs alone, Outcome 3 Anaemia prevalence.

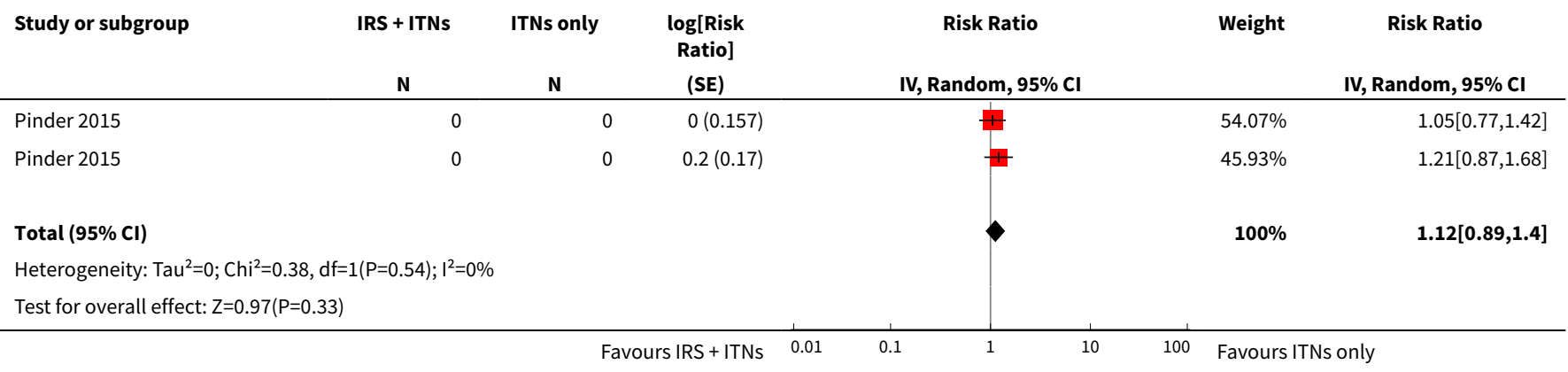

\section{ADDITIONAL TABLES}

Table 1. WHO-recommended insecticides for IRS against malaria vectors

\begin{tabular}{|c|c|}
\hline Insecticides and formulations & Dosage $\left(\mathrm{g} \mathrm{Al} / \mathrm{m}^{2}\right)$ \\
\hline DDT WP & $1-2$ \\
\hline Malathion WP & 2 \\
\hline Fenitrothion WP & 2 \\
\hline Pirimiphos-methyl WP, EC & $1-2$ \\
\hline Pirimiphos-methyl CS & 1 \\
\hline Bendiocarb WP, WP-SB & $0.1-0.4$ \\
\hline Propoxur WP & $1-2$ \\
\hline Alpha-cypermethrin WP, SC, WG-SB & $0.02-0.03$ \\
\hline
\end{tabular}


Table 1. WHO-recommended insecticides for IRS against malaria vectors (Continued)

\begin{tabular}{lc} 
Bifenthrin WP & $0.025-0.05$ \\
\hline Cyfluthrin WP & $0.02-0.05$ \\
\hline Deltamethrin WP, WG, WG-SB, SC-PE & $0.02-0.025$ \\
\hline Etofenprox WP & $0.1-0.3$ \\
\hline Lambda-cyhalothrin WP, CS & $0.02-0.03$ \\
\hline & \\
Abbreviations: Al: active ingredient; CS: capsule suspension; DDT: dichloro-diphenyl-trichlorethane; EC: emulsifiable concentrate; \\
IRS: indoor residual spraying; SC: suspension concentrate; SC-PE: polymer-enhanced suspension concentrate; WHO: World Health \\
Organization; WG: water-dispersible granule; WG-SB: water-dispersible granules packaged in water-soluble bags; WP: wettable powder; \\
WP-SB: wettable powder in sealed water-soluble bags.
\end{tabular}

WP-SB: wettable powder in sealed water-soluble bags.

Table 2. WHO-recommended long-lasting insecticidal nets

\begin{tabular}{|c|c|c|}
\hline Product name & Product type & $\begin{array}{l}\text { Status of WHO } \\
\text { recommendation }\end{array}$ \\
\hline DawaPlus 2.0 & Deltamethrin coated on polyester & Interim \\
\hline Duranet & Alpha-cypermethrin incorporated into polyethylene & Full \\
\hline Interceptor & Alpha-cypermethrin coated on polyester & Full \\
\hline LifeNet & Deltamethrin incorporated into polypropylene & Interim \\
\hline MAGNet & Alpha-cypermethrin incorporated into polyethylene & Full \\
\hline MiraNet & Alpha-cypermethrin incorporated into polyethylene & Interim \\
\hline Olyset Net & Permethrin incorporated into polyethylene & Full \\
\hline Olyset Plus & Permethrin and PBO incorporated into polyethylene & Interim \\
\hline Panda Net 2.0 & Deltamethrin incorporated into polyethylene & Interim \\
\hline PermaNet 2.0 & Deltamethrin coated on polyester & Full \\
\hline PermaNet 3.0 & $\begin{array}{l}\text { Combination of deltamethrin coated on polyester with strengthened border (side pan- } \\
\text { els), and deltamethrin and PBO incorporated into polyethylene (roof) }\end{array}$ & Interim \\
\hline Royal Sentry & Alpha-cypermethrin incorporated into polyethylene & Full \\
\hline SafeNet & Alpha-cypermethrin coated on polyester & Full \\
\hline Veeralin & Alpha-cypermethrin and PBO incorporated into polyethylene & Interim \\
\hline Yahe & Deltamethrin coated on polyester & Interim \\
\hline Yorkool & Deltamethrin coated on polyester & Full \\
\hline
\end{tabular}

Abbreviations: LLIN: long-lasting insecticidal nets; PBO: piperonyl butoxide; WHO: World Health Organization.

Adapted from WHO 2014b.

Indoor residual spraying for preventing malaria in communities using insecticide-treated nets (Review) 
Table 3. WHO-recommended insecticide products for treatment of mosquito nets for malaria vector control

\begin{tabular}{lll}
\hline Insecticide & Formulation & $\begin{array}{l}\text { Dosage (mg Al/m } \mathbf{m}^{2} \text { of } \\
\text { netting) }\end{array}$ \\
\hline Alpha-cypermethrin & SC 10\% & $20-40$ \\
\hline Cyfluthrin & EW 5\% & 50 \\
\hline Deltamethrin & SC 1\%; WT 25\%; and WT 25\% + binder & $15-25$ \\
\hline Etofenprox & EW 10\% & 200 \\
\hline Lambda-cyhalothrin & CS 2.5\% & $10-15$ \\
\hline Permethrin & EC 10\% & $200-500$ \\
\hline ICON MAXX (long-lasting lambda-cyhalothrin formulation) & CS 10\% + binder & $50-83$ \\
\hline
\end{tabular}

Abbreviations: Al: active ingredient; EC: emulsifiable concentrate; EW: emulsion, oil in water; CS: capsule suspension; SC: suspension concentrate; WT: water dispersible tablet; WHO: World Health Organization.

Adapted from WHO 2014c.

Table 4. Characteristics of indoor residual spraying

\begin{tabular}{llll}
\hline Study & $\begin{array}{l}\text { Active ingredient, formula- } \\
\text { tion, and dose }\end{array}$ & $\begin{array}{l}\text { Frequency of ap- } \\
\text { plication }\end{array}$ & $\begin{array}{l}\text { Coverage } \\
\end{array}$
\end{tabular}

\section{Comparison 1: IRS using non-pyrethroid-like insecticides plus ITNs versus ITNs alone}

\begin{tabular}{|c|c|c|c|c|c|}
\hline $\begin{array}{l}\text { Corbel } \\
2012\end{array}$ & $\begin{array}{l}\text { Bendiocarb 80\% wettable pow- } \\
\text { der (FICAM 80, Bayer) } 400 \text { mg/ } \\
\text { m }^{2}\end{array}$ & $\begin{array}{l}\text { Every } 8 \text { months, } \\
\text { June } 2008 \text { to De- } \\
\text { cember } 2009\end{array}$ & Aimed for $80 \%$ & Unreported & $\begin{array}{l}\text { An gambiae } \\
\text { s.l. and An fu- } \\
\text { nestus s.l. }\end{array}$ \\
\hline $\begin{array}{l}\text { Kafy } 2017 \\
\text { (Years } 2 \\
\text { and 3) }\end{array}$ & $\begin{array}{l}\text { Bendiocarb 80\% wettable pow- } \\
\text { der (FICAM 80, Bayer) } 200 \text { mg/ } \\
\text { m² }^{2}\end{array}$ & $\begin{array}{l}\text { Twice a year, Au- } \\
\text { gust and late De- } \\
\text { cember, } 2013 \text { and } \\
2014\end{array}$ & $\begin{array}{l}\text { 2013: } 82 \% \\
2014: 83 \%\end{array}$ & Unreported & $\begin{array}{l}\text { An gambiae } \\
\text { s.l. and An fu- } \\
\text { nestus s.l. }\end{array}$ \\
\hline $\begin{array}{l}\text { Pro- } \\
\text { topopoff } \\
2018\end{array}$ & $\begin{array}{l}\text { Pirimiphos-methyl 30\% capsule } \\
\text { suspension (Actellic 300CS) } 1 \mathrm{~g} \\
\text { active ingredient/m² }\end{array}$ & $\begin{array}{l}\text { Once, February } \\
2015\end{array}$ & $\begin{array}{l}\text { Standard ITN arm: } 0.5 \% \\
\text { (95\% CI } 0.1 \text { to } 2.0) \\
\text { Standard ITN + IRS arm: } \\
94 \% \text { ( } 95 \% \mathrm{CI} 92 \text { to } 96) \\
\text { Pyrethroid-PBO net arm: } 4 \% \\
\text { (95\% Cl } 0.5 \text { to } 29) \\
\text { Pyrethroid-PBO net + IRS } \\
\text { arm: } 94 \% \text { ( } 95 \% \mathrm{Cl} 87 \text { to } 97) \\
\text { Buffer size between clus- } \\
\text { ters: minimum outer buffer } \\
\text { zone of } 300 \text { m. Only the in- } \\
\text { ner core area was used for }\end{array}$ & Unreported & $\begin{array}{l}\text { An gambi- } \\
\text { aes.s., An ara- } \\
\text { biensis and } A n \\
\text { funestus }\end{array}$ \\
\hline
\end{tabular}


Table 4. Characteristics of indoor residual spraying (Continued)

the measurement of study outcomes.

\begin{tabular}{|c|c|c|c|c|c|}
\hline West 2014 & $\begin{array}{l}\text { Bendiocarb } 80 \% \text { wettable pow- } \\
\text { der (FICAM 80, Bayer) } 400 \mathrm{mg} / \mathrm{m}^{2}\end{array}$ & $\begin{array}{l}\text { Twice December } \\
2011 \text { to January } \\
2012 \text { and April } \\
2012 \text { to May } 2012\end{array}$ & $\begin{array}{l}\text { Aimed for } 80 \% \text { (actual cov- } \\
\text { erage was } 89.3-92.1 \% \text { ) }\end{array}$ & $\begin{array}{l}\text { RTI Interna- } \\
\text { tional on be- } \\
\text { half of PMI }\end{array}$ & $\begin{array}{l}\text { An gambiae } \\
\text { s.s. and } A n \\
\text { arabiensis }\end{array}$ \\
\hline
\end{tabular}

\section{Comparison 2: IRS using pyrethroid-like insecticides plus ITNs versus ITNs alone}

\begin{tabular}{|c|c|c|c|c|c|}
\hline $\begin{array}{l}\text { Kafy } 2017 \\
\text { (Year } 1 \text { ) }\end{array}$ & $\begin{array}{l}\text { Deltamethrin }\left(25 \mathrm{mg} / \mathrm{m}^{2} \text {, formu- }\right. \\
\text { lation not reported, Chema In- } \\
\text { dustries) }\end{array}$ & $\begin{array}{l}\text { Twice, in August } \\
\text { and late Decem- } \\
\text { ber } 2012\end{array}$ & $99 \%$ & Unreported & $\begin{array}{l}\text { An gambiae } \\
\text { s.l. and } A n \text { fu- } \\
\text { nestus s.l. }\end{array}$ \\
\hline $\begin{array}{l}\text { Keating } \\
2011\end{array}$ & $\begin{array}{l}\text { DDT wettable powder } 1-2 \mathrm{~g} \text { ac- } \\
\text { tive ingredient } / \mathrm{m}^{2}\end{array}$ & $\begin{array}{l}\text { Once, June-July } \\
2009\end{array}$ & $\begin{array}{l}\text { Aimed for } 80 \% \text { ( } 84.8 \% \\
\text { of households sampled } \\
\text { sprayed within } 12 \text { months) }\end{array}$ & Unreported & $\begin{array}{l}\text { An arabiensis } \\
\text { and An gambi- } \\
\text { ae s.s. }\end{array}$ \\
\hline $\begin{array}{l}\text { Pinder } \\
2015\end{array}$ & $\begin{array}{l}\text { DDT } 75 \% \text { wettable powder (Hin- } \\
\text { dustan Insecticides) } 2 \mathrm{~g} \text { active } \\
\text { ingredient } / \mathrm{m}^{2}\end{array}$ & $\begin{array}{l}\text { Once per year, Ju- } \\
\text { ly } 2010 \text { and Ju- } \\
\text { ly-August } 2011\end{array}$ & $\begin{array}{l}\text { Aimed for } 80 \% \text { (actual cov- } \\
\text { erage was } 83-86 \% \text { ) }\end{array}$ & $\begin{array}{l}\text { Operators } \\
\text { from the } \\
\text { Gambian Na- } \\
\text { tional Malar- } \\
\text { ia Control } \\
\text { Programme } \\
\text { and team } \\
\text { leaders from } \\
\text { the regional } \\
\text { health team }\end{array}$ & $\begin{array}{l}\text { An gambiae } \\
\text { s.l. }\end{array}$ \\
\hline
\end{tabular}

Abbreviations: Cl: confidence interval; DDT: dichloro-diphenyl-trichlorethane; IRS: indoor residual spraying; ITN: insecticide-treated net; PBO: piperonyl butoxide.

Table 5. ITN coverage and compliance

\begin{tabular}{lllll}
\hline Study $\quad$ Arm & $\begin{array}{l}\text { Coverage mea- } \\
\text { sure }\end{array}$ & $\begin{array}{l}\text { Coverage: mean }(95 \% \mathrm{Cl}) \\
\text { unless stated otherwise } a\end{array}$
\end{tabular}$\quad$ Compliance measure $\quad$ Compliance

\section{Comparison 1: IRS using non-pyrethroid-like insecticides plus ITNs versus ITNs alone}

\begin{tabular}{|c|c|c|c|c|c|}
\hline \multirow[t]{2}{*}{$\begin{array}{l}\text { Corbel } \\
2012\end{array}$} & Control & \multirow{2}{*}{$\begin{array}{l}\text { Total number of } \\
\text { hung nets rela- } \\
\text { tive to the total } \\
\text { number of sleep- } \\
\text { ing units }\end{array}$} & $\begin{array}{l}38 \%(36 \text { to } 41) \\
\text { Low }\end{array}$ & \multirow[t]{2}{*}{$\begin{array}{l}\text { Proportion of children aged } \\
<6 \text { years sleeping under the } \\
\text { net the night preceding the } \\
\text { visit }\end{array}$} & $\begin{array}{l}\text { Mean }(95 \% \mathrm{Cl}): 43 \% \\
(40 \text { to } 45) \\
\text { Low }\end{array}$ \\
\hline & $\begin{array}{l}\text { Interven- } \\
\text { tion }\end{array}$ & & $\begin{array}{l}45 \% \text { (43 to } 48) \\
\text { Low }\end{array}$ & & $\begin{array}{l}\text { Mean }(95 \% \mathrm{Cl}): 43 \% \\
(40 \text { to } 46) \\
\text { Low }\end{array}$ \\
\hline \multirow[t]{2}{*}{ Kafy 2017} & Control & \multirow[t]{2}{*}{$\begin{array}{l}\text { An annual inter- } \\
\text { vention assess- } \\
\text { ment survey on } \\
\text { household net } \\
\text { ownership }\end{array}$} & $\begin{array}{l}\text { 2013: } 82.1 \% \\
\text { 2014: } 98.6 \% \\
\text { High }\end{array}$ & \multirow[t]{2}{*}{$\begin{array}{l}\text { Defined as the proportion } \\
\text { of affirmative responses } \\
\text { to the question "Did this } \\
\text { child sleep under an ITN last } \\
\text { night?" }\end{array}$} & $\begin{array}{l}\text { 2013: } 74 \% \\
\text { 2014: } 82 \% \\
\text { High }\end{array}$ \\
\hline & $\begin{array}{l}\text { Interven- } \\
\text { tion }\end{array}$ & & & & $\begin{array}{l}\text { 2013: } 75 \% \\
\text { 2014: } 82 \%\end{array}$ \\
\hline
\end{tabular}


Table 5. ITN coverage and compliance (Continued)

\begin{tabular}{|c|c|c|c|c|c|}
\hline & & & & & High \\
\hline \multirow[t]{4}{*}{$\begin{array}{l}\text { Pro- } \\
\text { topopoff } \\
2018\end{array}$} & $\begin{array}{l}\text { Standard } \\
\text { ITNs }\end{array}$ & $\begin{array}{l}\text { Household own- } \\
\text { ing } \geq 1 \text { LLIN } \\
\text { (study LLIN or } \\
\text { any other LLIN) }\end{array}$ & $\begin{array}{l}\text { At } 9 \text { months' postinterven- } \\
\text { tion: } 97 \%(95 \% \mathrm{Cl} 93 \text { to } 99) \\
\text { High }\end{array}$ & $\begin{array}{l}\text { Residents declaring using } \\
\text { an ITN the previous night } \\
\text { (study ITN or any other ITN) }\end{array}$ & $\begin{array}{l}\text { At } 9 \text { months' postin- } \\
\text { tervention: } 80 \% \\
\text { (95\% Cl } 75 \text { to } 85 \text { ) } \\
\text { High }\end{array}$ \\
\hline & $\begin{array}{l}\text { Standard } \\
\text { ITNs + IRS }\end{array}$ & & $\begin{array}{l}\text { At } 9 \text { months' postinterven- } \\
\text { tion: } 76 \%(95 \% \mathrm{Cl} 70 \text { to } 80) \\
\text { Moderate }\end{array}$ & & $\begin{array}{l}\text { At } 9 \text { months' postin- } \\
\text { tervention: } 76 \% \\
\text { (95\% Cl } 70 \text { to } 80 \text { ) } \\
\text { Moderate }\end{array}$ \\
\hline & $\begin{array}{l}\text { Pyrethroid- } \\
\text { PBO net }\end{array}$ & & $\begin{array}{l}\text { At } 9 \text { months postinterven- } \\
\text { tion: } 98 \%(95 \% \mathrm{Cl} 97 \text { to } 99) \\
\text { High }\end{array}$ & & $\begin{array}{l}\text { At } 9 \text { months' postin- } \\
\text { tervention: } 78 \% \\
\text { (95\% Cl } 73 \text { to } 82 \text { ) } \\
\text { Moderate }\end{array}$ \\
\hline & $\begin{array}{l}\text { Pyrethroid- } \\
\text { PBO net + } \\
\text { IRS }\end{array}$ & & $\begin{array}{l}\text { At } 9 \text { months' postinterven- } \\
\text { tion: } 98 \%(95 \% \mathrm{Cl} 95 \text { to } 99) \\
\text { High }\end{array}$ & & $\begin{array}{l}\text { At } 9 \text { months' postin- } \\
\text { tervention: } 77 \% \\
\text { (95\% Cl } 70 \text { to } 83 \text { ) } \\
\text { Moderate }\end{array}$ \\
\hline \multirow[t]{4}{*}{ West 2014} & Control & $\begin{array}{l}\% \text { of households } \\
\text { with } \geq 1 \text { ITN per } \\
\text { sleeping space }\end{array}$ & $\begin{array}{l}\text { February-March: } 52.2 \text { ( } 47.8 \text { to } \\
56.5 \text { ) } \\
\text { June-July: } 51.6 \text { ( } 47 \text { to } 56 \text { ) } \\
\text { October-December: } 52.8 \\
\text { (47.6 to } 58 \text { ) } \\
\text { Moderate }\end{array}$ & $\begin{array}{l}\% \text { of study children that re- } \\
\text { ported sleeping under an } \\
\text { ITN the night previous to } \\
\text { the survey }\end{array}$ & $\begin{array}{l}\text { February-March: } \\
46.6 \text { ( } 41.7 \text { to } 51.6) \\
\text { June-July: } 40.7 \text { ( } 34.7 \\
\text { to } 47) \\
\text { October-December: } \\
36 \text { ( } 29.8 \text { to } 42.6) \\
\text { Low }\end{array}$ \\
\hline & $\begin{array}{l}\text { Interven- } \\
\text { tion }\end{array}$ & & $\begin{array}{l}\text { February-March: } 57.2 \text { (53.6 to } \\
60.7 \text { ) }\end{array}$ & & $\begin{array}{l}\text { February-March: } 53 \\
\text { (47.5 to } 58.3 \text { ) }\end{array}$ \\
\hline & & & $\begin{array}{l}\text { June-July: } 57.4 \text { (54 to } 60.9 \text { ) } \\
\text { October-December: } 56.8 \\
\text { (51.7 to } 61.8 \text { ) } \\
\text { Moderate }\end{array}$ & & $\begin{array}{l}\text { June-July: } 44.1 \text { (39.2 } \\
\text { to } 49.2) \\
\text { October-December: } \\
36.1 \text { ( } 31 \text { to } 41.5)\end{array}$ \\
\hline & & & & & Low \\
\hline
\end{tabular}

\section{Comparison 2: IRS using pyrethroid-like insecticides plus ITNs versus ITNs alone}

\begin{tabular}{|c|c|c|c|c|c|}
\hline \multirow[t]{2}{*}{ Kafy 2017} & Control & \multirow{2}{*}{$\begin{array}{l}\text { An annual inter- } \\
\text { vention assess- } \\
\text { ment survey on } \\
\text { household net } \\
\text { ownership }\end{array}$} & \multirow[t]{2}{*}{$\begin{array}{l}99.6 \% \\
\text { High }\end{array}$} & \multirow{2}{*}{$\begin{array}{l}\text { Defined as the proportion } \\
\text { of affirmative responses } \\
\text { to the question "Did this } \\
\text { child sleep under an ITN last } \\
\text { night?" }\end{array}$} & $\begin{array}{l}79 \% \\
\text { High }\end{array}$ \\
\hline & $\begin{array}{l}\text { Interven- } \\
\text { tion }\end{array}$ & & & & $\begin{array}{l}79 \% \\
\text { High }\end{array}$ \\
\hline $\begin{array}{l}\text { Keating } \\
2011\end{array}$ & Control & $\begin{array}{l}\text { Measured as } \\
\text { people living in }\end{array}$ & $\begin{array}{l}72 \%(70.2 \text { to } 73.7) \\
\text { Moderate }\end{array}$ & $\begin{array}{l}\text { Measured as people using } \\
\text { ITN in the previous night }\end{array}$ & $\begin{array}{l}\text { Mean }(95 \% \mathrm{Cl}): 46.2 \\
\text { (43.9 to } 48.6)\end{array}$ \\
\hline
\end{tabular}


Table 5. ITN coverage and compliance (Continued)

\begin{tabular}{|c|c|c|c|c|c|}
\hline & \multirow{3}{*}{$\begin{array}{l}\text { Interven- } \\
\text { tion }\end{array}$} & \multirow{3}{*}{$\begin{array}{l}\text { household own- } \\
\text { ing } \geq 1 \text { ITN }\end{array}$} & \multirow{3}{*}{$\begin{array}{l}75.8 \% \text { ( } 74.2 \text { to } 77.4) \\
\text { Moderate }\end{array}$} & & Low \\
\hline & & & & & $\begin{array}{l}\text { Mean }(95 \% \mathrm{Cl}): 50.7 \% \\
(48.6 \text { to } 52.8)\end{array}$ \\
\hline & & & & & Moderate \\
\hline \multirow[t]{8}{*}{$\begin{array}{l}\text { Pinder } \\
2015\end{array}$} & Control & Not reported & Not reported & $\begin{array}{l}\text { Measured as people using } \\
\text { ITN in the previous night }\end{array}$ & $\begin{array}{l}\text { Mean average across } \\
\text { all clusters: }\end{array}$ \\
\hline & & & & & 2011: 92\% \\
\hline & & & & & 2012: $96 \%$ \\
\hline & & & & & High \\
\hline & $\begin{array}{l}\text { Interven- } \\
\text { tion }\end{array}$ & & & & $\begin{array}{l}\text { Mean average across } \\
\text { all clusters: }\end{array}$ \\
\hline & & & & & 2011: 89\% \\
\hline & & & & & 2012: 93\% \\
\hline & & & & & High \\
\hline
\end{tabular}

Abbreviations: $\mathrm{Cl}$ : confidence interval; IRS: indoor residual spraying; ITN: insecticide-treated net; LLIN: long-lasting insecticidal mosquito net.

${ }^{a}$ Coverage and compliance cutoffs (low, moderate, and high) prespecified in protocol.

Table 6. Entomological inoculation rate results (Continued)

\begin{tabular}{|c|c|c|c|c|}
\hline \multirow[t]{2}{*}{ Trial } & \multirow[t]{2}{*}{ Methods of EIR measurement } & \multirow[t]{2}{*}{ Comparison } & \multicolumn{2}{|c|}{ Mean EIR $(95 \% \mathrm{Cl})$} \\
\hline & & & IRS + ITNS & $\begin{array}{l}\text { ITNs } \\
\text { alone }\end{array}$ \\
\hline \multicolumn{5}{|c|}{ Comparison 1: IRS using non-pyrethroid-like insecticides + ITNs versus ITNs alone } \\
\hline $\begin{array}{l}\text { Corbel } \\
2012\end{array}$ & $\begin{array}{l}\text { Mean number of infected bites per man per year } \\
\text { (estimated from the number of anopheline vectors caught } \\
\text { using human landing catches and the proportion of } \\
\text { anopheline vectors infective) }\end{array}$ & $\begin{array}{l}\text { IRS with standard ITN versus } \\
\text { standard ITN alone }\end{array}$ & $\begin{array}{l}7.3 \\
(3.8 \text { to } \\
14.2)\end{array}$ & $\begin{array}{l}9.4 \\
(5.1 \text { to } \\
17.1)\end{array}$ \\
\hline \multirow[t]{2}{*}{$\begin{array}{l}\text { Pro- } \\
\text { topopoff } \\
2018\end{array}$} & \multirow{2}{*}{$\begin{array}{l}\text { Mean number of infected bites per household per night } \\
\text { (the number of infective anopheline vectors caught using } \\
\text { light traps in } 1 \text { night per month was used as a proxy for this) }\end{array}$} & $\begin{array}{l}\text { IRS with standard ITN versus } \\
\text { standard ITN alone }\end{array}$ & $\begin{array}{l}0.05 \\
(n=413)\end{array}$ & $\begin{array}{l}1.76 \\
(n=449)\end{array}$ \\
\hline & & $\begin{array}{l}\text { IRS with pyrethroid-PBO net } \\
\text { versus pyrethroid-PBO net } \\
\text { alone }\end{array}$ & $\begin{array}{l}0.00 \\
(n=459)\end{array}$ & $\begin{array}{l}0.26 \\
(n=452)\end{array}$ \\
\hline West 2014 & $\begin{array}{l}\text { Mean number of infected bites per household per month } \\
\text { (estimated from the number of infective anopheline vec- } \\
\text { tors caught using light traps in } 1 \text { night) }\end{array}$ & $\begin{array}{l}\text { IRS with standard ITN versus } \\
\text { standard ITN alone }\end{array}$ & $\begin{array}{l}1.3 \\
(0.4 \text { to } 4.4)\end{array}$ & $\begin{array}{l}1.1 \\
\text { (0.4 to } 2.8)\end{array}$ \\
\hline
\end{tabular}

\section{Comparison 2: IRS using pyrethroid-like insecticides + ITNs versus ITNs alone}




\section{Table 6. Entomological inoculation rate results (Continued)}

\begin{tabular}{|c|c|c|c|c|}
\hline \multirow[t]{2}{*}{$\begin{array}{l}\text { Pinder } \\
2015\end{array}$} & \multirow{2}{*}{$\begin{array}{l}\text { Mean number of infected bites per person per transmission } \\
\text { season } \\
\text { (estimated from the number of anopheline vectors caught } \\
\text { using light traps and the proportion of anopheline vectors } \\
\text { infective) }\end{array}$} & $\begin{array}{l}\text { IRS with standard ITN versus } \\
\text { standard ITN alone: } 2010\end{array}$ & $\begin{array}{l}1.08 \\
(0.16 \text { to } \\
4.02)\end{array}$ & $\begin{array}{l}2.44 \\
(0.69 \text { to } \\
6.39)\end{array}$ \\
\hline & & $\begin{array}{l}\text { IRS with standard ITN versus } \\
\text { standard ITN alone: } 2011\end{array}$ & $\begin{array}{l}0.29 \\
(0.00 \text { to } \\
2.66)\end{array}$ & $\begin{array}{l}1.45 \\
(0.15 \text { to } \\
5.69)\end{array}$ \\
\hline
\end{tabular}

Abbreviations: Cl: confidence interval; EIR: entomological inoculation rate; IRS: indoor residual spraying; ITNs: insecticide-treated nets; n: number of participants; PBO: piperonyl butoxide.

Table 7. Sporozoite rate results (Continued)

\begin{tabular}{|c|c|c|c|c|c|c|}
\hline \multirow[t]{2}{*}{ Trial } & \multirow[t]{2}{*}{ Assessment method } & \multirow[t]{2}{*}{ Comparison } & \multicolumn{2}{|c|}{ Reported results } & \multicolumn{2}{|c|}{ Effect size $(95 \% \mathrm{Cls})$} \\
\hline & & & IRS + ITNs & ITNs alone & IRS + ITNs & $\begin{array}{l}\text { ITNs } \\
\text { alone }\end{array}$ \\
\hline \multicolumn{7}{|c|}{ Comparison 1: IRS using non-pyrethroid-like insecticides plus ITNs versus ITNs alone } \\
\hline $\begin{array}{l}\text { Corbel } \\
2012\end{array}$ & $\begin{array}{l}\% \text { of An gambiae s.l. caught } \\
\text { from human landing catches } \\
\text { with sporozoites } \\
\text { (ELISA) }\end{array}$ & $\begin{array}{l}\text { IRS with standard ITN } \\
\text { versus standard ITN } \\
\text { alone }\end{array}$ & $\begin{array}{l}3.22 \% \\
(95 \% \mathrm{Cl} 1.76 \\
\text { to } 4.68)\end{array}$ & $\begin{array}{l}2.83 \% \\
(95 \% \mathrm{Cl} 1.69 \\
\text { to } 3.97)\end{array}$ & Not reported & \\
\hline \multirow[t]{2}{*}{$\begin{array}{l}\text { Pro- } \\
\text { topopoff } \\
2018\end{array}$} & $\begin{array}{l}\% \text { of An gambiae s.l. caught } \\
\text { from light traps with sporo- } \\
\text { zoites }\end{array}$ & $\begin{array}{l}\text { IRS with standard ITN } \\
\text { versus standard ITN } \\
\text { alone }\end{array}$ & $\begin{array}{l}0.4 \% \\
(1 / 269)\end{array}$ & $\begin{array}{l}2.8 \% \\
(19 / 683)\end{array}$ & & \\
\hline & (ELISA) & $\begin{array}{l}\text { IRS with pyrethroid- } \\
\text { PBO net versus } \\
\text { pyrethroid-PBO net } \\
\text { alone }\end{array}$ & $\begin{array}{l}0.0 \% \\
(0 / 343)\end{array}$ & $\begin{array}{l}0.7 \% \\
(2 / 305)\end{array}$ & & \\
\hline West 2014 & & $\begin{array}{l}\text { IRS with standard ITN } \\
\text { versus standard ITN } \\
\text { alone }\end{array}$ & $\begin{array}{l}1.8 \% \\
(95 \% \mathrm{Cl} 0.5 \text { to } \\
6.2 ; \mathrm{n}=717)\end{array}$ & $\begin{array}{l}2.5 \% \\
(95 \% \mathrm{Cl} 2.1 \text { to } \\
3.1 ; \mathrm{n}=3059)\end{array}$ & $\begin{array}{l}\text { OR } 0.72 \\
(0.21 \text { to } 2.53)\end{array}$ & \\
\hline
\end{tabular}

\section{Comparison 2: IRS using pyrethroid-like insecticides plus ITNs versus ITNs alone}

\begin{tabular}{|c|c|c|c|c|c|}
\hline \multirow[t]{2}{*}{$\begin{array}{l}\text { Pinder } \\
2015\end{array}$} & $\begin{array}{l}\% \text { of An gambiae s.l. caught } \\
\text { from light traps with sporo- } \\
\text { zoites }\end{array}$ & $\begin{array}{l}\text { IRS with standard ITN } \\
\text { versus standard ITN } \\
\text { alone: } 2010\end{array}$ & $\begin{array}{l}0.19 \% \\
(4 / 2131)\end{array}$ & $\begin{array}{l}0.32 \% \\
(9 / 2829)\end{array}$ & $\begin{array}{l}\text { RR } 0.59 \\
(0.18 \text { to } 1.91)\end{array}$ \\
\hline & (ELISA) & $\begin{array}{l}\text { IRS with standard ITN } \\
\text { versus standard ITN } \\
\text { alone: } 2011\end{array}$ & $\begin{array}{l}0.65 \% \\
(5 / 773)\end{array}$ & $\begin{array}{l}0.09 \% \\
(1 / 1131)\end{array}$ & $\begin{array}{l}\text { RR } 7.32 \\
\text { (0.86 to } 62.5)\end{array}$ \\
\hline
\end{tabular}

Abbreviations: $\mathrm{Cl}$ : confidence interval; ELISA: enzyme-linked immunosorbent assay; IRS: indoor residual spraying; ITN: insecticide-treated net; MD: mean difference; OR: odds ratio; PBO: piperonyl butoxide; RR: risk ratio.

a Not adjusted for clustering. 
Table 8. Adult mosquito density results (Continued)

\begin{tabular}{|c|c|c|c|c|c|c|}
\hline \multirow[t]{2}{*}{ Trial } & \multirow[t]{2}{*}{$\begin{array}{l}\text { Methods of adult mosqui- } \\
\text { to density measurement }\end{array}$} & \multirow[t]{2}{*}{ Comparison } & \multicolumn{2}{|c|}{$\begin{array}{l}\text { Reported results } \\
\text { Mean }(95 \% \mathrm{Cls})\end{array}$} & \multicolumn{2}{|c|}{ Effect size ( $95 \% \mathrm{Cls})$} \\
\hline & & & IRS + ITNS & $\begin{array}{l}\text { ITNs } \\
\text { alone }\end{array}$ & IRS + ITNS & $\begin{array}{l}\text { ITNs } \\
\text { alone }\end{array}$ \\
\hline \multicolumn{7}{|c|}{ Comparison 1: IRS using non-pyrethroid-like insecticides + ITNs versus ITNs alone } \\
\hline $\begin{array}{l}\text { Corbel } \\
2012\end{array}$ & $\begin{array}{l}\text { Mean number of bites per } \\
\text { man per year from human } \\
\text { landing catches } \\
\text { (16 person-nights per vil- } \\
\text { lage (total } 28 \text { villages divid- } \\
\text { ed evenly into } 4 \text { arms) per } \\
\text { survey (total } 8 \text { surveys)) }\end{array}$ & $\begin{array}{l}\text { IRS with standard ITN versus } \\
\text { standard ITN alone }\end{array}$ & $\begin{array}{l}228 \\
(149 \text { to } \\
348 ; n= \\
896)\end{array}$ & $\begin{array}{l}331 \\
(218 \text { to } \\
504 ; n= \\
896)\end{array}$ & \multicolumn{2}{|c|}{$\begin{array}{l}\text { Rate ratio: } 0.69 \text { (0.38 to } \\
1.25)\end{array}$} \\
\hline \multirow[t]{2}{*}{$\begin{array}{l}\text { Pro- } \\
\text { topopoff } \\
2018\end{array}$} & $\begin{array}{l}\text { Mean number of vectors } \\
\text { caught in light traps per } \\
\text { night per household }\end{array}$ & $\begin{array}{l}\text { IRS with standard ITN versus } \\
\text { standard ITN alone }\end{array}$ & $\begin{array}{l}2.37 \\
(n=425)\end{array}$ & $\begin{array}{l}2.83 \\
(n=471)\end{array}$ & \multirow{2}{*}{\multicolumn{2}{|c|}{ Not reported }} \\
\hline & $\begin{array}{l}\text { ( } 7 \text { randomly selected hous- } \\
\text { es per cluster (total } 48 \text { clus- } \\
\text { ters divided evenly into } 4 \\
\text { arms) for } 1 \text { night per month } \\
\text { (total } 8 \text { months)) }\end{array}$ & $\begin{array}{l}\text { IRS with pyrethroid-PBO net ver- } \\
\text { sus pyrethroid-PBO net alone }\end{array}$ & $\begin{array}{l}1.85 \\
(n=493)\end{array}$ & $\begin{array}{l}1.84 \\
(n=468)\end{array}$ & & \\
\hline West 2014 & $\begin{array}{l}\text { Mean number of An gambi- } \\
\text { ae s.l. per house per night } \\
\text { ( } 8 \text { randomly selected hous- } \\
\text { es per cluster (total } 40 \text { clus- } \\
\text { ters divided evenly into } 2 \\
\text { arms) for } 1 \text { night per month } \\
\text { (total } 21 \text { months)) }\end{array}$ & $\begin{array}{l}\text { IRS with standard ITN versus } \\
\text { standard ITN alone }\end{array}$ & $\begin{array}{l}0.4 \\
(0.1 \text { to } 1.4 \\
n=1893)\end{array}$ & $\begin{array}{l}1.7 \\
(0.5 \text { to } 6.4 \\
n=1892)\end{array}$ & \multicolumn{2}{|c|}{$\begin{array}{l}\text { Rate ratio } 0.23 \text { (0.04 to } \\
1.44)\end{array}$} \\
\hline
\end{tabular}

\section{Comparison 2: IRS using pyrethroid-like insecticides + ITNs versus ITNs alone}

\begin{tabular}{|c|c|c|c|c|c|}
\hline \multirow[t]{3}{*}{$\begin{array}{l}\text { Pinder } \\
2015\end{array}$} & $\begin{array}{l}\text { Mean number of An gambi- } \\
\text { ae s.l. per trap per night } \\
\text { (6 sentinel rooms in } 32 \text { clus- }\end{array}$ & $\begin{array}{l}\text { IRS with standard ITN versus } \\
\text { standard ITN alone: } 2010 \text { light } \\
\text { traps }\end{array}$ & $\begin{array}{l}3.70 \\
(2.03 \text { to } \\
5.37)\end{array}$ & $\begin{array}{l}4.92 \\
(3.05 \text { to } \\
6.79)\end{array}$ & $\begin{array}{l}M D-1.22 \\
(-3.58 \text { to } 1.14)\end{array}$ \\
\hline & & $\begin{array}{l}\text { IRS with standard ITN versus } \\
\text { standard ITN alone: } 2010 \text { exit } \\
\text { traps }\end{array}$ & $\begin{array}{l}0.40 \\
(-0.15 \text { to } \\
0.66)\end{array}$ & $\begin{array}{l}0.54 \\
(0.18 \text { to } \\
0.89)\end{array}$ & $\begin{array}{l}\text { MD }-0.13 \\
(-0.54 \text { to } 0.28)\end{array}$ \\
\hline & & $\begin{array}{l}\text { IRS with standard ITN versus } \\
\text { standard ITN alone: } 2011 \text { light } \\
\text { traps }\end{array}$ & $\begin{array}{l}1.27 \\
(0.39 \text { to } \\
2.15)\end{array}$ & $\begin{array}{l}1.96 \\
(0.69 \text { to } \\
3.24)\end{array}$ & $\begin{array}{l}\text { MD }-0.69 \\
(-2.15 \text { to } 0.77)\end{array}$ \\
\hline
\end{tabular}


Abbreviations: Cl: confidence interval; IRS: indoor residual spraying; ITNs: insecticide-treated nets; MD: mean difference; PBO: piperonyl butoxide.

\section{AP PEN DICES}

\section{Appendix 1. Search strategies}

\begin{tabular}{|c|c|}
\hline PubMed search set & Search terms \\
\hline 1 & Malaria [ Mesh], Title/Abstract \\
\hline 2 & Mosquito* Title/Abstract \\
\hline 3 & "Anopheles"[Mesh] \\
\hline 4 & 1 or 2 or 3 \\
\hline 5 & "indoor residual spraying" or IRS* Title/Abstract \\
\hline 6 & "house spray" Title/Abstract \\
\hline 7 & $\begin{array}{l}\text { ( "Insecticides/administration and dosage"[Mesh] or "Insecticides/supply and distribution"[Mesh] } \\
\text { or "Insecticides/therapeutic use"[Mesh] ) or "Pyrethrins"[Mesh] }\end{array}$ \\
\hline 8 & $\begin{array}{l}\text { malathion or fenitrothion or pirimiphos-methyl or bendiocarb or propoxur or alpha-cypermethrin } \\
\text { or bifenthrin or cyfluthrin or deltamethrin or etofenprox or lambda-cyhalothrin or DDT Title/Ab- } \\
\text { stract }\end{array}$ \\
\hline 9 & 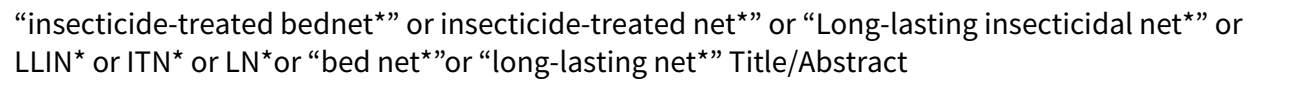 \\
\hline 10 & “Insecticide-Treated Bednets" [Mesh] \\
\hline 11 & ("Mosquito Control/instrumentation"[Mesh] OR "Mosquito Control/methods"[Mesh]) \\
\hline 12 & 5 or 6 or 7 or 8 \\
\hline 13 & 9 or 10 or 11 \\
\hline 14 & 4 and 12 and 13 \\
\hline 15 & "Randomized Controlled Trial" [Publication Type] OR "Controlled Clinical Trial" [Publication Type] \\
\hline 16 & single-blind* or double-blind* Title/Abstract \\
\hline 17 & randomized or placebo or trial or groups or randomly Title/Abstract \\
\hline 18 & "before and after " Title/Abstract \\
\hline 19 & "Epidemiologic Studies"[Mesh] \\
\hline 20 & "time series" Title/Abstract \\
\hline 21 & 20 OR 19 OR 18 OR 17 OR 16 OR 15 \\
\hline
\end{tabular}




\section{Embase}

1 malaria/ or malaria.mp.

2 Anopheles/ or anopheles.mp.

3 mosquito*.mp. or mosquito/

41 or 2 or 3

5 indoor residual spraying.mp. or indoor residual spraying/

6 indoor residual spray.mp.

7 house spray.mp.

8 house spraying.mp.

9 IRS.ab. or IRS.ti.

10 (malathion or fenitrothion or pirimiphos-methyl or bendiocarb or propoxur or alpha-cypermethrin or bifenthrin or cyfluthrin or deltamethrin or etofenprox or lambda-cyhalothrin or DDT).mp.

11 insecticide/ct, ad, cb, cm, dt [Clinical Trial, Drug Administration, Drug Combination, Drug Comparison, Drug Therapy]

12 pyrethroid/ct, ad, cb, cm, dt [Clinical Trial, Drug Administration, Drug Combination, Drug Comparison, Drug Therapy]

135 or 6 or 7 or 8 or 9 or 10 or 11 or 12

144 and 13

15 (Net* or bednet* or ITN* or LLIN* or "Insecticide-Treated Bednet*" or "Insecticide-Treated net*").mp. [mp=title, abstract, heading word, drug trade name, original title, device manufacturer, drug manufacturer, device trade name, keyword, floating subheading word]

16 bed net/

17 insecticide treated net/

1815 or 16 or 17

1914 and 18

20 randomized controlled trial/ or controlled clinical trial/

21 (randomized or randomised or placebo or double-blind* or single-blind*).mp.

22 epidemiology/

23 (before and after study).mp

24 time series.mp. or time series analysis/

25 field study.mp. or field study/

26 prospective study.mp. or prospective study/

2920 or 21 or 22 or 23 or 24 or 27 or 28

3019 and 29 


\section{LILACS}

(tw:(indoor residual spraying OR irs OR house spraying)) AND (tw:(bednets OR nets OR itn )) AND (tw:(malaria OR mosquito OR anopheles)) AND (tw:(randomized OR controlled OR trial OR comparison OR compared ))

\section{Cochrane Central Register of Controlled Trials}

Issue 3 of 12, April 2019

ID Search Hits

\#1 MeSH descriptor: [Malaria] explode all trees

\#2 malaria:ti,ab,kw (Word variations have been searched)

\#3 anopheles

\#4 MeSH descriptor: [Anopheles] explode all trees

\#5 mosquito*

\#6 \#1 or \#2 or \#3 or \#4 or \#5

\#7 "indoor residual spray"

\#8 "indoor residual spraying"

\#9 "house spray*"

\#10 IRS

\#11 malathion or fenitrothion or pirimiphos-methyl or bendiocarb or propoxur or alpha-cypermethrin or bifenthrin or cyfluthrin or deltamethrin or etofenprox or lambda-cyhalothrin or DDT

\#12 MeSH descriptor: [Insecticides] explode all trees and with qualifier(s): [Administration \& dosage - AD, Supply \& distribution - SD, Therapeutic use - TU]

\#13 MeSH descriptor: [Pyrethrins] explode all trees and with qualifier(s): [Administration \& dosage - AD, Supply \& distribution - SD, Therapeutic use - TU]

$\# 14$ \# 7 or \#8 or \#9 or \#10 or \#11 or \#12 or \#13

\#15 Net* or bednet* or ITN* or LLIN* or "Insecticide-Treated Bednet*" or "Insecticide-Treated net*"

\#16 MeSH descriptor: [Insecticide-Treated Bednets] explode all trees

\#17 \#15 or \#16

\#18 \#6 and \#14 and \#17

\section{WHAT'S NEW}

\begin{tabular}{lll}
\hline Date & Event & Description \\
\hline 23 August 2019 & Amended & $\begin{array}{l}\text { Amended text in 'Abstract, Data collection and analysis' section } \\
\text { for clarity. }\end{array}$ \\
\hline
\end{tabular}

\section{CONTRIBUTIONS OF AUTHORS}

All authors contributed to the protocol design, wrote the protocol, and approved the final version.

LC and JP screened articles, extracted data from the included studies, and conducted the analysis.

PG acted as arbitrator. 
All authors sought to interpret the data, and prepared and interpreted the GRADE summaries.

LC and JP wrote the full text and PG edit modified this. All authors read and approved the final manuscript.

\section{DECLARATIONS OF INTEREST}

LC: none.

JP: none.

PG is the Director of READ-It, a DFID-funded research programme that aims to increase the number of decisions in low-and middle-income countries based on reliable evidence.

\section{SOURCES OF SUPPORT}

\section{Internal sources}

- Liverpool School of Tropical Medicine, UK.

\section{External sources}

- Department for International Development, UK.

Project number: $300342-104$

- World Health Organization (WHO), Switzerland.

WHO Global Malaria Programme Agreement for Performance of Work (APW) Grant 2017 (number 709319)

- Partnership for Increasing the Impact of Vector Control (PIIVeC), UK.

Provided support to LC. PIIVeC is funded by the Medical Research Council of the UK (grant number MR/P027873/1) through the Global Challenges Research Fund.

\section{DIFFERENCES BETWEEN PROTOCOL AND REVIEW}

We amended the title from 'The combination of indoor residual spraying with insecticide-treated nets versus insecticide-treated nets alone for preventing malaria' to 'Indoor residual spraying for preventing malaria in communities using insecticide-treated nets'.

In the protocol, we initially limited the outcome of insecticide resistance to the specific insecticide used for IRS (Choi 2017). However, during the extraction process, it became apparent that resistance to pyrethroid insecticides was also an important outcome in trials using nonpyrethroid-like insecticides for IRS. Therefore, we extracted resistance outcome data for both classes of insecticide.

We also made changes to the way that we subgrouped trials. Initially, we intended to include all comparisons of IRS plus ITNs versus ITNs alone in one analysis, regardless of the target site of the insecticide used for IRS. However, we prespecified that we would subgroup the data by this target site to explore potential causes of heterogeneity. Following referee feedback, it became clear that the most important policy question was to assess the effectiveness of combining ITNs with a non-pyrethroid-like IRS. Therefore we decided not to conflate this analysis with that of the pyrethroid-like IRS interventions, and instead presented two separate comparisons.

We stated in the protocol that we would perform the following subgroup analyses to investigate heterogeneity.

- Use of LLINs/ITNs defined by individual use from the previous night:

* high ( $80 \%$ to $100 \%)$;

* moderate (50\% to $79 \%)$;

* low (less than 50\%).

- Coverage of IRS:

* high ( $80 \%$ to $100 \%)$;

* moderate $(50 \%$ to $79 \%)$;

* low (less than 50\%).

- Seasonality of malaria:

* perennial;

* seasonal;

* epidemic.

Due to few studies and lack of data surrounding certain subgroups, we were only able to perform the following subgroup analysis. 
- Use of LLINs/ITNs defined by individual use from the previous night:

* high ( $50 \%$ or more);

* low (less than $50 \%$ ).

Finally, we originally stated in the protocol that a P value less than 0.05 indicated statistically significant differences between subgroups but we have amended this to less than 0.1 .

\section{INDEX TERMS}

\section{Medical Subject Headings (MeSH)}

*Insecticide-Treated Bednets; Communicable Disease Control [methods]; Insecticides [ ${ }^{*}$ administration \& dosage]; Malaria [* prevention \& control]; Mosquito Control [*methods]

\section{MeSH check words}

Humans 